\title{
Structural Determinants of Isoform Selectivity in PI3K Inhibitors
}

\author{
Michelle S. Miller ${ }^{1}$ (D), Philip E. Thompson ${ }^{2}(\mathbb{D})$ and Sandra B. Gabelli ${ }^{1,3, *(D)}$ \\ 1 Department of Oncology, Johns Hopkins University School of Medicine, Baltimore, MD 21205, USA; \\ michelle.miller@jhmi.edu \\ 2 Medicinal Chemistry, Monash Institute of Pharmaceutical Sciences, Parkville, VIC 3052, Australia; \\ philip.thompson@monash.edu \\ 3 Departments of Medicine, Biophysics and Biophysical Chemistry, Johns Hopkins University School of \\ Medicine, Baltimore, MD 21205, USA \\ * Correspondence: gabelli@jhmi.edu; Tel.: +410-614-4145
}

Received: 25 January 2019; Accepted: 21 February 2019; Published: 26 February 2019

\begin{abstract}
Phosphatidylinositol 3-kinases (PI3Ks) are important therapeutic targets for the treatment of cancer, thrombosis, and inflammatory and immune diseases. The four highly homologous Class I isoforms, PI3K $\alpha$, PI3K $\beta$, PI $3 \mathrm{~K} \gamma$ and PI3K $\delta$ have unique, non-redundant physiological roles and as such, isoform selectivity has been a key consideration driving inhibitor design and development. In this review, we discuss the structural biology of PI3Ks and how our growing knowledge of structure has influenced the medicinal chemistry of PI3K inhibitors. We present an analysis of the available structure-selectivity-activity relationship data to highlight key insights into how the various regions of the PI3K binding site influence isoform selectivity. The picture that emerges is one that is far from simple and emphasizes the complex nature of protein-inhibitor binding, involving protein flexibility, energetics, water networks and interactions with non-conserved residues.
\end{abstract}

Keywords: PIK3CA; isoform selectivity; p110; p85; phosphatidylinositol 3-kinase; PI3K $\beta$; PI3K $\alpha$; PI3K $\gamma ;$ PI3K $\delta$

\section{Introduction}

With more than 500 members in the human kinome, kinases are the most common family of enzymatic drug targets for the treatment of cancer and other diseases [1]. However, with so many diverse members and functions, inhibitor selectivity is both necessary to dissect individual biological functions, and a key safety concern in translating these inhibitors to the clinic. This is perhaps most difficult to achieve among isoforms of related kinases, which contain highly conserved ATP binding sites. Phosphatidylinositol 3-kinases (PI3Ks), and in particular, the four members of Class I, are such a family. PI3Ks are a family of lipid kinases that phosphorylate phosphatidylinositides at the $3^{\prime}$ position of the inositol ring. They have been divided into three classes based on their substrate specificity and sequence homology. Class I PI3Ks, which will form the focus of this review, phosphorylate phosphatidylinositol-4,5-bisphosphate $\left(\mathrm{PIP}_{2}\right)$ downstream of either receptor tyrosine kinases or G-protein coupled receptors to form the second messenger phosphatidylinositol-3,4,5-trisphosphate $\left(\mathrm{PIP}_{3}\right)$, which signals for increased cell growth, metabolism, and cell-cycle progression [2]. Class I consists of four family members, each of which forms a heterodimer between a catalytic subunit, p110, and a regulatory subunit. The family is further subdivided into Class IA, where p110 $\alpha, \mathrm{p} 110 \beta$ and p $110 \delta$ form heterodimers with the p85 family of regulatory subunits $[3,4]$, and Class IB, where p110 $\gamma$ is the sole member and forms a heterodimer with either the $\mathrm{p} 87$ or p101 regulatory subunit [5-7].

Each isoform has been shown to have overlapping, but non-redundant physiological roles [8]. PI3K $\alpha$ and $\beta$ are both ubiquitously expressed. PI3K $\alpha$ plays a key role in glucose homeostasis 
and insulin signaling $[9,10]$ and is involved in driving myocardial growth via $\mathrm{PIP}_{3}$ dependent pathways [11-14]. PI3K $\beta$, in contrast, has been shown to regulate the activity of the platelet integrin $\alpha_{\mathrm{IIb}} \beta_{3}$ in the context of platelet adhesion and aggregation [15-17]. As such PI3K $\beta$ is under investigation as a novel treatment for thrombosis, and the first in-human trials have shown promising results [16]. PI $3 \mathrm{~K} \gamma$ and $\delta$ have more restricted expression, largely limited to the hematopoietic system. They both play important, non-redundant roles in the immune system, and so are both under consideration as immune modulatory targets [18-20]. PI3K $\gamma$ inhibition is being pursued for rheumatoid arthritis and asthma [20-22], and PI3K $\delta$ for activated PI3K $\delta$ syndrome (APDS) [23-27].

Their diverse functions notwithstanding, PI3Ks are perhaps most well-known as oncology targets. The PI3K pathway is one of the most frequently dysregulated in cancer. Oncogenic mutations in the gene encoding the $\mathrm{p} 110 \alpha$ catalytic subunit, PIK3CA, are common in breast, colon, and endometrial cancers [28-32]. Somatic, missense mutations have been identified throughout the sequence of $\mathrm{p} 110 \alpha$. Interestingly, about $80 \%$ of these mutations are concentrated at 3 'hotspots', Glu542Lys, Glu545Lys and His1047Arg [28,29]. The PI3K $\alpha$ selective inhibitor, alpelisib (NVP-BYL719), recently completed Phase III clinical trials with encouraging results in patients with tumors harboring PIK3CA mutations (Table 1) [33].

Mutations are not common in the other isoforms, but overexpression has been linked to cancer $[8,34,35]$. Cancers deficient in the phosphatase PTEN have been linked with increased PI3K $\beta$ expression and activity. Studies in PTEN-deficient cell lines, as well as conditional knock-out mice have shown that PI3K $\beta$ inactivation blocks prostate cancer development [36-40]. A number of PI3K $\beta$ selective inhibitors are currently in Phase I/II trials for PTEN-deficient cancers, including AZD8186 and GSK2636771 (Table 1) [41]. Rapid clearance of SAR260301 halted its clinical development [42].

Although the roles for PI3K $\alpha$ and PI3K $\beta$ were the first to be characterized, the first PI3K inhibitor to be approved for use was the PI3K $\delta$ selective inhibitor, idelalisib. Constitutively active PI3K $\delta$ signaling has been shown in many B-cell malignancies [43-45]. Idelalisib is a Food and Drug Administration (FDA) approved as a combination therapy with rituximab in relapsed chronic lymphocytic lymphoma (CLL) and as a monotherapy in relapsed follicular lymphoma (FL) and small cell lymphocytic lymphoma (SLL) (Table 1) [46-48]. Although effective in treating lymphoma, unpredictable immune-mediated toxicity is limiting its use for inflammatory diseases and non-cancer indications [49,50]. Two other PI3K inhibitors have also recently been approved: duvelisib $(\mathrm{PI} 3 \mathrm{~K} \gamma / \delta)$ for relapsed CLL or SLL [51,52] and copanlisib (pan-PI3K) for relapsed FL [53-56].

PI3K $\gamma$ has been implicated with a key role in the tumor microenvironment [57]. PI3K $\gamma$ signaling is activated in myeloid cells in response to tissue hypoxia [58-61]. PI3K $\gamma$ deletion and kinase-dead knock-in studies in mice have also demonstrated a vital role for PI $3 \mathrm{~K} \gamma$ in the myeloid cells that make up the immune-suppressive tumor microenvironment [60-63]. The PI3K $\gamma$ selective inhibitor, IPI-549 is undergoing clinical evaluation in patients with advanced solid tumors (Table 1) [57].

The development of isoform selective inhibitors has been vital to uncovering the unique functions of each isoform and their corresponding therapeutic potential. Significant progress has been made, and isoform selective inhibitors are now available for each of the four Class I isoforms. They continue to be useful in uncovering important details of PI3K physiology and the understanding of cancer signaling. While the clinic will ultimately decide about the efficacy and the relative benefit of pan and isoform selective inhibition, an understanding of the underlying mechanisms of isoform selectivity will continue to hold importance as resistance develops and the next generation of inhibitors is required. In this review, we will first focus on the available structural information for each of the isoforms, and then how this informs isoform selective inhibitor design and development. Pan PI3K inhibitors have been reviewed in detail elsewhere and will not be addressed in this review [64]. 
Table 1. Single and dual-isoform selective phosphatidylinositol 3-kinase (PI3K) inhibitors approved for use or under clinical evaluation.

\begin{tabular}{|c|c|c|c|c|c|c|c|}
\hline \multirow{2}{*}{ Inhibitor } & \multirow{2}{*}{ Other Names } & \multirow{2}{*}{ Target } & \multirow{2}{*}{$\begin{array}{l}\text { PDB ID } \\
\text { (isoform) }\end{array}$} & \multicolumn{4}{|c|}{$\mathrm{IC}_{50}(\mathrm{nM})$} \\
\hline & & & & PI3K $\alpha$ & PI3K $\beta$ & PI3K $\gamma$ & PI3Kס \\
\hline Alpelisib [65] & $\begin{array}{l}\text { NVP-BYL719 } \\
\text { MLN1117; }\end{array}$ & $\alpha$ & $4 J P S(\alpha)$ & 5 & 1200 & 250 & 290 \\
\hline Serabelisib [66] & $\begin{array}{l}\text { INK1117; } \\
\text { TAK-117 }\end{array}$ & $\alpha$ & - & 15 & 4500 & 1900 & 13,900 \\
\hline GDC-0326 [67] & & $\alpha$ & $5 \mathrm{DXT}(\alpha)$ & $0.2^{1}$ & 26.6 & 4 & 10.2 \\
\hline CYH33 [68] & & $\alpha$ & - & nd & nd & nd & nd \\
\hline AZD8186 [69] & & $\beta$ & - & 35 & 4 & 675 & 12 \\
\hline GSK2636771 [70] & & $\beta$ & - & 35,400 & 20 & nd & 40 \\
\hline SAR260301 [71] & & $\beta$ & 4BFR $(\beta)$ & 1539 & 23 & 10,000 & 468 \\
\hline IPI-549 [57] & & $\gamma$ & - & 3200 & 3500 & 16 & $>8400$ \\
\hline AMG319 [72] & & $\delta$ & $4 \mathrm{WWN}(\gamma)$ & 33,000 & 2700 & 850 & 18 \\
\hline GSK2292767 [73] & & $\delta$ & 5AE9 $(\delta)$ & 501 & 630 & 501 & 0.079 \\
\hline Idelalisib [74] & $\begin{array}{l}\text { CAL-101, } \\
\text { GS-1101 }\end{array}$ & $\delta$ & 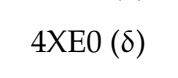 & 8600 & 4000 & 2100 & 19 \\
\hline Leniolisib [75] & CDZ173 & $\delta$ & $5083(\delta)$ & 244 & 424 & 2230 & 11 \\
\hline Nemiralisib [73] & GSK2269557 & $\delta$ & 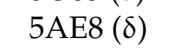 & 5011 & 1584 & 6309 & 0.12 \\
\hline Umbralisib [49] & TGR-1202 & $\delta$ & - & $>1400$ & $>756$ & $>120$ & 14 \\
\hline Parsaclisib [49] & INCB050465 & $\delta$ & - & nd & nd & nd & 1 \\
\hline Duvelisib [76] & IPI-145 & $\gamma / \delta$ & - & 1602 & 85 & 27 & 2.5 \\
\hline RV1729 [49] & & $\gamma / \delta$ & - & 192 & - & 25 & 12 \\
\hline RV6153 [49] & & $\gamma / \delta$ & - & 14,000 & 5000 & 28 & 2.5 \\
\hline Tenalisib [49] & RP6530 & $\gamma / \delta$ & - & 10,000 & 4000 & 33 & 25 \\
\hline
\end{tabular}

${ }^{1}$ Reported data is $\mathrm{Ki}_{\text {app }}$ rather than $\mathrm{IC}_{50}$ (half-maximal inhibitory concentration). nd-not disclosed.

\section{Structural Biology of PI3K}

The foundation for structure-based drug design is the availability of medium to high-resolution structures. p110 $\gamma$, the sole-member of Class IB, was the first PI3K to be crystallized [77]. Stable expression of $\mathrm{p} 110 \gamma$ in insect cells was achieved with an N-terminal truncation of the Adaptor Binding Domain (ABD), which mediates the interaction between p110 and the regulatory subunit [77]. This construct is hereafter referred to as $\triangle \mathrm{ABD}$.

All the Class I p110 isoforms consist of five domains (Figure 1a). The structure of $\triangle A B D-p 110 \gamma$ revealed the overall architecture of four of these domains, which were subsequently shown to be highly homologous to the other isoforms (PDB ID 1E8X, Figure 1b). The Ras-binding domain (RBD) in p110 $\gamma$ (residues $\gamma 220-311$ ) contains a five-stranded $\beta$-sheet flanked by two $\alpha$-helices, a similar fold to the RBD of two other well-known Ras effectors, Raf and RalGDS [78,79]. The RBD is situated in close proximity to the kinase domain, suggesting that Ras may activate $\mathrm{p} 110 \gamma$ via an allosteric mechanism. The fold of the C2 domain of p110 $\gamma$ (residues $\gamma 357-522$ ) is analogous to that of PLC 81 , containing an eight-stranded antiparallel $\beta$-sandwich [80]. The C2 domain is postulated to be involved in membrane binding. The helical domain (residues $\gamma 545-725)$ consists of five pairs of antiparallel $\alpha$-helices. The precise function of this domain is unknown. The fold of the kinase or catalytic domain (residues $\gamma 726-1092$ ) has a high level of similarity to that generally observed in protein kinases. It is a two-lobed structure, with ATP binding at the hinge region between these two lobes [77].

These initial structures of $\triangle \mathrm{ABD}-\mathrm{p} 110 \gamma$ revealed a number of important features of the ATP-binding site, which is of particular interest to the development of inhibitors (Figure 1c). In a similar fashion to that observed in protein kinases, N1 and N6 of the adenine ring system form complementary hydrogen bonding interactions with the amide backbone of $\gamma$ Glu880 and $\gamma$ Val882 at the hinge region between the $\mathrm{N}$ - and C-lobes of the kinase domain. The adenine ring moiety is sandwiched between hydrophobic residues ( $\gamma$ Ile831, $\gamma$ Ile879, $\gamma$ Phe961 and $\gamma$ Ile963) at the base and roof of the binding site. The ribose ring projects towards hydrophobic region II without making any specific 
interactions with the protein. The phosphate tail of ATP interacts with a loop designated the P-loop (p110 $\gamma$ residues 803-811), analogous to the glycine-rich loop in protein kinases. The $\alpha$-phosphate interacts with $\gamma$ Lys833, the $\beta$-phosphate with $\gamma$ Ser806 and the $\gamma$-phosphate with $\gamma$ Asn951 [81].

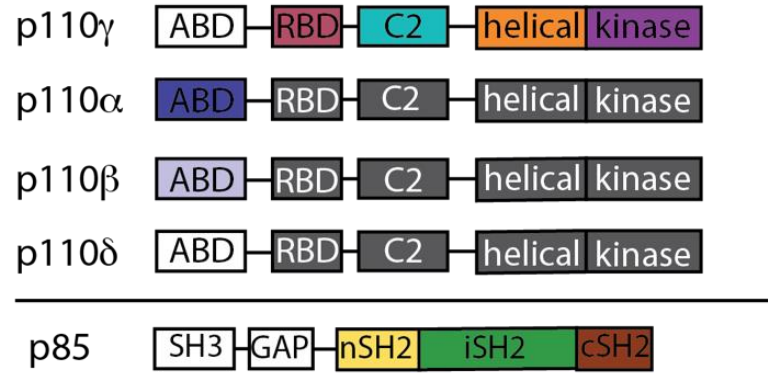

(a)

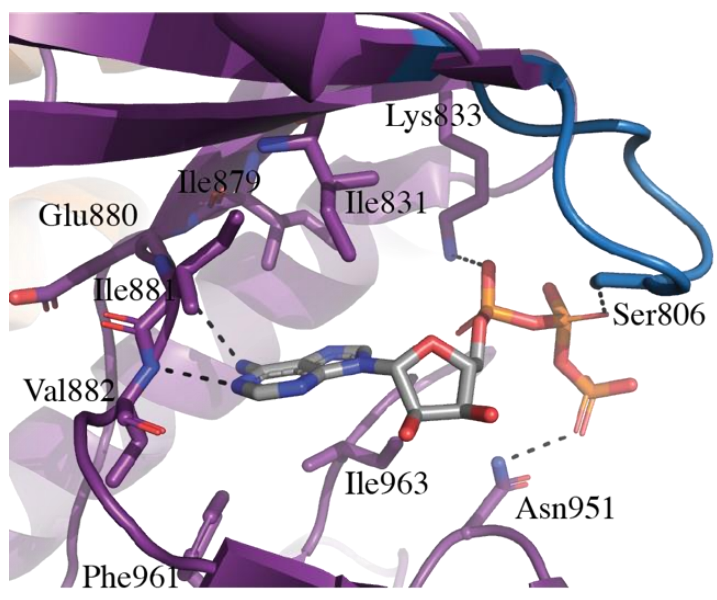

(c)

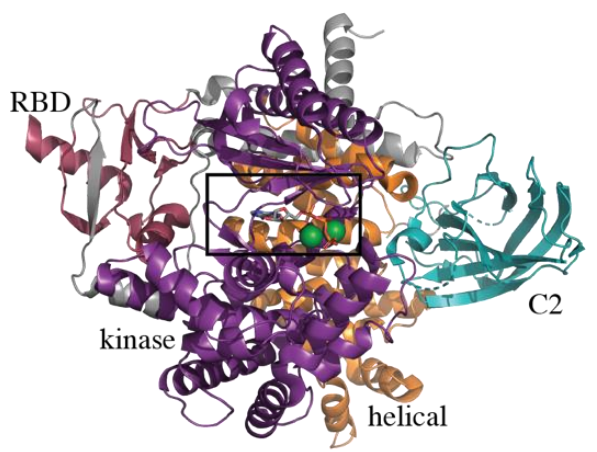

(b)

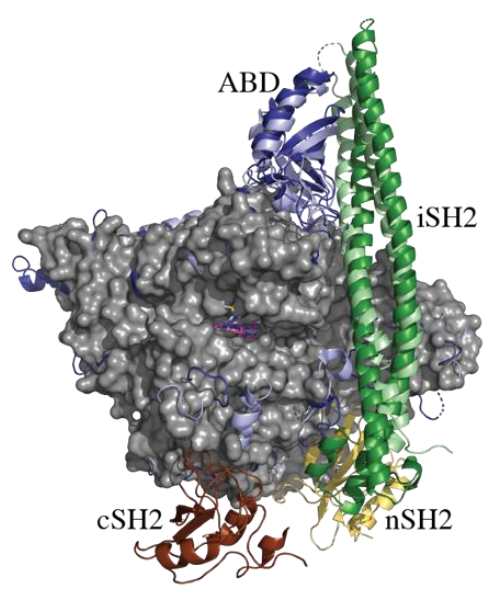

(d)

Figure 1. Structural biology of PI3K. (a) Domain organization of the catalytic subunits (p110) and regulatory subunit (p85) of Class I PI3K. Domains colored in white have not been crystallized in PI3K complex structures. (b) The structure of $\triangle$ ABD-p110 $\gamma$ in complex with ATP (PDB ID 1E8X). The domains are colored according to (a). Lutetium ions are shown as green ions, approximating the position of magnesium. The ATP binding site is within the black rectangle. (c) ATP binding site (PDB ID 1E8X). The adenine ring forms hydrogen bonds with the backbone of $\gamma$ Glu880 and $\gamma$ Val882 and stacks between $\gamma$ Ile831 and $\gamma$ Ile963. The $\alpha$-phosphate interacts with $\gamma$ Lys833, $\beta$-phosphate with $\gamma$ Ser806 and $\gamma$-phosphate with $\gamma$ Asn951. The P-loop has been highlighted in blue. (d) The structure of Class IA PI3K. p1108 is shown in gray as surface representation (PDB ID 2WXL). The ABD of p110 $\alpha$ (dark blue, PDB ID 4OVU) and p110 $\beta$ (light blue, PDB ID 2Y3A) are shown in cartoon representation, mediating the binding to iSH2 of $\mathrm{p} 85$ ( $\alpha$, dark green; $\beta$ in light green). The $\mathrm{nSH} 2$ from PI3K $\alpha$ is shown in yellow, and the cSH2 from PI3K $\beta$ is shown in brown.

It was another seven years before the structure of a Class IA PI3K was published [82]. One of the major complicating factors in the crystallization of the Class IA PI3K isoforms is the requirement to co-express with p85 for stability. Full-length p85 has an SH3 domain, Bcl-2 homology (BH) domain and two SH2 domains, connected by the inter-SH2 (iSH2) domain (Figure 1a). The minimum construct of $\mathrm{p} 85 \alpha$ required for stable expression of $\mathrm{p} 110 \alpha$ is the N-terminal SH2 (nSH2) and the iSH2 domains [83]. In 2007, Huang et al. [82] published the wild-type structure of $\mathrm{p} 110 \alpha$ in complex with this truncated construct of p85 $\alpha$ (PDB ID 2RD0) (Figure 1d). Despite only 35\% sequence identity, the overall fold of p110 $\alpha$ displays a high degree of similarity to p110 $\gamma$. The iSH2 domain is an extended coiled-coil 
which interacts with $\mathrm{p} 110 \alpha$ via the $\mathrm{ABD}$ and $\mathrm{C} 2$ domains. The electron density for the $\mathrm{nSH} 2$ domain of p $85 \alpha$ was disordered, and the domain was not able to be traced [82]. Two years later, the structure of an oncogenic mutant PI3K $\alpha, \mathrm{H} 1047 \mathrm{R}$, was determined in the presence of wortmannin (PDB ID 3HHM) [84]. The slightly higher resolution allowed for the tracing of the nSH2 domain.

Crystal structures of murine p1108 followed in early 2010 [85]. A tobacco etch virus (TEV) protease cleavage site was introduced between the ABD and the RBD. A complex containing p1108 and iSH2 of $\mathrm{p} 85 \alpha$ was expressed, and then the ABD cleaved with TEV protease, leaving just

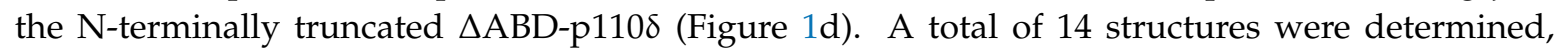
including the holo-enzyme and the enzyme in complex with a range of pan-PI3K and PI3K $\delta$ selective inhibitors [85].

The last isoform to be crystallized was PI3K $\beta$ [86]. Unlike p110 $\alpha$, it was found that the C-terminal $\mathrm{SH} 2$ domain $(\mathrm{cSH} 2)$ of $\mathrm{p} 85$ was more important than the $\mathrm{nSH} 2$ for stabilization and inhibition of p110 $\beta$ [86]. For crystallization, therefore, murine $p 110 \beta$ was expressed in complex with the iSH 2 and $\mathrm{CSH} 2$ domains of $\mathrm{p} 85 \beta$. No structure of the holo-enzyme was reported, only that in complex with the pan-PI3K inhibitor, GDC-0941 (PDB ID 2Y3A) (Figure 1d). It should be noted that the human p110 $\beta$ has a N-terminal extension of six amino acids compared with the mouse, which affects the numbering of amino acids. The numbering for human $\mathrm{p} 110 \beta$, which differs from the crystal structure numbering, will be used in this paper.

Inhibitor bound structures have continued to be published for each of the isoforms. For PI3K $\gamma$, a total of 97 structures have currently been deposited to the Protein Data Bank (PDB) (as of 25 January 2019) [87]. The first crystal structures of $P I 3 K \alpha$, while revealing key insights into mechanisms of regulation, were of limited use for structure-based drug design, as the soaking of substrate or inhibitors was precluded by the binding of the RBD of a symmetry-related molecule in the ATP-binding site. Hon et al. [88] were able to co-crystallize an inhibitor with a similar construct using different crystallization conditions (PDB ID 4A55). However, a resolution of $3.5 \AA$ is still less than ideal for revealing molecular details of binding and insights into inhibitor selectivity. In an attempt to address these issues, three further constructs have been published that yield higher resolution, inhibitor bound structures. Firstly, a double mutant in the RBD (M232K, L233K) was engineered to influence crystal packing. The mutant packs differently, such that the linker between the ABD and RBD from a neighboring molecule inserts in the space near the ATP-binding site, but does not occlude it, allowing for the soaking or co-crystallization with inhibitors [65,89]. The two crystal structures of this construct in the PDB (PDB ID 4JPS, 4ZOP) are higher resolution ( $2.2 \AA$ and $2.6 \AA$ ) than the wild-type structure (2.9-3.5 $\AA$ ). Another alternative was an N-terminal fusion of p85-niSH2 to p110 $\alpha$, with a glycine/serine linker between the two (PDB ID 4L1B, 4L23, 4L2Y, 4YKN) [90,91]. This has the benefit of increasing homogeneity of the complex, and results in a corresponding increased resolution compared with the original wild-type structures (2.5-2.9 $\AA$ ). Finally, an isolated p110 $\alpha \Delta$ ABD construct with a C-terminal truncation of lipid binding residues, was also produced (PDB ID 4TUU, 4TV3) [92]. While not catalytically active, this construct still binds PI3K $\alpha$ inhibitors and crystallizes with medium resolution (2.6-2.8 $\AA$ ). A total of 41 structures of PI3K $\alpha$ have been deposited in the PDB (as of 25 January 2019). Representative structures from each of the constructs overlay well with the original wild-type structure (PDB ID 2RD0), with RMSDs ranging from 0.7-1.1.

Only one further murine PI3K $\beta$ crystal structure has been published, using a similar $\triangle \mathrm{ABD}$ construct to that of $\triangle \mathrm{ABD}-\mathrm{p} 110 \delta$ [71]. A total of 46 PI3K $\delta$ structures have been deposited into the PDB (as of 25 January 2019). In addition to the murine $\triangle A B D-p 110 \delta$ structure, human p1108/iSH2 structures have also been published (PDB ID 5T8F, 5UBT, 5VLR), with lower resolution than the $\triangle \mathrm{ABD}$ structures (2.8-2.9 ̊̊) [93-95].

\section{Structural Determinants of Isoform Selectivity}

Class I PI3Ks have a highly homologous ATP binding site that only differs in a handful of residues at the periphery of the binding site. These non-conserved residues cluster into two regions, 
designated Regions 1 and 2, which influence inhibitor selectivity [96,97]. The growing collection of structure-selectivity-activity relationships (SSAR) from extensive medicinal chemistry efforts has revealed that understanding the structural basis of isoform selectivity is far from a simple task. It is the complex, combinatorial product of differences in non-conserved residues, conformational flexibility, hydrogen bond networks, and interactions in the varying regions of the binding site. We have collated the available data gained from X-ray crystallography, computational modeling, and mutagenesis studies to provide an analysis of the various mechanisms of selectivity. We will first present a road-map of the various regions of the ATP-binding site, and then discuss the influence of these regions on the selectivity of various isoform selective inhibitors. The extensive literature on PI3K inhibitors, which has been the subject of a recent review (418 patents and 192 medicinal chemistry publications since 2012 [64]), precludes a detailed analysis of every inhibitor. In this review, we have chosen to concentrate on inhibitors with published data on isoform selectivity as well as structural information on binding mode, and particularly those inhibitors that yield insight into general principles of the structural determinants of isoform selectivity.

\subsection{Regions of the Binding Site}

\subsubsection{Hinge-Region}

One of the most important features of kinase inhibitors is the presence of a "hinge-binder" (Figure 2a,b). The ATP binding site sits at the interface between the two lobes of the kinase domain, and the presence of a hinge-binding motif, such as a morpholinyl or purinyl substituent, mimics the adenine ring of ATP and acts to anchor the inhibitor in the binding site via hydrogen bonds to the backbone of $\gamma$ Ile881 (valine in $\alpha, \beta$ and $\delta$ ) and / or $\gamma$ Val 882 (conserved across all isoforms). The presence of this hinge interaction is preserved in all inhibitor-bound structures determined to date. Although these two residues are invariant or highly similar between the isoforms (valine-isoleucine), the adjacent residues ( $\gamma$ Lys883, $\gamma$ Asp884 and equivalent) are not conserved, which may present opportunities for modifications of the hinge-binding moiety to influence selectivity (Figure 2c).

\subsubsection{Specificity Pocket}

The specificity pocket was first identified in the PIK39-p110 $\gamma$ crystal structure (PDB ID 2CHW, Figure 2d) [9]. PIK39 (2) is a PI3K $\delta$ selective inhibitor that exhibits mid-nanomolar potency at PI3K $\delta$, and 100x selectivity over PI3K $\beta$ and PI3K $\gamma$, and no inhibition of PI3K $\alpha$ at concentrations up to $100 \mu \mathrm{M}$ [9]. The inhibitor induces an outward movement of a conserved methionine residue on the P-loop to reveal a hydrophobic binding pocket, designated the specificity pocket. Inhibitors of this type are said to bind in a "propeller" conformation, as opposed to the relatively flat conformation of inhibitors that do not access the specificity pocket. As it was originally discovered in PI3K $\delta$ selective inhibitors, opening of the specificity pocket was thought to confer PI3K $\delta$ specificity, but now PI3K $\beta$ and PI $3 \mathrm{~K} \gamma$ selective propeller-shaped inhibitors have also been discovered, suggesting the situation is more complex $[57,71,98]$. The residues directly involved in the opening of the specificity pocket are conserved between the isoforms, but there is computational and biochemical evidence to suggest that non-conserved residues surrounding the pocket may variously influence the accessibility of the pocket. Such evidence suggests that the specificity pocket may be most energetically accessible in PI3K $\beta$ and $\delta$. However, the existence of $\mathrm{PI} 3 \mathrm{~K} \gamma$ and PI3K $\gamma / \delta$ selective propeller-shaped inhibitors indicates a level of accessibility in PI3K $\gamma$, too; this may be due to other features of the inhibitor which overcome the energetic restrictions to the pocket opening, or it may be more easily accessed than initially anticipated.

A comparison of $\mathbf{2}$ in both p110 $\gamma$ and p1108 (PDB ID 2WXF) crystal structures revealed that the movement in p1108 is limited to local changes in the P-loop, whereas opening of the specificity pocket in p110 $\gamma$ requires a more extensive conformational change that propagates through the P-loop into the helices of the N-lobe $[9,85]$. Sequence differences between the isoforms may account for variations in the conformational plasticity of the P-loop. p110 $\gamma$ has an extended loop between the $k \alpha 1$ and $k \alpha 2$ 
helices, which is absent in the three Class IA isoforms (Figure 2d). This loop packs next to the P-loop and may contribute to differences in flexibility [85].

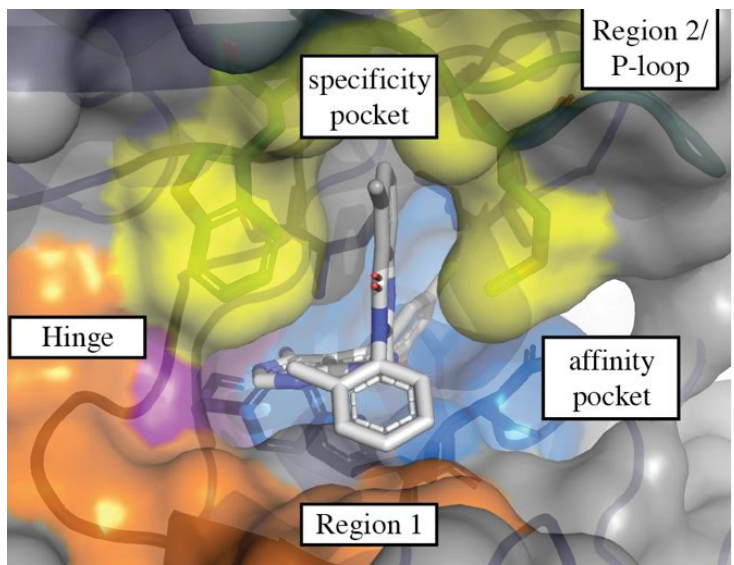

(a)

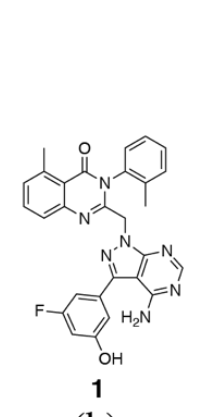

(b)

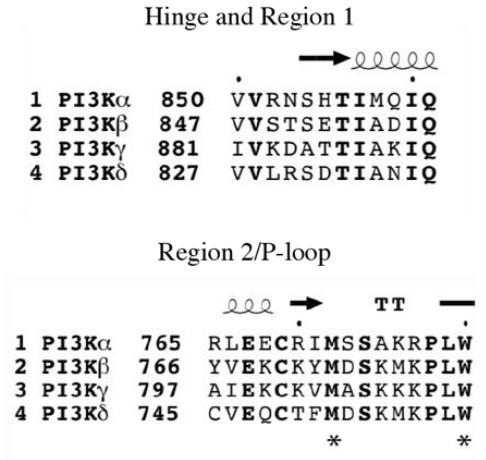

(c)

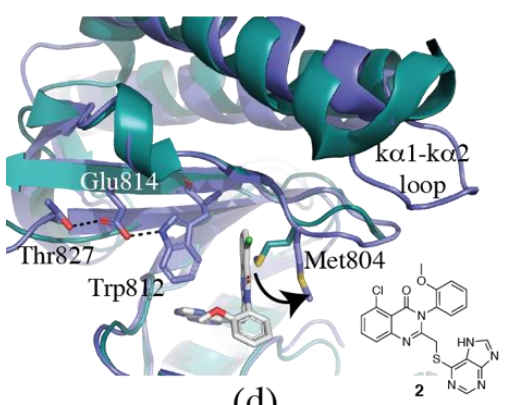

(d)

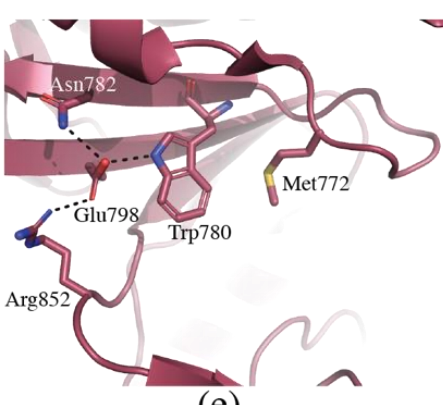

(e)

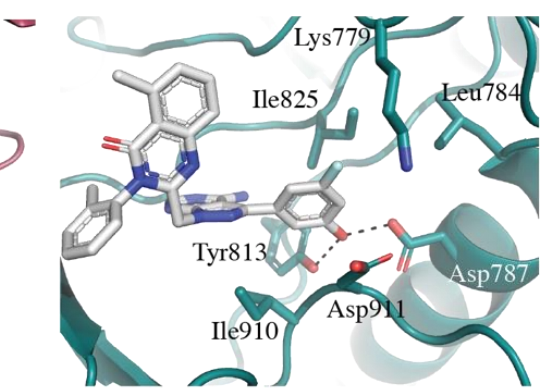

(f)

Figure 2. Regions of the binding site. (a) Overall picture of the inhibitor binding site with 1 bound (p1108, PDB ID 2WXG). The hinge region is shown in purple, the affinity pocket in blue and the open specificity pocket in yellow. Region 1 is shown in orange. The P-loop is shown in teal. (b) Structure of 1. (c) Sequence alignment of hinge and Regions 1 and 2. (d) The specificity pocket in p1108 and p110 $\gamma$. p1108 is shown in teal (PDB ID 2WXG) and p110 $\gamma$ is shown in slate (PDB ID 2CHW). The movement of $\gamma$ Met804 required for opening of the specificity pocket is marked by an arrow. PIK39 2 is shown in the binding site. The extended loop between the $\mathrm{k} \alpha 1$ and $\mathrm{k} \alpha 2$ helices in $\mathrm{p} 110 \gamma$ is indicated, along with the stabilizing hydrogen bond interactions with $\gamma \operatorname{Trp} 812$. (e) Stabilizing interactions of $\alpha \operatorname{Trp} 780$ in p110 $\alpha$ (PDB ID 4JPS). (f) The affinity pocket. The structure of 1 bound to p1108 (PDB ID 2WXG), with key residues in the affinity pocket marked.

Molecular dynamics simulations showed that in p1108 opening of the pocket involves a synchronized movement between $\delta \operatorname{Trp} 760$ and $\delta$ Met752 [85]. In p110 $\gamma$, however, $\gamma \operatorname{Tr} p 812$ (equivalent to $\delta \operatorname{Trp} 760$ ) is constrained by a hydrogen bond to $\gamma$ Glu814, which in turn interacts with $\gamma$ Thr827. This hydrogen bond network reduces the flexibility of $\gamma \operatorname{Trp} 812$, thus potentially disfavoring the opening of the specificity pocket (Figure 2d) [85].

The specificity pocket has now been observed in crystal structures of all Class I isoforms. A comparison between the 'closed' (PDB ID 4JPS) and 'open' (PDB ID 4A55) p110 $\alpha$ crystal structures reveals a similar network of hydrogen bonds restricting tryptophan movement to that found in $\mathrm{p} 110 \gamma$ : $\alpha \operatorname{Trp} 780$ (equivalent to $\delta \operatorname{Trp} 760$ ) is restrained by a hydrogen bond to $\alpha$ Glu798, which in turn is held in place by interactions with $\alpha \operatorname{Arg} 852$ and $\alpha$ Asn782 (Figure 2e). In the 'open' conformation, the hydrogen bond to $\alpha$ Glu798 is maintained, however the anchoring interactions with $\alpha \operatorname{Arg} 852$ and $\alpha$ Asn782 are absent. It should be noted that the resolution of the 'open' structure is only $3.5 \AA$, and detailed information on the positioning of side-chains may not be present [88]. Analysis of the available SSAR data surrounding the specificity pocket reveals that the propeller-shaped inhibitors consistently show the highest selectivity over PI3K $\alpha$ [85]. The hydrogen bond network restricting $\alpha \operatorname{Trp} 780$ movement 
may contribute to this, but it is also possible that there are more complex interactions restricting P-loop flexibility in $\mathrm{p} 110 \alpha$.

A detailed comparison between the 'closed' (PDB ID 2Y3A) and 'open' (PDB ID 4BFR) p110 $\beta$ structures is confounded because of the different constructs used for crystallization [71,86]. The 'closed' structure has the iSH2 and $\mathrm{cSH} 2$ domains from $\mathrm{p} 85 \beta$, while the 'open' structure is $\triangle \mathrm{ABD}$. There are some significant conformational changes between the two structures, however these are more likely to be caused by the presence or absence of the $p 85 \beta$ domains. Neither of the structures reveals a constricting hydrogen bond network to $\beta \operatorname{Trp} 781$, presumably contributing to the relative ease of opening of the specificity pocket in PI3K $\beta$ compared with $\mathrm{PI} 3 \mathrm{~K} \alpha$.

A reciprocal mutagenesis study identified a non-conserved residue in PI3K $\beta, \beta$ Tyr778, adjacent to the conserved methionine that may also contribute to the extent of conformational plasticity of the P-loop [98]. The residue in this position is aliphatic in p110 $\alpha$ and p110 $\gamma$ (isoleucine and valine, respectively), but aromatic in $\mathrm{p} 110 \beta$ and p110 (tyrosine and phenylalanine, respectively), which may account for the similar profiles of inhibitors for these two pairs of isoforms.

Each of these mechanisms likely contribute to the apparent differences in accessibility of the specificity pocket between the four isoforms. However, it is also apparent that inhibitor selectivity is not simply determined by the opening of the specificity pocket, but rather a complex amalgamation of inhibitor interactions throughout the binding site.

\subsubsection{Affinity Pocket}

The affinity pocket is a pocket that is not accessed by ATP, and is surrounded by the conserved

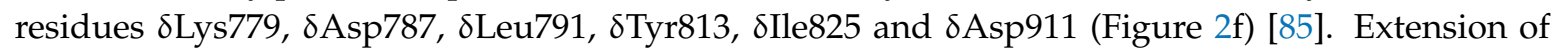
inhibitors into this pocket has been shown to increase potency and despite consisting of only invariant residues, can also surprisingly modulate selectivity. Differences in selectivity may be influenced by distinct hydrogen bonding networks to non-conserved residues surrounding the pocket. This will be discussed more below with specific inhibitor examples.

\subsubsection{Non-Conserved Regions}

We have previously described two regions of non-conserved residues that contribute to isoform selectivity [96,97]. Region 1 (alternatively described as hydrophobic region II or ribose binding pocket), which is a region of eight amino acids C-terminal to the hinge region (8829-836), has four positions of complete variability between the four isoforms, and two positions with a single isoform not conforming (Figure 2a,c). Isoform specific interactions with this region have been shown to be vital in the development of isoform selective inhibitors. Region 2 coincides with the P-loop, and while less variable than Region 1, key amino acid differences in this region still influence selectivity via specific interactions and may also affect the conformational plasticity of this loop and accessibility of the specificity pocket (Figure 2a,c).

\subsection{PI3K $\delta$ Selective Inhibitors}

The clinically approved PI3K $\delta$ inhibitor, idelalisib (3) along with the clinical candidate umbralisib (4) are both propeller shaped PI3K $\delta$ selective inhibitors (Table 1). Idelalisib (3) (PDB ID 4XE0) binds to p1108 in a similar fashion to PIK39 (2) (Figure 3a,b) [74]. The purine binds to the hinge region, with N3 and N9 forming hydrogen bonds with the backbone carbonyl and nitrogen of $\delta \mathrm{Glu} 826$ and $\delta$ Val828, respectively. The N7 of the purine forms a water-mediated hydrogen bond network with $\delta$ Asp 911 and N1 of the quinazolinone. The substituted quinazolinone moiety binds in the specificity pocket, with the phenyl group orienting perpendicular to the quinazolinone and extending toward Region 1. The structure of umbralisib (4, Figure $3 b)$ is related, with a 4-amino-pyrazolo-pyrimidine serving as the hinge binder and a chromone binding in the specificity pocket. It has traditionally been accepted that binding in the specificity pocket confers PI3K $\delta$ selectivity, but as has been discussed above, the emerging picture is significantly more complicated. So what sets PI3K $\delta$ selective propeller inhibitors 
apart from PI3K $\beta, \mathrm{PI} 3 \mathrm{~K} \gamma$ and dual selectivity inhibitors? The impact of the hinge region, affinity pocket and Region 1 (targeted by the 'third blade' of the propeller) cannot be underestimated and will be discussed in more detail below. As for the specificity pocket moiety, the most common motifs in PI3K $\delta$ selective inhibitors are 6,6 and 5,6-fused heterocyclic aromatic ring systems, which have been reviewed in detail by Perry et al. [49]. Halogen substitutions at the 5- and 8-positions of a quinazolinone core show a 10x range in PI3K $\delta$ potency and some limited variation in selectivity (Table 2) [99]. Such substitutions are predicted to modify the basicity of $\mathrm{N} 1$, which in the related crystal structure of p1108-idelalisib (3) makes a water-mediated hydrogen bond with $\delta$ Asp911. The 5,8-dichloro analog 10 has a dramatic increase of selectivity over PI3K $\gamma(470 \mathrm{x})$ compared with the monochloro analogs, 8 and $9\left(120 x\right.$ and $183 x$, respectively). The $\mathrm{N} 1 \mathrm{pK}_{\mathrm{a}}$ is reduced from $1.97(8)$ and $1.72(9)$ in the monochloro analogs to $0.48(\mathbf{1 0})$, at first suggesting a correlation; however, the $\mathrm{pK}_{\mathrm{a}}$ in the 8-chloro-5-fluoro analog 11 is further reduced to 0.28 , and the $\delta / \gamma$ selectivity is reduced back to $127 x$. A clear structural rationale is unavailable to account for these dramatic selectivity differences from subtle chemical changes. In another series of quinazolinone inhibitors, the 6-fluoro substituent in 12 dramatically reduces selectivity over PI3K $\alpha$ to only 8x [100]. Combining this with an 8-chloro substitution in 13 restores selectivity to $>100 x$. In a similar series reported by Patel et al. [101] (Table 2), a 6-F substitution (15) has a limited effect on $\delta / \alpha$ selectivity. 5-halogen substituents (16) show improvement in PI3K $\delta$ potency and selectivity compared with an unsubstituted ring. Other series expounding SSAR on limited halogen substitution around quinoline and quinoxaline cores have also been published [72,102]. In a series of benzimidazole based inhibitors, 5- or 6-fluoro substituents made significant differences in selectivity, from $>1800 x(6)$ to $189 x(5)$ at $\mathrm{PI} 3 \mathrm{~K} \alpha$, and less so over PI3K $\beta$ (52x (6), 181x (5)) and $\gamma(42 \mathrm{x}$ (6), 79x (5)) (Figure 3c) [103]. Longer or bulkier substitutions at the 5-position of a quinazolinone have also been explored (7) (Figure 3c) [104]. Although no crystal structures of these compounds bound to PI3K are available, docking studies suggest that these substitutions may access non-conserved $\delta \mathrm{Gln} 748$ ( $\alpha$ : Glu, $\beta$ : Lys, $\gamma$ :Lys) and $\delta$ Lys712 ( $\alpha$ :Met; $\beta$ : Lys; $\gamma:$ Ile), which may contribute to their selectivity (Figure 3a) [104]. It is clear from the limited SSAR available that substitutions around the bicyclic specificity pocket core can modulate both $\mathrm{PI} 3 \mathrm{~K} \delta$ potency and selectivity, although a structural rationale for many of these differences is elusive. Specific features of PI3K $\beta$ and $\gamma$ propeller-shaped inhibitors will be discussed further in the following sections.

It is well established that extension of the inhibitor into the affinity pocket not only increases the potency of inhibitors but can also modulate selectivity. In the SW series of inhibitors [85,105], a meta-fluorophenol binding moiety in the affinity pocket yields a potent PI3K $\delta$ inhibitor (1) with $>300 x$ selectivity against PI3K $\alpha$ and PI3K $\beta$, and almost 50x selectivity over PI3K $\gamma$ (PDB ID 2WXG). A simple change to an ortho-substituted fluorophenol (17) reduces potency at PI3K $\alpha, \beta$ and $\delta$, while increasing potency at $\mathrm{PI} 3 \mathrm{~K} \gamma$ (PDB ID $2 \mathrm{WXH})$. The result is an inhibitor that maintains good selectivity over PI3K $\alpha$ and $\beta$ (1000x and 77x, respectively), but completely loses selectivity over PI3K $\gamma$ [85]. The hydroxyl group in $\mathbf{1}$ can hydrogen bond to both the conserved $\delta$ Asp787 and $\delta$ Tyr813, while $\mathbf{1 7}$ can only form a hydrogen bond to $\delta$ Asp787 (Figure $4 a, b$ ). This may explain the loss of potency at PI3K $\alpha, \beta$ and $\delta$, but does not explain why the inhibitor gains potency at PI3K $\gamma$. The affinity pocket is comprised of conserved residues, making these selectivity differences difficult to rationalize. 


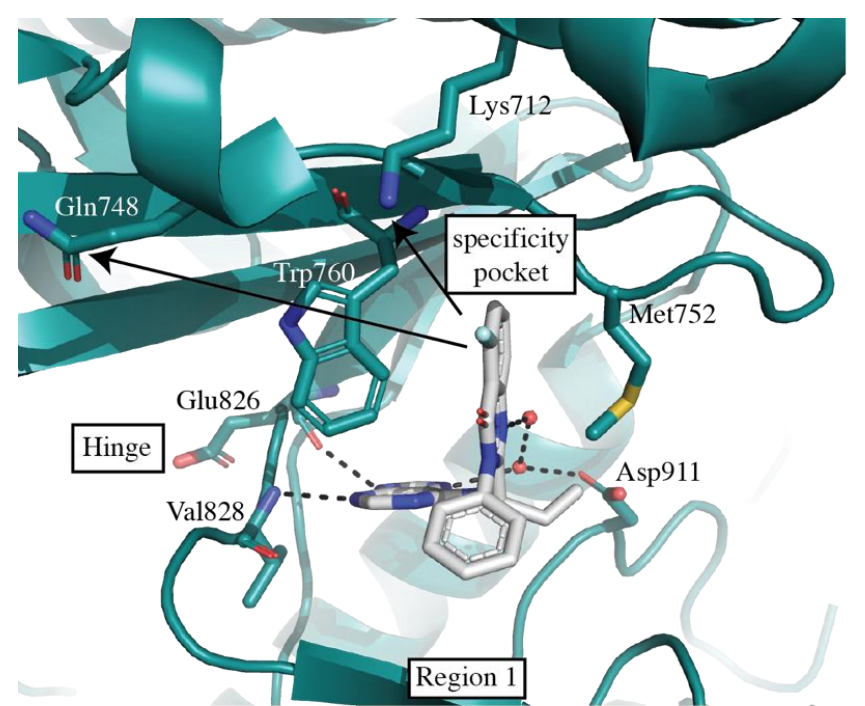

(a)
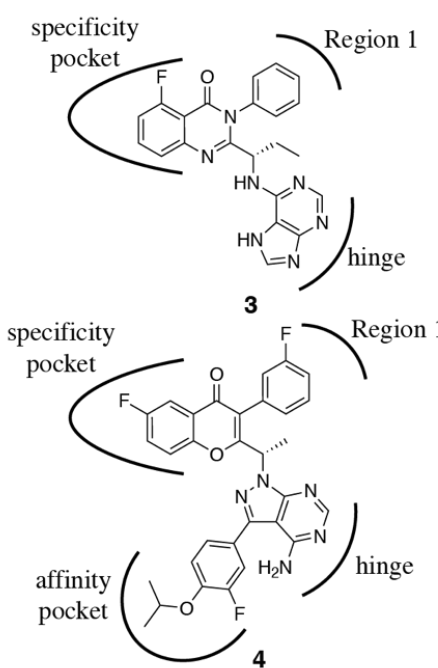

(b)
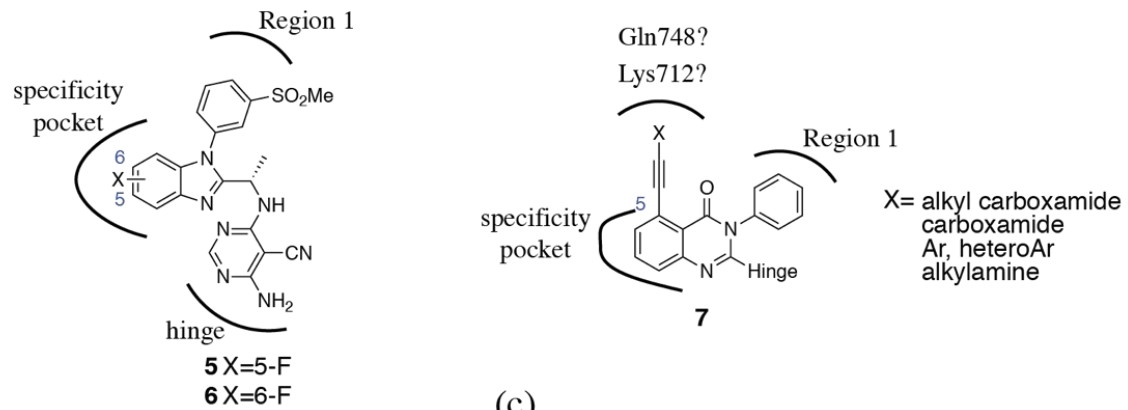

(c)

Figure 3. Modifications of the specificity pocket binding moiety. (a) Idelalisib (3) bound to p110 (PDB ID 4EX0). Substituents at the 5-position of 7 are predicted to interact with either $\delta$ Lys712 or $\delta$ Gln748. (b) Structure of idelalisib (3) and umbralisib (4). (c) Structures of 5-7.

Table 2. Effects of modifications around a quinoxalinone core on potency and selectivity. Substitutions modify the basicity of N1, which is colored in red.

\begin{tabular}{|c|c|c|c|c|c|c|c|}
\hline \multirow{2}{*}{ Compound } & \multirow{2}{*}{$\mathbf{R} 1$} & \multirow{2}{*}{ R2 } & \multirow{2}{*}{ R3 } & \multirow{2}{*}{$\begin{array}{c}\mathrm{IC}_{50}(\mathrm{nM}) \\
\text { PI3K }\end{array}$} & \multicolumn{3}{|c|}{ Fold Selectivity } \\
\hline & & & & & $\alpha / \delta$ & $\beta / \delta$ & $\gamma / \delta$ \\
\hline $8^{1}$ & $5-\mathrm{Cl}$ & & \multirow{4}{*}{$\mathrm{CN}$} & 0.6 & 1716 & 166 & 120 \\
\hline $9^{1}$ & $8-\mathrm{Cl}$ & & & 6 & 517 & 65 & 183 \\
\hline $10^{1}$ & $5,8-\mathrm{Cl}$ & & & 0.7 & 1857 & 108 & 470 \\
\hline $11^{1}$ & $5-\mathrm{F}, 8-\mathrm{Cl}$ & & & 0.4 & 1925 & 115 & 127 \\
\hline $12^{2}$ & $6-\mathrm{F}$ & & \multirow{2}{*}{$\mathrm{Cl}$} & 9.8 & 8 & 4 & 238 \\
\hline $13^{2}$ & $6-\mathrm{F}, 8-\mathrm{Cl}$ & & & 5.3 & 109 & 1.5 & $>357$ \\
\hline $14^{3}$ & $\mathrm{H}$ & & \multirow{3}{*}{$\mathrm{CN}$} & 15 & 530 & 290 & 74 \\
\hline $15^{3}$ & $6-\mathrm{F}$ & & & 4.8 & 600 & 520 & 160 \\
\hline $16^{3}$ & $5-\mathrm{Cl}, 6-\mathrm{F}$ & & & 2.9 & 780 & 470 & 74 \\
\hline
\end{tabular}

${ }^{1}$ data taken from [99], ${ }^{2}$ data taken from [100], ${ }^{3}$ data taken from [101]. 
The impact of subtle differences in the affinity pocket binding moieties has been also been observed by others. In a series of non-propeller shaped PI3K $\delta$ selective inhibitors, the change of an indazole (18) for an indole moiety (19) in the affinity pocket dramatically reduces the $\delta / \alpha$ selectivity of the inhibitors (Figure 4c) [106]. The indole has 200-600x selectivity for PI3K $\delta$ over the other three isoforms. When replaced with an indazole, the potency for PI3K $\alpha$ improves by $7.5 \mathrm{x}$, while equivalent potency is maintained at PI3K $\beta$ and $\gamma$. Potency at PI3K $\delta$ shows a modest $2 x$ decrease. The authors propose alternate hydrogen bonding networks as influencing the selectivity. In the crystal structure (PDB ID 4EZJ), the indole nitrogen in 19b (a fluorinated analog of 19 that has similar potency and selectivity) forms a hydrogen bond with $\gamma$ Asp841 ( $\delta$ Asp787), while the $\mathrm{CH}$ is positioned $3.1 \AA$ from the $\gamma$ Tyr867 ( $\delta$ Tyr813) hydroxyl, which in turn hydrogen bonds to the backbone carbonyl from $\gamma$ His 962 (8His909). The indazole 18 (PDB ID 4EZK), however, can hydrogen bond to both $\gamma$ Asp841 and $\gamma$ Tyr867, which forces a break in the hydrogen bond between $\gamma$ Tyr867 and $\gamma$ His962. The authors propose that this change may be more easily accommodated in the p1108 isoform [106]. The rationale for the PI3K $\alpha$ potency increase is unclear. Erra et al. [107] also found that modulations in the affinity pocket could influence selectivity over PI $3 \mathrm{~K} \alpha$. Changes to the phenyl substitution pattern greatly affected selectivity (20, 21, Figure 4d). The authors hypothesize that a double interaction with both $\delta$ Lys779 and $\delta$ Asp787 could compensate for the energy cost needed to open the specificity pocket in PI3K $\alpha$ [107]. However, in a series of pyrrolotriazinone propeller shaped compounds, a pyrazole moiety in the affinity pocket (22) forms a triple interaction with the conserved $\delta$ Asp787, 8 Lys779 and $\delta$ Asp911 (PDB ID 5I6U) and maintains good selectivity over PI3K $\alpha$ (Figure 4e) [101].

In a series of triazole aminopyrazine PI3K $\delta$ inhibitors, modulation of the affinity pocket binding moiety was able to increase PI3K $\delta$ potency and selectivity against the other isoforms from $63 \mathrm{nM}$ with 100-500x selectivity (23, PDB ID 5T2L) to $0.8 \mathrm{nM}$ with 2000-25000x selectivity (24, PDB ID of des-fluoro analog, 5T2M) (Figure 4e). Interactions with $\delta$ Tyr813 and $\delta$ Asp911 and water interaction networks seem to be key to PI3K $\delta$ potency and selectivity over the other isoforms [108]. Substitutions at the 5-position of a series of pyrrolotriazines that extend into the affinity pocket were able to increase selectivity against the PI3K $\gamma$ isoform [93]. Replacement of a 1-(2,2,2-trifluoroethyl)-1-pyrazole (25, PDB ID 5VLR) with a chloro substitution (26) increased selectivity over PI3K $\gamma$ from 37x to 180x. Replacement of the chloro with a trifluoromethyl group (27) showed similar selectivity over PI3K $\gamma$ (Figure 4f) [93].

One potential explanation for the apparent higher tolerance of PI3K $\delta$ for substitutions in the affinity pocket is a non-conserved residue beyond the affinity pocket. In p110 $\gamma$ crystal structures, $\gamma$ Arg849 forms a hydrogen bond with the backbone of $\gamma$ Tyr867, presumably restricting the flexibility of this residue (Figure $4 \mathrm{~g}$ ). The residue at the equivalent position in $p 110 \alpha$ and $\beta$ is also an arginine. However, in p1108, the residue at the equivalent position is $\delta \mathrm{Gln} 795$, and the shorter sidechain length precludes formation of a hydrogen bond and may allow for greater flexibility.

Surprisingly, even modification of the hinge binding moiety can influence selectivity. Like the affinity pocket, the hinge residues are conserved between the four isoforms. Modification of the hinge-binder of duvelisib from the purine ring to the 4-amino,5-cyano-pyrimidine 28 was able to increase selectivity for PI3K $\delta$ from 55-1200x to 200-4600x (Figure 5) [101]. A recent paper from GSK have investigated the combination of a pyridine sulfonamide, which they describe as a privileged PI3K $\delta$ fragment, with a series of hinge binding moieties (29, Figure 5) [109]. They observe marked differences in isoform selectivity that is dependent on the hinge binding moiety. It is very difficult to rationalize these differences in selectivity. 


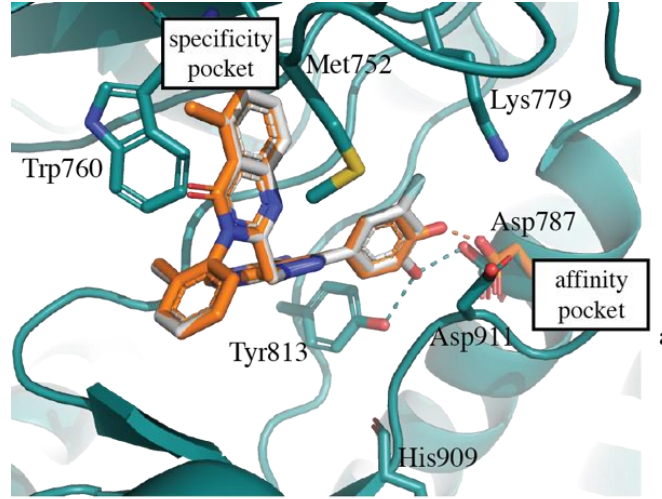

(a)

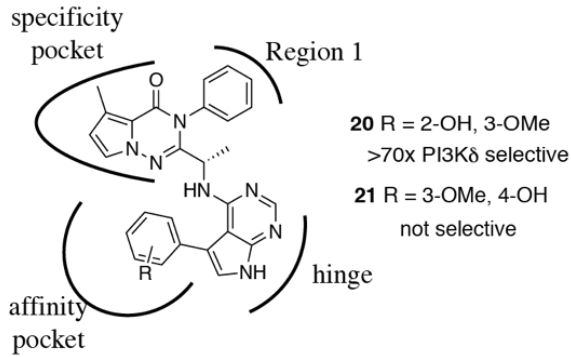

(d)

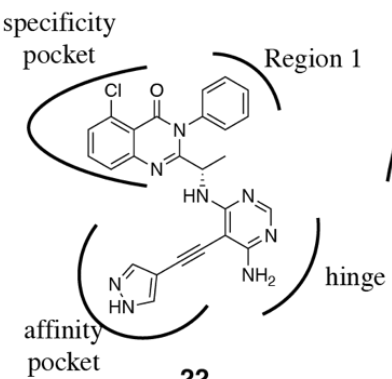

(e)

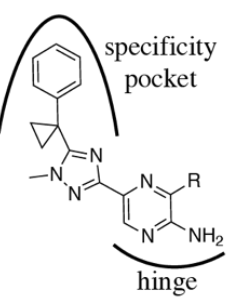

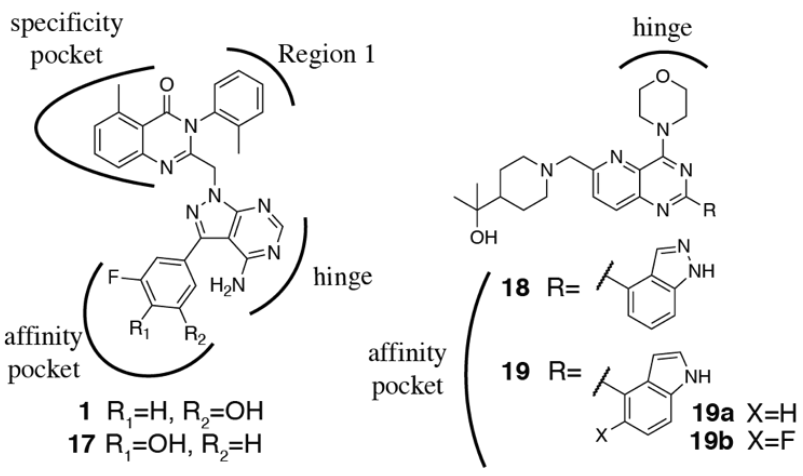

(b)

(c)

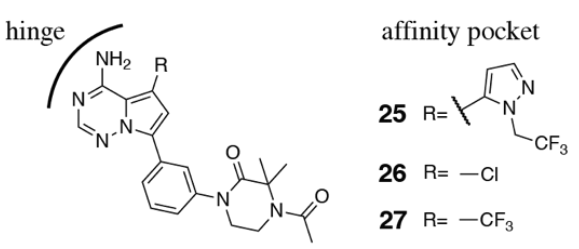

(f)

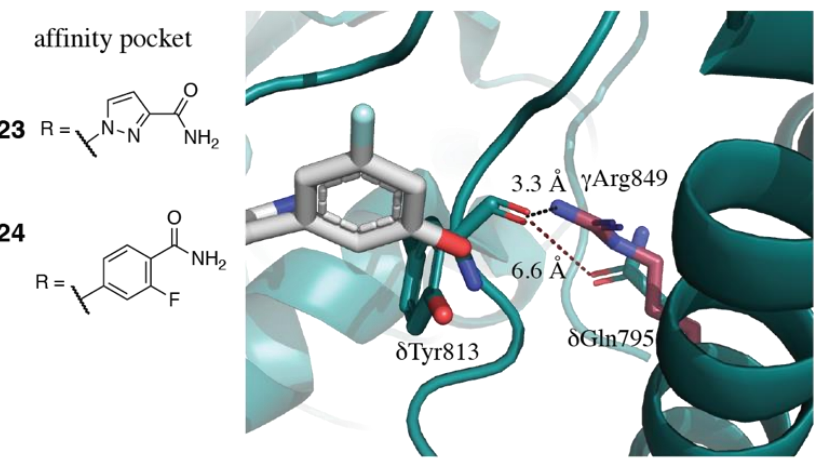

$(\mathrm{g})$

Figure 4. Modifications in the affinity pocket. (a) Impact of subtle differences in the affinity pocket. meta-substituted fluorophenol 1 (white, PDB ID 2WXG) can form hydrogen bonds with $\delta$ Asp787 and $\delta$ Tyr813 (indicated with teal dashed lines), while ortho-substituted fluorophenol 17 (orange, PDB ID $2 \mathrm{WXH}$ ) can only form hydrogen bonds with $\delta$ Asp787 (indicated with orange dashed lines) (b) Structures of 1 and 17 (c) Structures of inhibitors with indole and indazole affinity pocket binding motifs (d) Structures of inhibitors 20-21 (e) Structures of inhibitors 22-24 (f) Structures of inhibitors 25-27 (g) Rationalizing differences in affinity pocket selectivity. $\gamma$ Arg849 forms a hydrogen bond with the backbone of $\gamma$ Tyr867 (equivalent to $\delta$ Tyr813), restricting movement in the affinity pocket, while the side-chain of $\delta \mathrm{Gln} 795$ is too short to make the same interaction. Distances are marked with dashed lines. The fluorophenol moiety of $\mathbf{1}$ bound in the affinity pocket is shown for reference. 


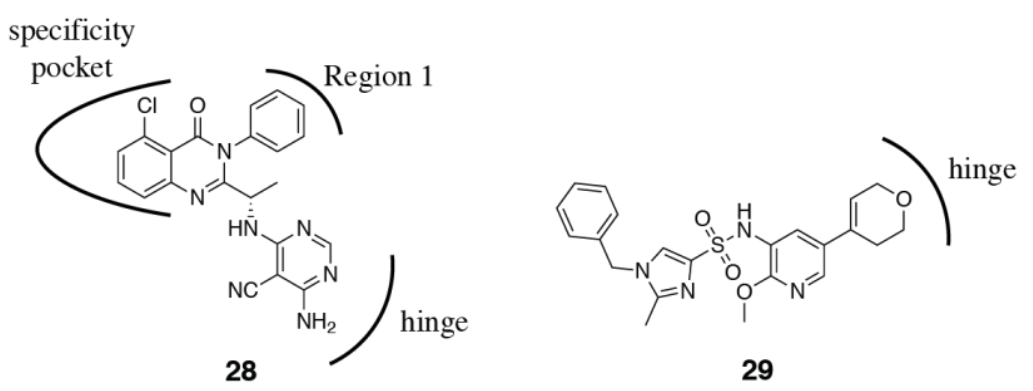

Figure 5. Structures of $\mathbf{2 8}$ and $\mathbf{2 9}$, which demonstrate differences in hinge-binding moieties that affect isoform selectivity.

In addition to the PI3K $\delta$ selective inhibitors that access the specificity pocket, there are a number of other inhibitors which utilize the so-called "tryptophan shelf" that is present in PI3K $[106]$. The tryptophan shelf is formed by the non-conserved $\delta \mathrm{Thr} 750$, which allows inhibitors to access the face of the conserved $\delta \operatorname{Trp} 760$, which forms the tryptophan shelf. In $p 110 \alpha, \beta$ and $\gamma$, this residue is either an arginine ( $\alpha$ Arg770) or a lysine ( $\beta$ Lys777 and $\gamma$ Lys802), which occludes the face of the tryptophan from access by inhibitors (Figure 6a). Sutherlin et al. [106] describe a new class of pyrido-pyrimidine PI3K $\delta$ selective inhibitors (19a and $\mathbf{b}$ ) that show greater than 200x selectivity without accessing the specificity pocket (PDB ID 4EZJ) (Figure 4c). Interestingly, mutagenesis of $\gamma$ Lys802 to a threonine to mimic the tryptophan shelf in PI3K $\delta$ did not significantly alter the potency of the inhibitors for PI $3 K \gamma$. The authors suggest, in a similar fashion to that discussed for the specificity pocket, that further mutations around $\gamma \operatorname{Trp} 812$ may be needed to recapitulate the flexibility of this residue in p1108, and thus the affinity of inhibitors for this isoform [106]. In another series of Genentech tryptophan shelf inhibitors, modification of the core influences the dihedral angle of the tryptophan shelf binding moiety and optimization of the interaction with $\delta \operatorname{Trp} 760$ improves PI3K $\delta$ selectivity $(\mathbf{3 0}, \mathbf{3 1}$, Figure 6b) [110,111]. Bulkier substituents further improved PI3K $\delta$ selectivity, as they are less able to be accommodated by the bulkier arginine and lysine residues in PI3K $\alpha, \beta$ and $\delta$ [111]. Safina et al. [112] describe the rational design of a PI3K $\delta$ inhibitor (33) from a PI3K $\alpha$ selective inhibitor (GDC-0326, 32) by introducing a tryptophan shelf substituent and optimizing the dihedral angles to position it for interaction with $\delta$ Trp760 (Figure 6c). Dalton et al. [113] describe the development of a covalent PI3K $\delta$ inhibitor (34) that achieves its isoform selectivity via the tryptophan shelf, and covalently interacts with the conserved lysine, $\delta$ Lys779 (PDB ID 6EYZ) (Figure 6c). Schwehm et al. [114] have reported the design of a novel tricyclic scaffold (35) which can be used as a tryptophan shelf binding motif (Figure 6c). Clinical candidates GSK2269557 (36) and GSK2292767 (37) both use the tryptophan shelf (PDB ID 5AE8, 5AE9) (Figure 6c) [73], as do a series of pyrazolopyridines described by Hamajima et al. (38, Figure 6c) [115].

To give further insight into how these families of inhibitors achieve their selectivity, crystal structures of the same inhibitor have been determined in two isoforms $[94,108,116]$. The crystal structure of the quinazoline-based inhibitor 39 in p1108 (PDB ID 5IS5) reveals that the acetyl-piperazine group of the ligand stacks with $\delta \operatorname{Trp} 760$ using the tryptophan shelf (Figure 7a) [116]. In p110 $\alpha$ (PDB ID 5ITD), however, the inhibitor cannot bind in the same conformation due to the presence of $\alpha \operatorname{Arg} 770$ $\pi$-stacking with $\alpha \operatorname{Trp} 780$ (equivalent to $\delta \operatorname{Trp} 760$ ). As a result, the inhibitor binds in an extended conformation in $\mathrm{p} 110 \alpha$ and loses the hydrophobic interactions present in the $\mathrm{p} 110 \delta$ complex, resulting in the inhibitor's preference for p1108 [116]. A follow up paper describes further development of this series of inhibitors to optimize the conformation and hydrophobic interactions with $\delta$ Trp760 [75]. Conversely, a similar set of p110 $\alpha$ (PDB ID 5UBR) and p1108 (PDB ID 5UBT) structures show that the pyrrolo-triazine inhibitor 40, binds to $\mathrm{p} 110 \alpha$ and p110 in the same conformation (Figure 7b) [94,117]. In $\mathrm{p} 1108$, the acetylpiperazinyl moiety sits at the tryptophan shelf, and the acyl group forms a hydrogen bond with the hydroxyl from $\delta$ Thr750. In p110 $\alpha, \alpha$ Arg770, which normally occludes the tryptophan shelf, has shifted out of the way to allow the inhibitor to stack with the tryptophan. However, there are no residues for the acyl group to hydrogen bond to. The requirement for the shift of 
the arginine and the lack of hydrogen bond probably contribute to the lower potency observed for PI3K $\alpha$. Further optimization of these inhibitors has been published [118]. A series of triazolo aminopyrazines also utilize the tryptophan shelf for PI3K $\delta$ selectivity. Crystal structures of $\mathbf{4 1}$ in both p110 (PDB ID 5T23) and p1108 (PDB ID 5T27) show that the morpholinyl substituent extends toward the tryptophan shelf in PI3K $\delta$, but must rotate in p110 $\gamma$, since access to the tryptophan residue is blocked by $\gamma$ Lys802(Figure 6a) [108].

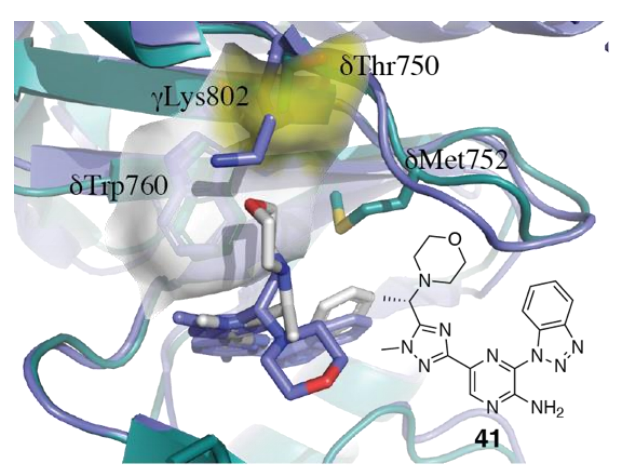

(a)

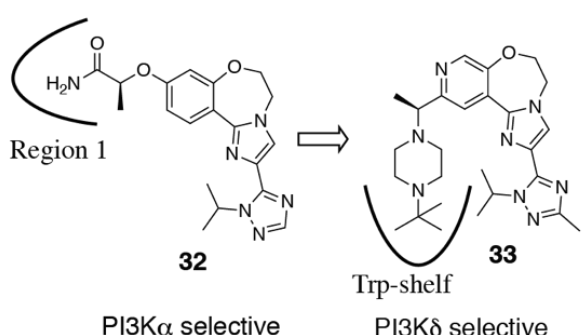

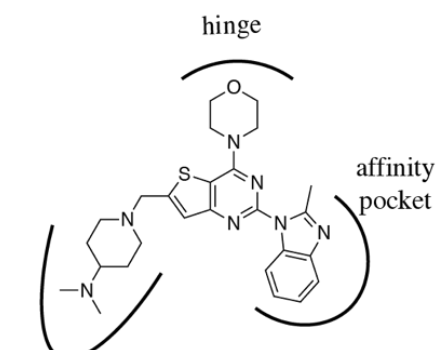

30

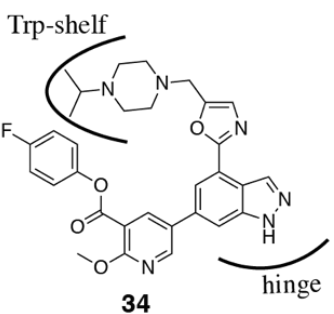

(b)
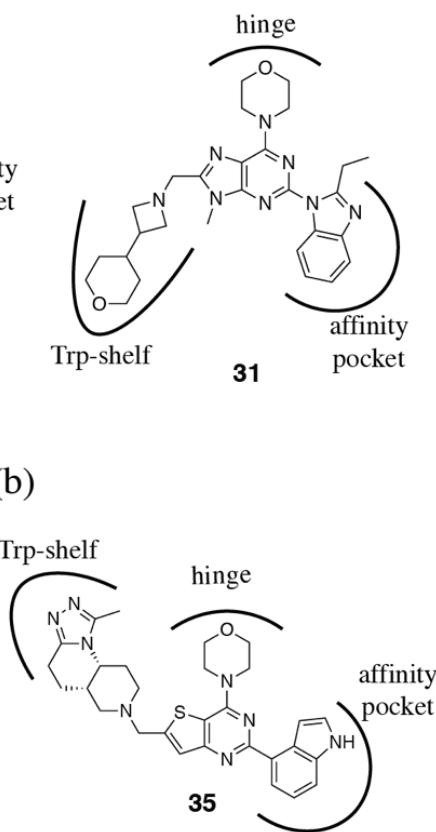

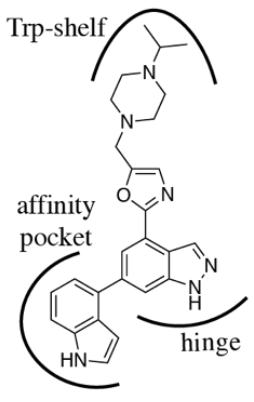

36

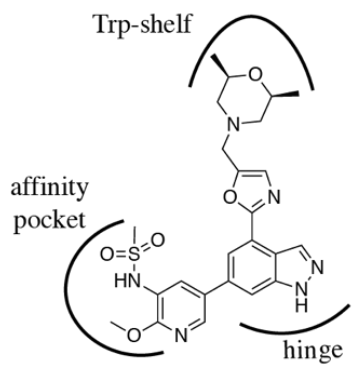

37

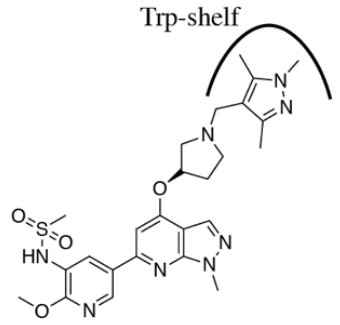

38

(c)

Figure 6. The tryptophan shelf. (a) The tryptophan shelf is formed by the exposed surface of $\delta \operatorname{Trp} 760$ (p1108 cartoon shown in teal, the surface of $\delta$ Trp760 shown in white, PDB ID 5T27) by the small side-chain of $\delta$ Thr750 (surface shown in yellow). In p110 $\gamma$ (slate, PDB ID 5T23), the longer side-chain of $\gamma$ Lys802 occludes the surface of the tryptophan. The different conformations of $\mathbf{4 1}$ bound to p110 (inhibitor colored in white) and p110 $\gamma$ (inhibitor colored in purple) are shown. (b) Structures of 30-31.

(c) Structures of 32-38.

Combinations that take advantage of both the tryptophan shelf and specificity pocket have also been explored. Bulky substitutions at the 4-position of a quinoline specificity pocket binding motif (42) explore the tryptophan shelf from the specificity pocket (PDB ID 5KAE) (Figure 8) [119,120]. A recent paper from GSK have described a novel binding mode for PI3K $\delta$ inhibitors (see compound 29), that involves a "conformational switch" of $\delta \operatorname{Trp} 760$ (Figure 5) [109]. The conformation of $\delta \operatorname{Trp} 760$ flips, such that the indole nitrogen is available to hydrogen bond with inhibitor functional groups that sit at 
the tryptophan shelf. Due to the anchoring hydrogen bonds to the equivalent tryptophan in PI3K $\alpha$ and PI3K $\gamma$ (described in Section 3.1.2), this switch is likely to be energetically unfavorable in these isoforms.
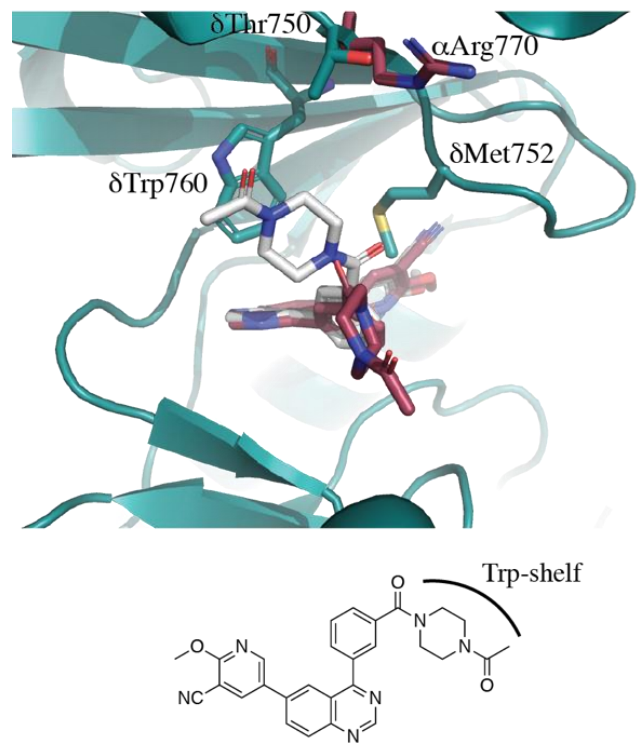

39

(a)

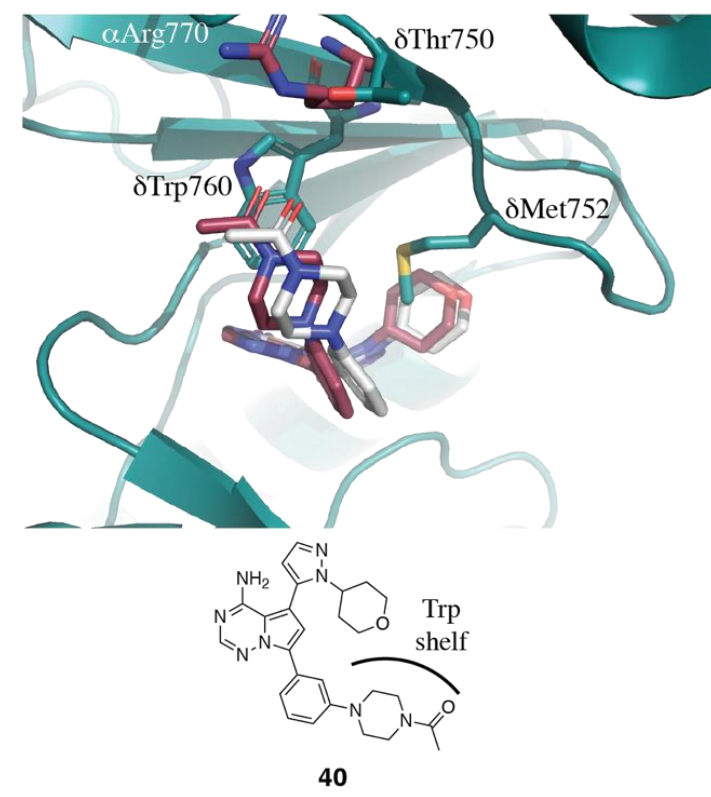

(b)

Figure 7. Comparing tryptophan shelf inhibitors in $\mathrm{p} 110 \alpha$ and $\mathrm{p} 110 \delta$. (a) 39 bound to p1108 (39 in white, p1108 in teal, PDB ID 5IS5) and p110 $\alpha$ (39 in raspberry, PDB ID 5ITD). For simplicity, the cartoon structure of $\mathrm{p} 110 \alpha$ has not been shown. The conformation of $\alpha$ Arg770, which restricts access to the tryptophan shelf in PI3K $\alpha$, has been shown. (b) 40 bound to p1108 (40 in white, p1108 in teal, PDB ID 5UBT) and $\mathrm{p} 110 \alpha$ (40 in raspberry, PDB ID 5UBR). The conformation of $\alpha$ Arg770, which restricts access to the tryptophan shelf in PI3K $\alpha$, has been shown, while the cartoon structure of $\mathrm{p} 110 \alpha$ has been removed for clarity.

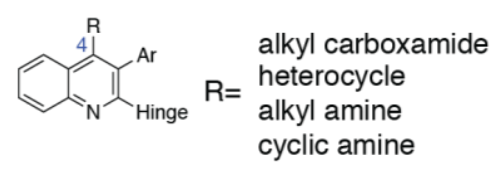

42

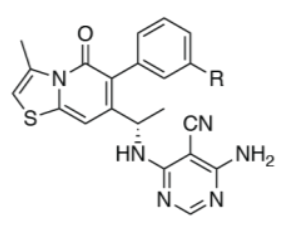

43

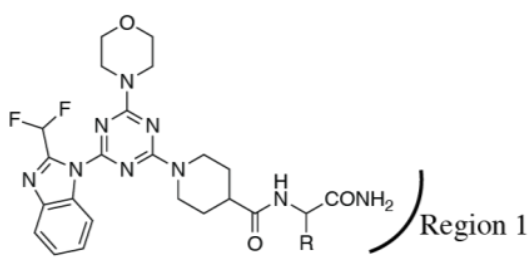

44

Figure 8. Structures of 42-44.

In addition to the specificity pocket, tryptophan shelf and interactions within the affinity pocket, interactions with the Region 1 non-conserved residues (also known as the ribose-binding region or hydrophobic region II) also influence selectivity. There are two key non-conserved residues in particular, which are accessible to inhibitors and are different between all four isoforms: $\delta$ Asp832 (histidine, glutamate and threonine in $\mathrm{p} 110 \alpha, \beta$ and $\gamma$, respectively) and $\delta$ Asn836 (glutamine, aspartate and lysine in $\mathrm{p} 110 \alpha, \beta$ and $\gamma$, respectively) (Figure 2c). Substitutions extending from the phenyl ring in idelalisib (3), or equivalent positions in different chemotypes, which extend toward Region 1 , have been shown to influence selectivity [72,74,103]. Perry et al. [121] in their search for novel propeller-shaped chemotypes, also describe some SSAR of $\mathbf{4 3}$, concentrating on substituents that extend toward Region 1 (Figure 8). Substitution of a primary or secondary amine maintains potency at PI3K $\delta$ and increases selectivity against PI3K $\alpha$ and PI3K $\gamma$, but reduces selectivity against PI3K $\beta$. This can be explained by interactions with interactions with the Region 1 residue, $\delta$ Asn 836 and equivalent in the other isoforms. $\delta$ Asn 836 can accommodate the substitution, but a similar interaction is disfavored in PI3K $\alpha$ by the longer sidechain in $\alpha \mathrm{Gln} 859$. The protonatable amine favors interaction with the negatively charged 
$\beta$ Asp856, resulting in an increase in potency, but results in a repulsive interaction with $\gamma$ Lys890, thus improving selectivity against PI3K $\gamma$ [121]. Our group has also published a series of PI3K $\delta$ inhibitors targeting $\delta$ Asn 836 with a carboxamide motif (44, Figure 8) [122]. The inhibitor showed a 40x decrease in potency when $\delta$ Asn 836 was mutated to an aspartate (present in $\mathrm{PI} 3 \mathrm{~K} \beta$ at the equivalent position), confirming the interaction is important for isoform selectivity.

\subsection{PI3K $\beta$ Selective Inhibitors}

Many of the PI3K $\beta$ selective inhibitors have also been shown to adopt a "propeller-shaped" binding mode. This may explain why many of the reported PI3K $\beta$ selective inhibitors show only moderate selectivity against PI3K $\delta$. Very few of the inhibitors in this category have shown the exquisite selectivity common in PI3K $\delta$ inhibitors, with most showing less than $100 x$ selectivity against PI $3 K \delta$. If, as has already been discussed, the specificity pocket is more easily accessible in both PI3K $\beta$ and PI3K $\delta$, how do inhibitors distinguish between PI3K $\beta$ and PI3K $\delta$ ?

One possibility is the lack of the tryptophan shelf in PI3K $\beta$. The equivalent residue to threonine is a lysine in PI3K $\beta$. The lysine sits on top of the tryptophan and provides an additional constraint to the specificity pocket in PI3K $\beta$ [71]. The PI3K $\beta$ specificity pocket may therefore favor smaller, more hydrophobic moieties. However, a well-positioned hydrogen bond donor may be able to pick up an interaction with the amino group of lysine and increase selectivity for PI3K $\beta$. Indeed, a survey of PI3K $\beta$ selective inhibitors shows that the specificity pocket binding motifs are generally, but not exclusively, smaller than those found in PI3K $\delta$ inhibitors. In a series of pyrimidone PI3K $\beta$ inhibitors (45) with a phenyl specificity pocket motif, substitutions around the phenyl ring significantly affected the selectivity for PI3K $\beta$ against the other isoforms [123]. Meta substitutions in particular seemed to improve both PI3K $\beta$ potency and selectivity. The PI3K $\beta$ inhibitor AZD6482/KIN193 (46) has an ortho-carboxyl substituent on the phenyl ring, however, the lack of a direct comparison in the same assay between this and TGX-221 (47) makes it unclear what effect this substitution has on the PI3K $\beta / \delta$ selectivity (Figure 9) [16,124].

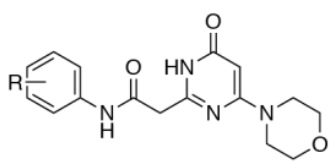

45

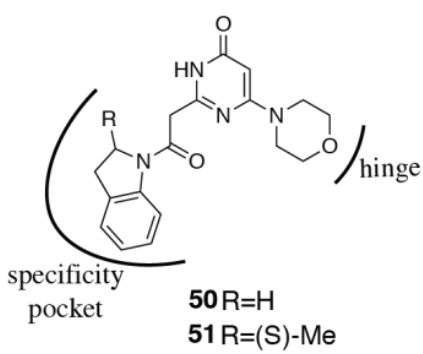

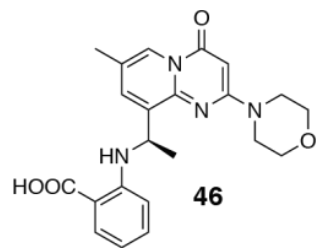

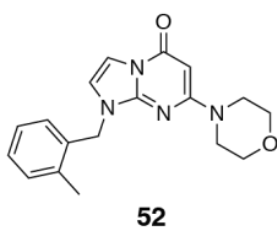

52
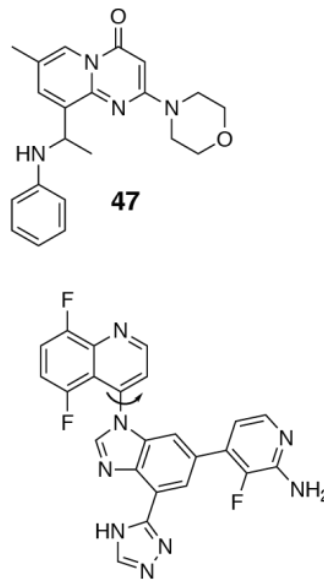

53
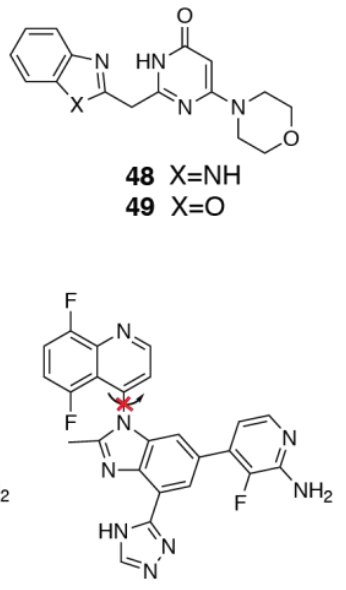

54

Figure 9. Structures of PI3K $\beta$ selective inhibitors 45-54. In the structure of 53, there is free rotation around the bond highlighted with an arrow. The addition of a methyl group at the 2-position of the benzimidazole ring in $\mathbf{5 4}$ restricts rotation, thus forming two atropisomers.

Three related series of inhibitors have also been published, with either a benzimidazole (48), benzoxazole $(\mathbf{4 9})$ or indoline $(\mathbf{5 0}, \mathbf{5 1})$ ring system as the specificity pocket binding moiety (Figure 9) $[71,125]$. The $\beta / \delta$ selectivity of these series is diminished compared with the original PI3K $\beta$ selective inhibitor TGX-221, suggesting smaller substituents are favored by PI3K $\beta$ [15]. However, in a study focusing on $\mathrm{PI} 3 \mathrm{~K} \beta / \alpha$ selectivity, bulkier substituents were found to increase the selectivity over PI3K $\alpha$ [126]. 
Optimal positioning of the specificity pocket binding motif may also have a greater influence on PI3K $\beta$ / $\delta$ selectivity. In a series of imidazopyrimidone PI3K $\beta$ inhibitors, the replacement of a 6,6-bicycle with a 6,5-fused ring system, in addition to shortening the linker to the specificity pocket binding motif (i.e., 52, Figure 9) maintains potency at $\mathrm{PI} 3 \mathrm{~K} \beta$, but also gains activity at $\mathrm{PI} 3 \mathrm{~K} \delta$, thereby reducing the selectivity compared with TGX-221 [127,128]. An overlay of 52 docked into a PI3K $\beta$ homology model shows a significant shift in the position of the phenyl ring in the pocket compared with TGX-221, which may account for the loss in selectivity [127]. In contrast, restricting flexibility of the specificity pocket binding motif and locking it in a propeller shape can increase selectivity. Chandrasekhar et al. [129] describe the development of a pair of atropisomeric compounds, one of which shows improved PI3K $\beta$ potency and selectivity compared with the original analog with unrestricted rotation (53, 54, Figure 9).

The effect of changes in the linker may also affect long-range interactions with the non-conserved residues in Region 1. An interesting study focused on improving the solubility of compound 50 found that a simple methyl substitution (51) increased selectivity for PI3K $\beta$ over PI3K $\delta$ from $7 x$ to $20 x$ (Figure 9). Crystal structures have been determined of $\mathbf{5 1}$ bound to both p110 $\beta$ (PDB ID 4BFR) and p1108 (PDB ID 4V0I), but yield no clues as to the rationalization of the selectivity, since the inhibitor makes no new interactions with the protein [71,130]. In an attempt to explain this striking difference, Robinson et al. [130] used the program, WaterMap, which computationally investigates solvation thermodynamics in the binding site of proteins with ligands bound. They proposed that differences in water networks in $\mathrm{p} 110 \beta$ and $\mathrm{p} 110 \delta$, caused by the non-conserved residues in Region 1 may explain the observed differences in selectivity [130]. This may also provide some rationale for other selectivity differences observed without direct interactions with the protein. For example, in a series of TGX derivatives, methylation of the aniline nitrogen dramatically improves potency at PI3K $\alpha, \gamma$ and $\delta$ without affecting PI3K $\beta$, thus reducing selectivity [69]. The presence or absence of the hydrogen bond donor could have different effects on the water network of the various isoforms due to differences in Region 1. Interactions with Region 1 have been shown to be inconsequential with respect to the $\alpha / \beta$ selectivity of TGX-221 (46) [96], which is presumably more affected by accessing the specificity pocket, but may be more important in distinguishing between PI3K $\beta$ and $\delta$.

The inhibitor BL140 (55), a derivative of TGX-221, with a thiazole replacing the phenyl to improve solubility, has similar PI3K $\beta$ potency, but dramatically improved PI3K $\beta / \delta$ selectivity, from $\sim 80 \mathrm{x}$ to $>700 x$ (Figure 10) [70]. The $\alpha / \beta$ selectivity is slightly reduced from $435 x$ to $154 x$, but still maintains a good level. Unfortunately, no structural or modeling data is available to attempt to rationalize these changes. One possibility is that the inclusion of polar atoms in the ring alters the water networks in a way that favors PI3K $\beta$, as proposed by Robinson et al. [130]. However, it may also be possible that the smaller thiazole ring is not able to force open the specificity pocket, instead making direct interactions with the non-conserved residues of Region 1 and achieving its selectivity in this fashion. The lack of specificity pocket opening could thus explain the gain of potency at the $\alpha$ isoform.

Other inhibitors have shown that interactions with the non-conserved residues of Region 1 play a significant role in determining selectivity. One study looked at rationally building in PI3K $\beta$ inhibitory activity to the PI3K $\delta$ inhibitor, idelalisib (3) [100]. The design strategy was to introduce hydrogen bond donors to the phenyl ring that could interact with $\beta$ Asp862 (Asp856 follows the murine numbering). Quite strikingly, the introduction of a 4-hydroxy substituent (56) to the phenyl ring extending toward Region 1 increased PI3K $\beta$ potency by more than $1000 \mathrm{x}$, while maintaining PI3K $\delta$ inhibition (Figure 10). This indicates the importance of Region 1 for modulating inhibitor selectivity. PI3K $\beta$ selectivity was built into a pan-PI3K inhibitor starting point, ZSTK474 57, using a similar design strategy. The amine group of MIPS-9922 (58) was shown to achieve its selectivity via interaction with $\beta$ Asp862 (Figure 10) [131,132]. Compound 59, which has $>150 x$ selectivity for PI3K $\beta$, extends a morpholine substituent towards the same residue (Figure 10) [133]. Targeting this region proved essential in attempts to improve selectivity against PI3K $\alpha$ to avoid potential side effects related to glucose regulation [134]. 
In many of the PI3K $\beta$ selective inhibitors, the carbonyl sits in the affinity pocket, interacting with $\beta$ Tyr839 or $\beta$ Lys833 [71,98,123,125,126,134-136]. These do not extend as deeply into the affinity pocket as many of the PI3K $\delta$ inhibitors [85]. This smaller binding motif may be important for PI3K $\beta / \delta$ selectivity in particular. In a series of dihydropyrazolo inhibitors, the replacement of a hydroxyl group (60) with the larger carboxyl group (61) reduces $\beta / \delta$ selectivity from 63x to only 8x (Figure 10) [137]. The clinical candidate, GSK2636771 (62) has a carboxyl group in the equivalent position. Unfortunately, an in-depth SSAR analysis has not been published, but presumably this contributes to the limited PI3K $\beta$ / $\delta$ selectivity (10x) of 62 (Figure 10) [138].

Changes in the hinge-binding region can also surprisingly affect the selectivity, as was found in the case of PI3K $\delta$ selective inhibitors. In the chromenone series described by Barlaam et al. [69], a 2-methyl makes little difference in $\mathrm{PI} 3 \mathrm{~K} \beta$ potency compared with the non-substituted morpholine 63 (Figure 10). The chirality of the substituent also is irrelevant for PI3K $\beta$. However, the R-methyl (64) improves PI3K $\alpha$ and $\gamma$ potency, while the S-methyl (65) reduces potency for PI3K $\alpha, \gamma$ and $\delta$, thus improving selectivity (Figure 10) [69].<smiles></smiles>

55

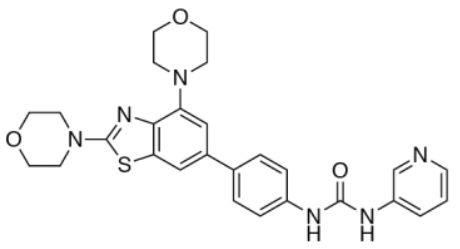

59

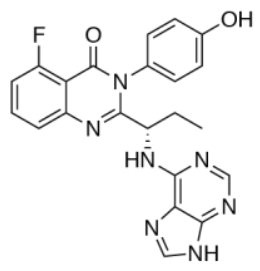

56

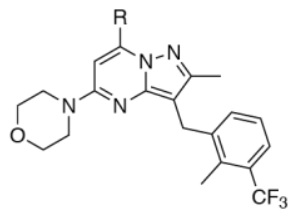

$60 \mathrm{R}=\mathrm{OH}$ $61 \mathrm{R}=\mathrm{COOH}$
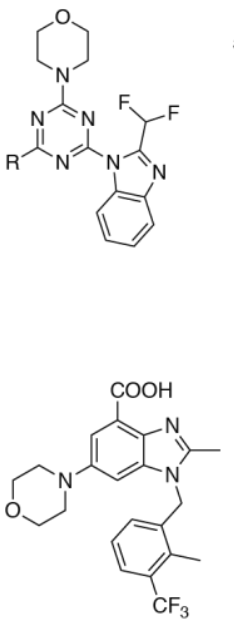

62<smiles>CCN1CCOCC1</smiles><smiles>CCN1CCN(C(=O)C(N)Cc2ccccc2)CC1</smiles><smiles>C[C@H](Nc1cc(F)cc(F)c1)c1cc(C(=O)N(C)C)cc2c(=O)cc(N3CCOC(P)C3)oc12</smiles>

$63 \mathrm{R}=\mathrm{H}$ $64 \mathrm{R}=(\mathrm{R})-\mathrm{Me}$ $65 \mathrm{R}=(\mathrm{S})-\mathrm{Me}$

Figure 10. Structures of PI3K $\beta$ selective inhibitors 55-65.

\subsection{PI3K $\alpha$ Selective Inhibitors}

The first PI3K $\alpha$ selective inhibitor to be described was PIK-75 (66, Figure 11a) $[9,139]$. It inhibits $\mathrm{PI} 3 \mathrm{~K} \alpha$ with an $\mathrm{IC}_{50}$ of $5.8 \mathrm{nM}$, and shows $13 x$ selectivity over PI3K $\gamma, 88 x$ selectivity over PI3K $\delta$ and $>200 x$ selectivity over PI3K $\beta$ [9]. SAR around the PIK75 scaffold has been carried out by multiple groups [139-145]. The bromo was shown to be important for overall potency $[139,141,143,145]$. The sulfonyl group appears to important for selectivity; replacement with a carbonyl retains potency at $\mathrm{PI} 3 \mathrm{~K} \alpha$, but loses selectivity against the other isoforms $[140,141]$. The nitro group is important for potency and selectivity; replacement with an amino group increased potency at PI3K $\alpha$ by $10 \mathrm{x}$, but resulted in a loss of selectivity against PI3K $\beta$ and PI3K $\delta$ [140]. Changing the N-methyl substitution to an ethyl showed conflicting effects on PI3K $\alpha$ selectivity; Schmidt-Kittler et al. [140] showed an overall improvement in PI3K $\alpha$ selectivity, while the 6-cyanoimidazopyridine analogs of Kendall et al. [141] showed a loss of selectivity over PI3K $\delta$ with an N-ethyl substitution. Substitutions around the phenyl ring appear to be important for selectivity [140]. Replacing the 2-methyl with a 2-chloro was equipotent at PI3K $\alpha$, but lost PI3K $\delta$ selectivity [140]. A 4-fluoro substitution increased selectivity over PI3K $\gamma$, but lost selectivity over PI3K $\delta$, while a 4-glycylphenylalanine gave $600 x$ selectivity against PI3K $\beta$, 60x against PI3K $\gamma$ and 100x against PI3K $\delta$ [140]. Despite the extensive SAR available, the absence of a co-crystal structure with any isoform has limited rationalization of the selectivity. At least four 
groups have published different computational predictions of binding modes [146-149]. Site-directed mutagenesis was able to test each of these hypotheses experimentally and found that PI3K $\alpha$ specific interactions with $\alpha$ His855 and $\alpha$ Ser773 in Regions 1 and 2, respectively, were important for the isoform selectivity [97]. This corresponds most closely with the model proposed by Frédérick and Denny [146], where the imidazopyridine ring interacts with the hinge region, the bromine extends into the affinity pocket, the sulfonyl interacts with $\alpha$ His855, and the nitro group interacts with $\alpha$ Ser773. The latter interaction would explain the loss of selectivity against $\mathrm{PI} 3 \mathrm{~K} \beta$ and $\delta$ when the nitro is substituted to an amino group, as both these isoforms have an aspartate at this position. PI3K $\gamma$ has an alanine, and its potency is unaffected by the substitution [140]. The model also suggests hydrophobic interactions with $\alpha \operatorname{Trp} 780$ and an interaction between the nitro group and $\alpha$ Arg770, which occludes the tryptophan shelf in PI3K $\alpha$ [146]. However, mutation of $\alpha$ Arg770 to an alanine did not significantly affect the IC $_{50}$ of PIK75, suggesting this interaction is less important than that with $\alpha$ Ser773 [97]. Subsequent to the modeling and mutagenesis studies, a crystal structure of PIK75 in complex with the protein kinase GSK-3 $\beta$ was determined (PDB ID 6GN1) [150]. Similar to Frédérick and Denny's [146] model, the imidazopyridine ring binds at the hinge region, with the bromine extending into the affinity pocket. The nitro group, however, rather than interacting with residues on the P-loop, extends into the affinity pocket and forms an intramolecular interaction with the bromo group [150]. This binding mode would not seem to correspond to the mutagenesis or available SAR, and it seems likely that PIK75 adopts an alternative binding mode in PI3K.

Genentech have also reported the importance of the P-loop residues in PI3K $\alpha$ selectivity [151]. Modification of the core of their pan-PI3K inhibitor, GDC-0941 (67), to an isomeric thiophene (68), increased PI3K $\alpha / \beta$ selectivity from 10x to 100x (Figure 11a). They postulate that this is a conformational effect and influences the positioning of the sulfonyl and its potential for hydrogen bonding with the non-conserved $\alpha$ Arg770 and the backbone of $\alpha$ Ser773 [151]. Also starting from GDC-0941, Nacht et al. [152] describe the design of a targeted PI3K $\alpha$ selective covalent inhibitor (69, Figure 11a). They extend an enone from the piperidine ring to react with the PI3K $\alpha$-specific residue, $\alpha \mathrm{Cys} 862$, thus imparting selectivity and forming a covalent linkage (PDB ID 3ZIM). In the other isoforms, the residue at this position is leucine in $\mathrm{PI} 3 \mathrm{~K} \beta$ and $\mathrm{PI} 3 \mathrm{~K} \delta$ and glutamine in $\mathrm{PI} 3 \mathrm{~K} \gamma$, removing the possibility of irreversible inhibition.

The most effective region of the binding site to target for PI $3 \mathrm{~K} \alpha$ selectivity has been found to be Region 1. In the development of benzoxazepin $\beta$-sparing PI3K inhibitors, Genentech describes the importance of the moiety extending towards Region 1 for modulating selectivity (70, Figure 11b) $[151,153,154]$. In particular, they found that positively charged substituents favor PI3K $\beta$, due to the negatively charged $\beta$ Glu858 and $\beta$ Asp862, while bulky, aromatic, uncharged substituents show favorable PI3K $\alpha / \beta$ selectivity [153]. This was an unexpected finding, as the uncharged substituents do not seem able to form hydrogen bonds with the non-conserved residues $\alpha$ His855 and $\alpha$ Gln859. Staben et al. [153] propose that the alternative conformation of $\beta$ Trp777 observed in the PI3K $\beta$ crystal structure (PDB ID 2Y3A) may contribute to this observed selectivity. In PI3K $\alpha, \alpha \operatorname{Trp} 780$ is anchored by a hydrogen bond from the indole nitrogen to $\alpha$ Glu798, and a similar hydrogen bond is observed with $\gamma$ Glu814 in PI3K $\gamma$. A valine residue at the equivalent position in $\mathrm{PI} 3 \mathrm{~K} \beta$ not only does not provide a hydrogen bonding partner, but may also disfavor a similar orientation of the tryptophan ring. In this case, one potential explanation is that the steric bulk of substituents are not as well accommodated by the alternative tryptophan conformation in PI3K $\beta$ [153].

These studies eventually culminated in the discovery of GDC-0326 (32), a PI3K $\alpha$ selective inhibitor (Figure 11b) [67]. The structures of GDC-0326 bound to both PI3K $\alpha$ (PDB ID 5DXT) and PI3K $\delta$ (PDB ID 5DXU) have been determined [67]. In PI3K $\alpha$, the carboxamide in GDC-0326 forms complementary interactions with $\alpha \mathrm{Gln} 859$, and a hydrogen bond to the backbone carbonyl of $\alpha$ Ser854 (Figure 11c). In PI3K $\delta$, the inhibitor forms two hydrogen bonds with the backbone carbonyl of $\alpha$ Ser831, and with the side chain of $\delta$ Asp832. The serine hydrogen bond is at an increased distance and the aspartate 
hydrogen bond appears to be at a suboptimal angle, providing some rationale for the observed selectivity [67].

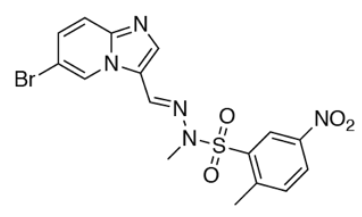

66

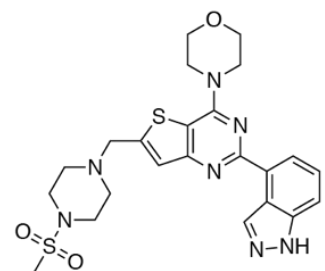

67

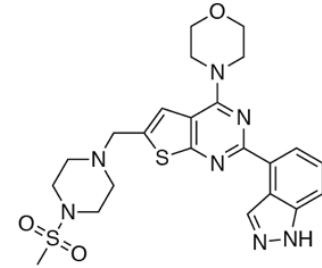

68

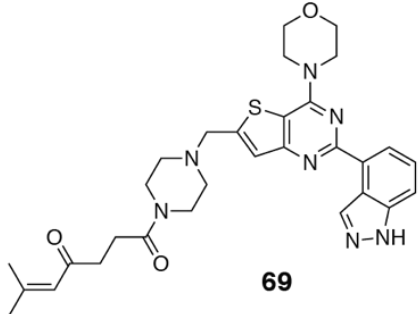

69

(a)

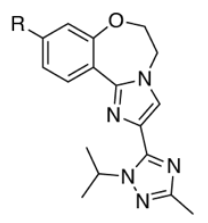

70

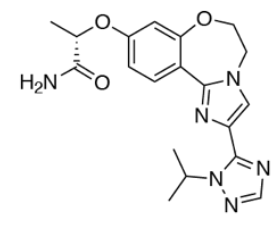

32

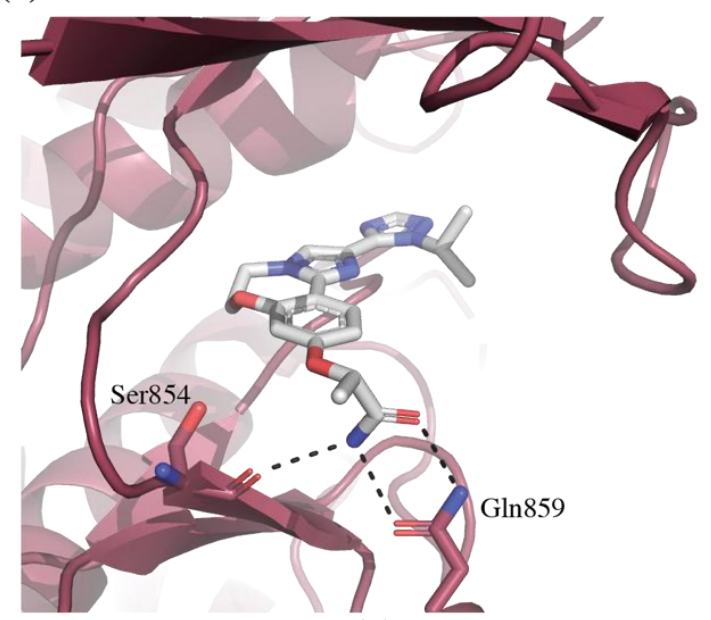

(b)

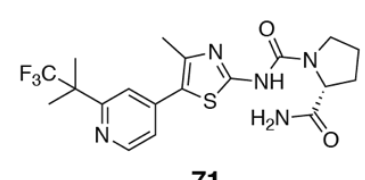

(c)

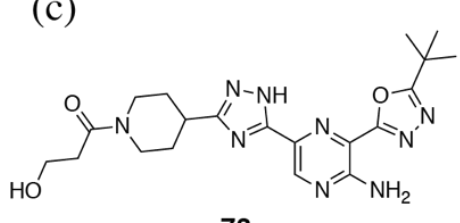<smiles>CCCS(=O)(=O)Nc1cc(-c2ccc3ncnc(NCCN(C)C)c3c2)cnc1OC</smiles>

74<smiles>Cc1nc(NC(=O)N2CCC[C@H]2C(N)=O)sc1-c1csc(C(C)(C)C)n1</smiles>

72

73

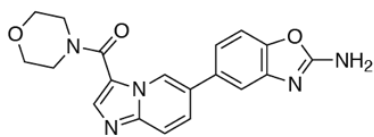

75

(d)

Figure 11. PI3K $\alpha$ selective inhibitors. (a) Structures of 66-69. (b) Structures of Genentech $\beta$-sparing (70) and $\alpha$-selective inhibitors (32). (c) 32 in complex with p110 $\alpha$ (raspberry, PDB ID 5DXT) showing Region 1 interactions with $\alpha \mathrm{Gln} 859$ and the backbone of $\alpha$ Ser854. (d) Structures of 71-75.

Novartis reported the optimization of a series of 2-aminothiazole inhibitors which also target $\alpha \operatorname{Gln} 859[65,155,156]$. Before the determination of the crystal structure of the clinical candidate, BYL719 (71) in PI3K $\alpha$ (PDB ID 4JPS), modeling [157] and site-directed mutagenesis [158] studies with A-66 (72), a related 2-aminothiazole analog, strongly implicated an interaction with $\alpha \mathrm{Gln} 859$ as determining the exquisite PI3K $\alpha$ selectivity of these compounds (Figure 11d). The subsequent determination of the crystal structure confirmed these studies [65].

Astra-Zeneca have also published their efforts toward developing a PI3K $\alpha$ inhibitor, predominantly targeted towards optimizing interactions with $\alpha \mathrm{Gln} 859$ (73, Figure 11d) [159-161]. Rather than a carboxamide moiety, their compounds exhibit a pyrazole ring that is thought to interact with $\alpha \mathrm{Gln} 859$. Fan et al. [162] have also reported a series of PI3K $\alpha$ selective inhibitors (74) targeting 
$\alpha G \ln 859$, via a bidentate interaction between a methoxy group and sulfonamide nitrogen, both extending from a substituted pyridine ring (Figure 11d).

In PI3K $\beta$ and $\delta$ selective inhibitors, substitutions in the affinity pocket have been shown to modulate selectivity. This appears to be less important in PI3K $\alpha$ selective inhibitors, with affinity pocket binding motifs contributing more to potency than isoform selectivity [153,154].

Intellikine's inhibitor, MLN1117 (75), has none of the above mentioned features, but still exhibits greater than $125 x$ selectivity for PI3K $\alpha$ (Figure 11d) [66]. Unfortunately, no structure or SSAR data has been published to allow for an understanding of the molecular determinants of this selectivity.

\subsection{PI3K $\gamma$ Selective Inhibitors}

The structural basis of selectivity for some of the earliest PI3K $\gamma$ selective inhibitors is difficult to rationalize. The first series of $\mathrm{PI} 3 \mathrm{~K} \gamma$ inhibitors to be published were based on the rhodanine or thiazolidinedione scaffold $[163,164]$. Crystal structures of several family members reveal that the rhodanine portion binds in the affinity pocket, while the variable motif binds to the hinge region $[163,164]$. No other regions of the binding pocket are engaged. As we have discussed, the affinity pocket contains only conserved residues, but has been shown to vary in flexibility and water networks, so motifs binding in this pocket do appear to modulate isoform selectivity. The rhodanine series of inhibitors generally show good selectivity over PI3K $\beta$ and $\delta$, but only moderate PI3K $\alpha$ selectivity. Interestingly, the two inhibitors that show the best PI3K $\gamma / \alpha$ selectivity (30x), AS-252424 (76) and AS-604850 (77) (PDB ID 2A4Z), both have hinge-binders that extend towards $\gamma$ Ala885, which is a serine in all the other isoforms (Figure 12a) $[163,164]$. In all the other isoforms, this residue is a serine and forms a hydrogen bond with the backbone of $\delta$ Val828 [165]. Disruption of this hydrogen bond in $\mathrm{PI} 3 \mathrm{~K} \alpha, \beta$ and $\delta$ without sufficient compensation elsewhere in the binding site may contribute to the selectivity observed in these inhibitors.

Cellzome published a series of triazolopyridines as PI3K $\gamma$ inhibitors (78, Figure 12a) (PDB ID 4AOF) [166-168]. The amino-triazolopyridine forms a bidentate interaction with the hinge region. The derivatization focused on the affinity pocket binding portion. As has previously been noted, affinity pocket binding motifs have a surprisingly important effect on selectivity. Substituents at the 3-position of the phenyl ring were preferred, generally showing submicromolar potency, while selectivity over $\mathrm{PI} 3 \mathrm{~K} \alpha$ and $\delta$ varied from as little as $4 \mathrm{x}$ to as much as 500x [166]. Subsequent development of these compounds focused on heterocyclic and glycinamide ureas in place of the free amino group for $\mathrm{PI} 3 \mathrm{~K} \gamma / \delta$ dual-selective inhibitors [169].

In the course of development of 4-aza-isoindolinone PI3K $\gamma$ selective inhibitors (79, Figure 12b), Vertex Pharmaceuticals discovered a novel hydrophobic binding cleft adjacent to the hinge region, which confers selectivity for PI3K $\gamma$ (Figure 12c) [165,170-172]. The binding cleft is formed by the combination of two key non-conserved residues, $\gamma$ Ala885 (serine in all other isoforms) and $\gamma$ Gly829 (glutamate in PI3K $\alpha$, glycine in PI3K $\beta$ and $\delta$ ) that allow access to this area of the binding site (PDB ID 4PS3) [165]. In particular, bulky protrusions into the hydrophobic cleft give good selectivity over $\mathrm{PI} 3 \mathrm{~K} \alpha$, due to unfavorable interactions with the glutamate residue.

IPI-549 (80) which is currently in clinical trials for advanced solid tumors, is an exquisitely selective propeller-shaped PI3K $\gamma$ inhibitor (Figure 12b) [57]. Starting with an 8-chloroisoquinolinone core as a specificity pocket binding motif, commonly found in PI3K $\delta$ inhibitors, the hinge region was explored. A pyrazolopyrimidine-2-amine hinge-binding motif, which resembles the triazolopyridines in the Cellzome inhibitors, showed 10x selectivity for PI3K $\gamma$ over PI3K $\delta$. Further selectivity was achieved via substituted alkynes at the 8-position of the isoquinolinone core. PI3K $\delta$ selective inhibitors with 8-alkynyl substituents were docked and found to interact with $\delta \mathrm{G} \ln 748$ ( $\gamma$ Lys800) or $\delta$ Lys712 ( $\gamma$ Ile764) (Figure 3a) [119]. These are both non-conserved residues. It is possible that the N-methylpyrazole group interacts with $\gamma$ Lys800 or $\gamma$ Ile764, or another non-conserved residue in this area.

The existence of PI3K $\beta, \gamma$ and $\delta$ selective propeller-shaped inhibitors brings into question the initial hypothesis that the specificity pocket conveys PI3K $\delta$ selectivity. It appears to be much more 
complicated, with selectivity being determined by an amalgamation of interactions within the binding site. It could be that the specificity pocket is most easily accessible by PI3K $\delta$, followed by PI3K $\beta$ and $\gamma$, and finally by PI3K $\alpha$. Despite the abundance of crystallographic data available, the isoform specificity of the specificity pocket remains unclear.
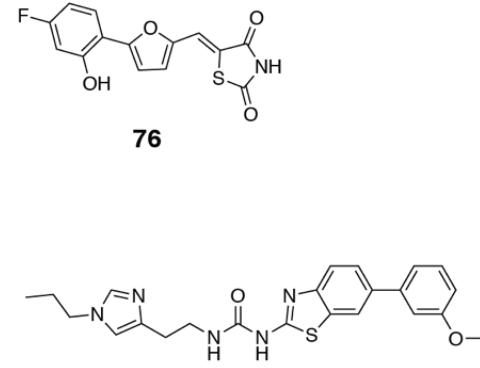

79

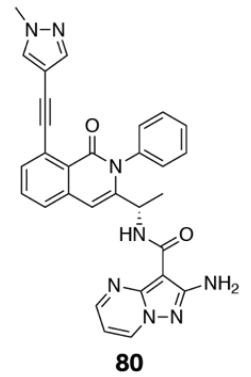

(b)

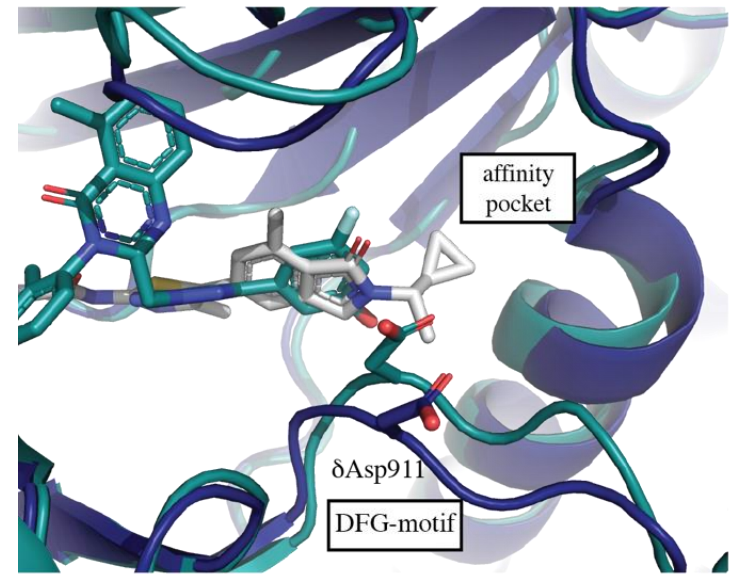

(d)

(a)

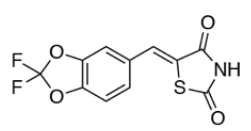

77

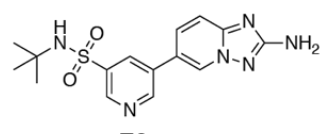

78

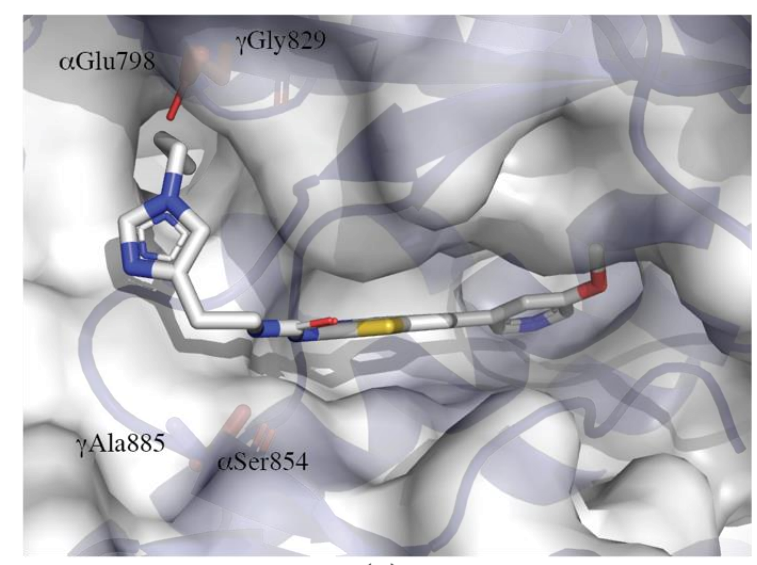

(c)

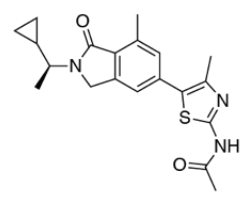

81

(e)

Figure 12. PI3K $\gamma$ selective inhibitors. (a) Structures of 76-78. (b) Structures of 79-80. (c) The hydrophobic binding cleft in p110 (PDB ID 4PS3). The structure of p110 $\gamma$ bound to 79 is shown in dark blue cartoon and light gray surface representation. An overlay with p110 $\alpha$ (raspberry, PDB ID 4JPS) highlights how $\alpha$ Glu798 obscures the binding cleft. The cartoon of $\mathrm{p} 110 \alpha$ has been hidden for clarity. (d) The "alkyl-push". The structure of 81 bound to p1108 (dark blue, PDB ID 6FTN). The cyclopropyl tail of $\mathbf{8 1}$ (shown in white) extends deeper into the affinity pocket than previously observed. The structure of $\mathbf{1}$ bound to p1108 (teal, PDB ID 2WXG) has been shown as a comparison for typical affinity pocket binding moieties. A shift in the loop containing the DFG-motif and helix at the back of the affinity pocket can be observed. (e) Structure of $\mathbf{8 1}$.

A recently published series of aminothiazole PI3K $\gamma$ inhibitors (81) with an N-isopropylcyclopropane tail that inserts deep into the affinity pocket shows remarkable PI3K $\gamma$ selectivity (PDB ID 6FTN) (Figure 12d,e) [173]. Removal of the N-alkyl tail shows a dramatic 100x drop in PI3K $\gamma$ potency, while increasing potency at $\mathrm{PI} 3 \mathrm{~K} \alpha$ and $\beta$ by more than $10 \mathrm{x}$. PI3K $\delta$ potency remained essentially unchanged. 
The N-alkyl tail extends further into the affinity pocket than other reported inhibitors, inducing the formation of a new pocket by a so-called "alkyl-push" and this may be a key feature that contributes to the PI3K $\gamma$ selectivity $[49,173]$. Surprisingly, the inhibitor did not successfully co-crystallize in PI3K $\gamma$, and the published structure is in complex with PI3K $\delta$, which may not reveal all the relevant structural details for understanding the selectivity. The authors hypothesize that $\mathrm{PI} 3 \mathrm{~K} \gamma$ has greater flexibility that the other isoforms.

\subsection{Rational and Irrational Isoform Selectivity}

An interesting case study published by Bruce et al. [155] presents the anticipated conclusion from all of this knowledge: the ability to rationally design individual PI $3 \mathrm{~K} \alpha, \gamma$ and $\delta$ selective inhibitors starting from a pan-PI3K core structure (82, Figure 13a). By introducing a prolinyl-carboxamide extending towards $\alpha G \ln 859$, they are able to introduce PI3K $\alpha$ selectivity to the core structure (83). By introducing long alkyl chains, they are able to target the hydrophobic binding cleft near the hinge region and introduce PI3K $\gamma$ selectivity (84). Finally, a PI3K $\delta$ inhibitor is developed with an amide linked to an isoxazole (85). The rationale for the PI3K $\delta$ selectivity is less clear, perhaps it interacts with a non-conserved residue of Region 1 or can access the tryptophan shelf.

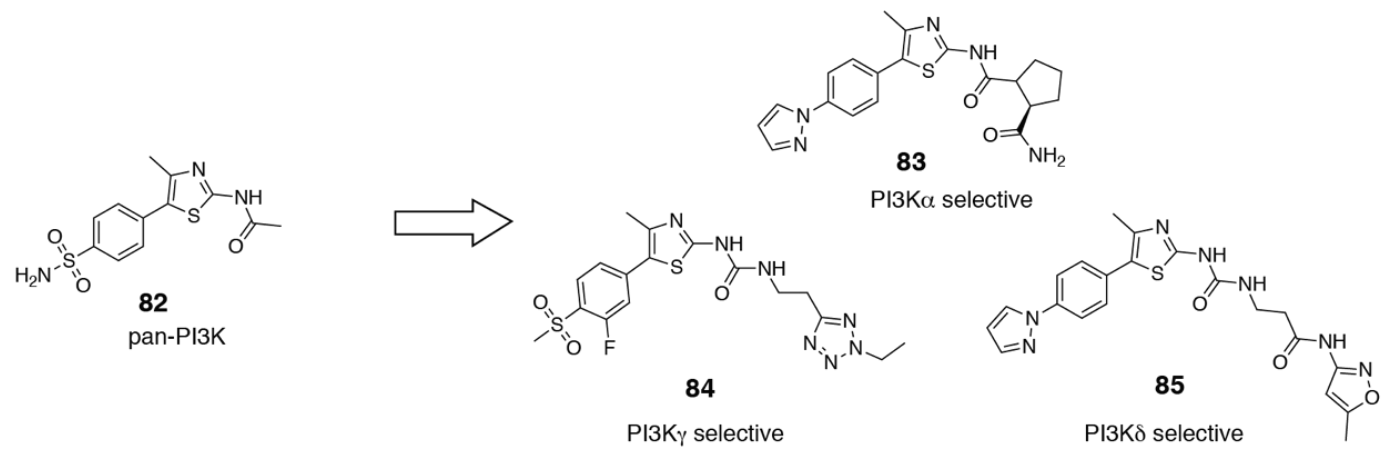

(a)

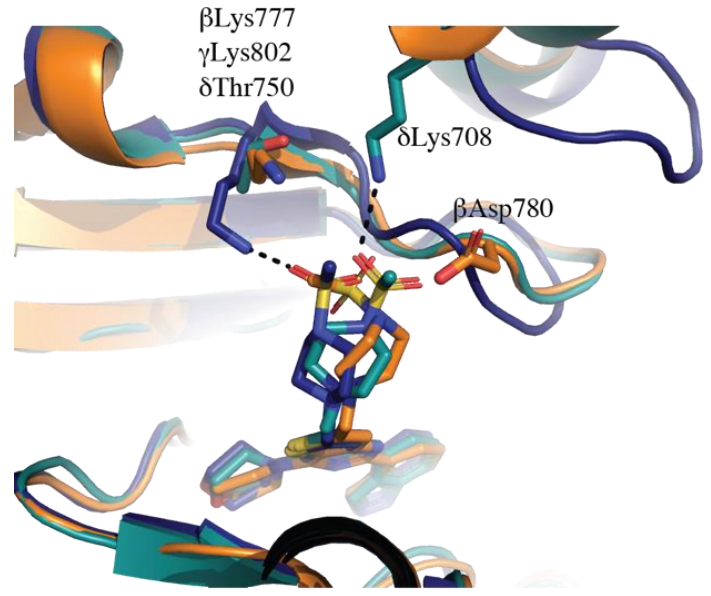

(b)

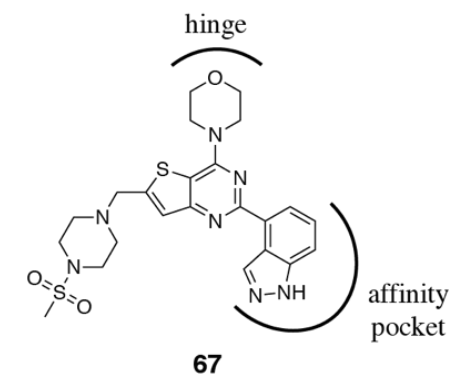

(c)

Figure 13. Rational and irrational selectivity. (a) The rational design of isoform selective inhibitors 83-85 from a pan-PI3K core (82). (b) GDC-0941 (67) bound to p110 (orange, PDB ID 2Y3A), p110 $\gamma$ (dark blue, PDB ID 3DBS) and p1108 (teal, PDB ID 2WXP). The sulfonyl group shifts conformation depending on which non-conserved residues are present. Hydrogen bonds have been shown in black dashed lines. (c) The structure of GDC-0941 (67).

Another interesting case study, this time in the irrationality of inhibitor selectivity, is the Genentech pan-PI3K inhibitor, GDC-0941 (67, Figure 13b,c) [174]. It has been crystallized in complex with PI3K $\beta$, $\gamma$ and $\delta$ (PDB ID 2Y3A, 3DBS, 2WXP, respectively) $[85,86,174]$. In PI3K $\gamma$, the methyl sulfonyl group 
interacts with the non-conserved $\gamma$ Lys802 (Figure 13b) [174]. In PI3K $\delta$, where this lysine is replaced by a threonine, the sulfonyl group has shifted, and now interacts with $\delta$ Lys708 ( $\alpha$ Gln728, $\beta$ Arg729, $\gamma$ Ser760) and the backbone of $\delta$ Asp753 [85]. In PI3K $\beta$, the piperidinesulfonamide adopts yet another conformation. Note however, that care should be taken when interpreting hydrogen bonds in the PI3K $\beta$ structure due to the low resolution (3.5 $\AA$ ). Hydrogen bonds with $\beta$ Lys777 (equivalent to $\gamma$ Lys802) and $\beta$ Asp780 (equivalent to $\delta$ Asp753) are possible, but electron density is missing for these side-chains. This highlights the role of inhibitor flexibility allowing the adoption of multiple conformations in the binding site and resulting in pan-PI3K inhibition despite interaction with non-conserved residues. It also emphasizes the complex nature of isoform selectivity and the difficulties associated with rational design.

\subsection{PI3Ka Oncogenic Mutant Selectivity}

One aspect of selectivity that is seldom discussed is that of selectivity for the PI3K $\alpha$ hotspot mutants, $\alpha$ Glu542Lys, $\alpha$ Glu545Lys and $\alpha$ His1047Arg over the wild-type PI3K $\alpha$. Given the essential functions of $\mathrm{PI} 3 \mathrm{~K} \alpha$, selectively inhibiting the relevant oncogenic mutants may widen the therapeutic window and reduce adverse effects of treatment $[175,176]$. Wang et al. [177] describe their attempts via high throughput screening to develop an inhibitor selective for His1047Arg-PI3K $\alpha$. The identified hits have $\mathrm{IC}_{50}$ values in the micromolar range, and although some show differential inhibition between the mutant and wild-type forms, they generally favor the wild-type enzyme. Sabbah et al. [178] identified a series of $N$-phenyl 4-hydroxy-2-quinolone-3-carboxamides that display 10-20x selectivity for a His1047Arg colon cancer cell line over the isogenic WT cell line. Unfortunately, they do not present data determined from assaying with purified enzyme. Gkeka et al. [179] explore the potential of a non-ATP pocket that was identified in a PI3K $\alpha$ crystal structure for selective inhibition of the His1047Arg mutant [88]. Ultimately, they conclude that this binding site is unlikely to yield productive allosteric inhibitors. Our lab has explored the use of fragment-based screening to identify novel binding sites that have the potential for allosteric inhibition [180]. One site that was identified is in the region of the phosphopeptide binding site and coincides with the position of two of the three hotspot mutations, $\alpha$ Glu542Lys and $\alpha$ Glu545Lys, suggesting the potential for development of oncogenic mutant inhibitors at this site.

\section{Conclusions}

The highly homologous ATP-binding site of Class I PI3Ks has yielded more opportunities for isoform selective inhibitors than was originally anticipated. Key regions of the binding site: the specificity pocket, tryptophan shelf, hydrophobic binding cleft, "alkyl-push" and Region 1 have been identified that allow for a degree of rational design to be attempted. However, there are still key aspects to inhibitor selectivity that remain unclear. How exactly does the specificity pocket contribute to selectivity? How do hinge and affinity binding motifs contribute to selectivity, when these regions are made up of conserved residues? Isoform selectivity, and inhibitor binding in general, results from a complex amalgamation of interactions throughout the binding site, influenced by protein and inhibitor conformational flexibility.

Author Contributions: Conceptualization, M.S.M., P.E.T., S.B.G.; writing-original draft preparation, M.S.M.; writing-review and editing, M.S.M., P.E.T., S.B.G.

Funding: This research was funded by DoD CDMRP, grant number W81XWH-16-1-0486 (SBG) and by NIH NCI grant number CA062924 (SBG).

Conflicts of Interest: The authors declare no conflict of interest. The funders had no role in the design of the study; in the collection, analyses, or interpretation of data; in the writing of the manuscript, or in the decision to publish the results. 


\section{References}

1. Ferguson, F.M.; Gray, N.S. Kinase inhibitors: The road ahead. Nat. Rev. Drug Discov. 2018, 17, $353-377$. [CrossRef] [PubMed]

2. Maheshwari, S.; Miller, M.S.; O’Meally, R.; Cole, R.N.; Amzel, L.M.; Gabelli, S.B. Kinetic and structural analyses reveal residues in phosphoinositide 3-kinase $\alpha$ that are critical for catalysis and substrate recognition. J. Biol. Chem. 2017, 292, 13541-13550. [CrossRef] [PubMed]

3. Geering, B.; Cutillas, P.R.; Nock, G.; Gharbi, S.I.; Vanhaesebroeck, B. Class IA phosphoinositide 3-kinases are obligate p85-p110 heterodimers. Proc. Natl. Acad. Sci. USA 2007, 104, 7809-7814. [CrossRef] [PubMed]

4. Mellor, P.; Furber, L.A.; Nyarko, J.N.K.; Anderson, D.H. Multiple roles for the $\mathrm{p} 85 \alpha$ isoform in the regulation and function of PI3K signalling and receptor trafficking. Biochem. J. 2012, 441, 23-37. [CrossRef] [PubMed]

5. Suire, S.; Coadwell, J.; Ferguson, G.J.; Davidson, K.; Hawkins, P.; Stephens, L. p84, a New G $\beta \gamma$-Activated

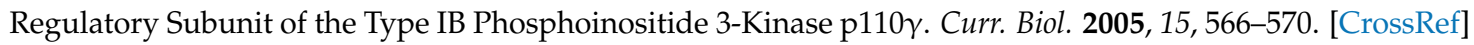
[PubMed]

6. Stephens, L.; Eguinoa, A.; Erdjument-Bromage, H.; Lui, M.; Cooke, F.; Coadwell, J.; Smrcka, A.; Thelen, M.; Cadwallader, K.; Tempst, P.; et al. The G $\beta \gamma$ Sensitivity of a PI3K Is Dependent upon a Tightly Associated Adaptor, p101. Cell 1997, 89, 105-114. [CrossRef]

7. Shymanets, A.; Vadas, O.; Czupalla, C.; LoPiccolo, J.; Brenowitz, M.; Ghigo, A.; Hirsch, E.; Krause, E.; Wetzker, R.; Williams, R.L.; et al. Different inhibition of G $\beta \gamma$-stimulated class IB phosphoinositide 3-kinase (PI3K) variants by a monoclonal antibody. Specific function of p101 as a G $\beta \gamma$-dependent regulator of PI3K $\gamma$ enzymatic activity. Biochem. J. 2015, 469, 59-69. [CrossRef] [PubMed]

8. Thorpe, L.M.; Yuzugullu, H.; Zhao, J.J. PI3K in cancer: Divergent roles of isoforms, modes of activation and therapeutic targeting. Nat. Rev. Cancer 2015, 15, 7-24. [CrossRef] [PubMed]

9. Knight, Z.A.; Gonzalez, B.; Feldman, M.E.; Zunder, E.R.; Goldenberg, D.D.; Williams, O.; Loewith, R.; Stokoe, D.; Balla, A.; Toth, B.; et al. A Pharmacological Map of the PI3-K Family Defines a Role for p110 $\alpha$ in Insulin Signaling. Cell 2006, 125, 733-747. [CrossRef] [PubMed]

10. Sopasakis, V.R.; Liu, P.; Suzuki, R.; Kondo, T.; Winnay, J.; Tran, T.T.; Asano, T.; Smyth, G.; Sajan, M.P.; Farese, R.V.; et al. Specific roles of the p110alpha isoform of phosphatidylinsositol 3-kinase in hepatic insulin signaling and metabolic regulation. Cell Metab. 2010, 11, 220-230. [CrossRef] [PubMed]

11. McMullen, J.R.; Shioi, T.; Zhang, L.; Tarnavski, O.; Sherwood, M.C.; Kang, P.M.; Izumo, S. Phosphoinositide 3-kinase $(\mathrm{p} 110 \alpha)$ plays a critical role for the induction of physiological, but not pathological, cardiac hypertrophy. Proc. Natl. Acad. Sci. USA 2003, 100, 12355-12360. [CrossRef] [PubMed]

12. Luo, J.; McMullen, J.R.; Sobkiw, C.L.; Zhang, L.; Dorfman, A.L.; Sherwood, M.C.; Logsdon, M.N.; Horner, J.W.; DePinho, R.A.; Izumo, S.; et al. Class IA Phosphoinositide 3-Kinase Regulates Heart Size and Physiological Cardiac Hypertrophy. Mol. Cell. Biol. 2005, 25, 9491-9502. [CrossRef] [PubMed]

13. Weeks, K.L.; Bernardo, B.C.; Ooi, J.Y.Y.; Patterson, N.L.; McMullen, J.R. The IGF1-PI3K-Akt Signaling Pathway in Mediating Exercise-Induced Cardiac Hypertrophy and Protection. Adv. Exp. Med. Biol. 2017, 1000, 187-210. [PubMed]

14. Aoyagi, T.; Matsui, T. Phosphoinositide-3 kinase signaling in cardiac hypertrophy and heart failure. Curr. Pharm. Des. 2011, 17, 1818-1824. [CrossRef] [PubMed]

15. Jackson, S.P.; Schoenwaelder, S.M.; Goncalves, I.; Nesbitt, W.S.; Yap, C.L.; Wright, C.E.; Kenche, V.; Anderson, K.E.; Dopheide, S.M.; Yuan, Y.; et al. PI 3-kinase p110ß: A new target for antithrombotic therapy. Nat. Med. 2005, 11, 507-514. [CrossRef] [PubMed]

16. Nylander, S.; Kull, B.; Björkman, J.A.; Ulvinge, J.C.; Oakes, N.; Emanuelsson, B.M.; Andersson, M.; Skärby, T.; Inghardt, T.; Fjellström, O.; et al. Human target validation of phosphoinositide 3-kinase (PI3K) $\beta$ : Effects on platelets and insulin sensitivity, using AZD6482 a novel PI3K $\beta$ inhibitor. J. Thromb. Haemost. 2012, 10, 2127-2136. [CrossRef] [PubMed]

17. Schoenwaelder, S.M.; Ono, A.; Nesbitt, W.S.; Lim, J.; Jarman, K.; Jackson, S.P. Phosphoinositide 3-kinase p110 beta regulates integrin alpha IIb beta 3 avidity and the cellular transmission of contractile forces. J. Biol. Chem. 2010, 285, 2886-2896. [CrossRef] [PubMed]

18. Kaneda, M.M.; Messer, K.S.; Ralainirina, N.; Li, H.; Leem, C.J.; Gorjestani, S.; Woo, G.; Nguyen, A.V.; Figueiredo, C.C.; Foubert, P.; et al. PI3K $\gamma$ is a molecular switch that controls immune suppression. Nature 2016, 539, 437-442. [CrossRef] [PubMed] 
19. Hawkins, P.T.; Stephens, L.R. PI3K signalling in inflammation. BBA Mol. Cell Biol. Lipids 2015, 1851, 882-897. [CrossRef] [PubMed]

20. Cushing, T.D.; Metz, D.P.; Whittington, D.A.; McGee, L.R. PI3K $\delta$ and PI3K $\gamma$ as Targets for Autoimmune and Inflammatory Diseases. J. Med. Chem. 2012, 55, 8559-8581. [CrossRef] [PubMed]

21. Rowan, W.C.; Smith, J.L.; Affleck, K.; Amour, A. Targeting phosphoinositide 3-kinase $\delta$ for allergic asthma. Biochem. Soc. Trans. 2012, 40, 240-245. [CrossRef] [PubMed]

22. Yoo, E.J.; Ojiaku, C.A.; Sunder, K.; Panettieri, R.A. Phosphoinositide 3-Kinase in Asthma: Novel Roles and Therapeutic Approaches. Am. J. Respir. Cell Mol. Biol. 2017, 56, 700-707. [CrossRef] [PubMed]

23. Lucas, C.L.; Kuehn, H.S.; Zhao, F.; Niemela, J.E.; Deenick, E.K.; Palendira, U.; Avery, D.T.; Moens, L.; Cannons, J.L.; Biancalana, M.; et al. Dominant-activating germline mutations in the gene encoding the PI(3)K catalytic subunit p1108 result in T cell senescence and human immunodeficiency. Nat. Immunol. 2014, 15, 88-97. [CrossRef] [PubMed]

24. Angulo, I.; Vadas, O.; Garçon, F.; Banham-Hall, E.; Plagnol, V.; Leahy, T.R.; Baxendale, H.; Coulter, T.; Curtis, J.; Wu, C.; et al. Phosphoinositide 3-kinase $\delta$ gene mutation predisposes to respiratory infection and airway damage. Science 2013, 342, 866-871. [CrossRef] [PubMed]

25. Kracker, S.; Curtis, J.; Ibrahim, M.A.A.; Sediva, A.; Salisbury, J.; Campr, V.; Debré, M.; Edgar, J.D.M.; Imai, K.; Picard, C.; et al. Occurrence of B-cell lymphomas in patients with activated phosphoinositide 3-kinase $\delta$ syndrome. J. Allergy Clin. Immunol. 2014, 134, 233-236. [CrossRef] [PubMed]

26. Coulter, T.I.; Chandra, A.; Bacon, C.M.; Babar, J.; Curtis, J.; Screaton, N.; Goodlad, J.R.; Farmer, G.; Steele, C.L.; Leahy, T.R.; et al. Clinical spectrum and features of activated phosphoinositide 3-kinase $\delta$ syndrome: A large patient cohort study. J. Allergy Clin. Immunol. 2017, 139, 597-606. [CrossRef] [PubMed]

27. Elkaim, E.; Neven, B.; Bruneau, J.; Mitsui-Sekinaka, K.; Stanislas, A.; Heurtier, L.; Lucas, C.L.; Matthews, H.; Deau, M.-C.; Sharapova, S.; et al. Clinical and immunologic phenotype associated with activated phosphoinositide 3-kinase $\delta$ syndrome 2: A cohort study. J. Allergy Clin. Immunol. 2016, 138, 210-218. [CrossRef] [PubMed]

28. Samuels, Y.; Wang, Z.; Bardelli, A.; Silliman, N.; Ptak, J.; Szabo, S.; Yan, H.; Gazdar, A.; Powell, S.M.; Riggins, G.J.; et al. High frequency of mutations of the PIK3CA gene in human cancers. Science 2004, 304, 554. [CrossRef] [PubMed]

29. Samuels, Y.; Waldman, T. Oncogenic Mutations of PIK3CA in Human Cancers. Curr. Top. Microbiol. Immunol. 2011, 347, 21-41.

30. Kang, S.; Seo, S.S.; Chang, H.J.; Yoo, C.W.; Park, S.Y.; Dong, S.M. Mutual exclusiveness between PIK3CA and KRAS mutations in endometrial carcinoma. Int. J. Gynecol. Cancer 2008, 18, 1339-1343. [CrossRef] [PubMed]

31. Hayes, M.P.; Wang, H.; Espinal-Witter, R.; Douglas, W.; Solomon, G.J.; Baker, S.J.; Ellenson, L.H. PIK3CA and PTEN Mutations in Uterine Endometrioid Carcinoma and Complex Atypical Hyperplasia. Clin. Cancer Res. 2006, 12, 5932-5935. [CrossRef] [PubMed]

32. Oda, K.; Stokoe, D.; Taketani, Y.; McCormick, F. High Frequency of Coexistent Mutations of PIK3CA and PTEN Genes in Endometrial Carcinoma. Cancer Res. 2005, 65, 10669-10673. [CrossRef] [PubMed]

33. American Association for Cancer Research. Alpelisib Extends PFS in PIK3CA-Mutant Breast Cancer. Cancer Discov. 2019, 9, 6-7.

34. Kang, S.; Denley, A.; Vanhaesebroeck, B.; Vogt, P.K. Oncogenic transformation induced by the p110beta, -gamma, and -delta isoforms of class I phosphoinositide 3-kinase. Proc. Natl. Acad. Sci. USA 2006, 103, 1289-1294. [CrossRef] [PubMed]

35. Denley, A.; Kang, S.; Karst, U.; Vogt, P.K. Oncogenic signaling of class I PI3K isoforms. Oncogene 2008, 27, 2561-2574. [CrossRef] [PubMed]

36. Berenjeno, I.M.; Guillermet-Guibert, J.; Pearce, W.; Gray, A.; Fleming, S.; Vanhaesebroeck, B. Both p110 $\alpha$ and $\mathrm{p} 110 \beta$ isoforms of PI3K can modulate the impact of loss-of-function of the PTEN tumour suppressor. Biochem. J. 2012, 442, 151-159. [CrossRef] [PubMed]

37. Wee, S.; Wiederschain, D.; Maira, S.-M.; Loo, A.; Miller, C.; Stegmeier, F.; Yao, Y.-M.; Lengauer, C. PTEN-deficient cancers depend on PIK3CB. Proc. Natl. Acad. Sci. USA 2008, 105, 13057-13062. [CrossRef] [PubMed]

38. Dbouk, H.A.; Pang, H.; Fiser, A.; Backer, J.M. A biochemical mechanism for the oncogenic potential of the p110ß catalytic subunit of phosphoinositide 3-kinase. Proc. Natl. Acad. Sci. USA 2010, 107, 19897-19902. [CrossRef] [PubMed] 
39. Schwartz, S.; Wongvipat, J.; Trigwell, C.B.; Hancox, U.; Carver, B.S.; Rodrik-Outmezguine, V.; Will, M.; Yellen, P.; de Stanchina, E.; Baselga, J.; et al. Feedback suppression of PI3K $\alpha$ signaling in PTEN-mutated tumors is relieved by selective inhibition of PI3K $\beta$. Cancer Cell 2015, 27, 109-122. [CrossRef] [PubMed]

40. Lynch, J.T.; Polanska, U.M.; Hancox, U.; Delpuech, O.; Maynard, J.; Trigwell, C.; Eberlein, C.; Lenaghan, C.; Polanski, R.; Avivar-Valderas, A.; et al. Combined Inhibition of PI3K $\beta$ and mTOR Inhibits Growth of PTEN-null Tumors. Mol. Cancer Ther. 2018, 17, 2309-2319. [CrossRef] [PubMed]

41. Mateo, J.; Ganji, G.; Lemech, C.; Burris, H.A.; Han, S.-W.; Swales, K.; Decordova, S.; DeYoung, M.P.; Smith, D.A.; Kalyana-Sundaram, S.; et al. A First-Time-in-Human Study of GSK2636771, a Phosphoinositide 3 Kinase Beta-Selective Inhibitor, in Patients with Advanced Solid Tumors. Clin. Cancer Res. 2017, 19, 5981-5992. [CrossRef] [PubMed]

42. Bédard, P.L.; Davies, M.A.; Kopetz, S.; Juric, D.; Shapiro, G.I.; Luke, J.J.; Spreafico, A.; Wu, B.; Castell, C.; Gomez, C.; et al. First-in-human trial of the PI3K $\beta$-selective inhibitor SAR260301 in patients with advanced solid tumors. Cancer 2018, 124, 315-324. [CrossRef] [PubMed]

43. Lampson, B.L.; Brown, J.R. PI3K $\delta$-selective and PI3K $\alpha / \delta$-combinatorial inhibitors in clinical development for B-cell non-Hodgkin lymphoma. Expert Opin. Investig. Drugs 2017, 26, 1267-1279. [CrossRef] [PubMed]

44. Chiu, H.; Mallya, S.; Nguyen, P.; Mai, A.; Jackson, L.V.; Winkler, D.G.; DiNitto, J.P.; Brophy, E.E.; McGovern, K.; Kutok, J.L.; et al. The Selective Phosphoinoside-3-Kinase p1108 Inhibitor IPI-3063 Potently Suppresses B Cell Survival, Proliferation, and Differentiation. Front. Immunol. 2017, 8, 747. [CrossRef] [PubMed]

45. Fruman, D.A.; Rommel, C. PI3K $\delta$ Inhibitors in Cancer: Rationale and Serendipity Merge in the Clinic. Cancer Discov. 2011, 1, 562-572. [CrossRef] [PubMed]

46. Miller, B.W.; Przepiorka, D.; Claro, R.A.; Lee, K.; Nie, L.; Simpson, N.; Gudi, R.; Saber, H.; Shord, S.; Bullock, J.; et al. FDA Approval: Idelalisib Monotherapy for the Treatment of Patients with Follicular Lymphoma and Small Lymphocytic Lymphoma. Clin. Cancer Res. 2015, 21, 1525-1529. [CrossRef] [PubMed]

47. Furman, R.R.; Sharman, J.P.; Coutre, S.E.; Cheson, B.D.; Pagel, J.M.; Hillmen, P.; Barrientos, J.C.; Zelenetz, A.D.; Kipps, T.J.; Flinn, I.; et al. Idelalisib and rituximab in relapsed chronic lymphocytic leukemia. N. Engl. J. Med. 2014, 370, 997-1007. [CrossRef] [PubMed]

48. Yang, Q.; Modi, P.; Newcomb, T.; Quéva, C.; Gandhi, V. Idelalisib: First-in-Class PI3K Delta Inhibitor for the Treatment of Chronic Lymphocytic Leukemia, Small Lymphocytic Leukemia, and Follicular Lymphoma. Clin. Cancer Res. 2015, 21, 1537-1542. [CrossRef] [PubMed]

49. Perry, M.W.D.; Abdulai, R.; Mogemark, M.; Petersen, J.; Thomas, M.J.; Valastro, B.; Westin Eriksson, A. Evolution of PI3K $\gamma$ and $\delta$ Inhibitors for Inflammatory and Autoimmune Diseases. J. Med. Chem. 2018. [CrossRef] [PubMed]

50. Cheah, C.Y.; Fowler, N.H. Idelalisib in the management of lymphoma. Blood 2016, 128, 331-336. [CrossRef] [PubMed]

51. Blair, H.A. Duvelisib: First Global Approval. Drugs 2018, 78, 1847-1853. [CrossRef] [PubMed]

52. Flinn, I.W.; Hillmen, P.; Montillo, M.; Nagy, Z.; Illés, Á.; Etienne, G.; Delgado, J.; Kuss, B.J.; Tam, C.S.; Gasztonyi, Z.; et al. The phase 3 DUO trial: Duvelisib versus ofatumumab in relapsed and refractory CLL/SLL. Blood 2018, 23, 2446-2455. [CrossRef] [PubMed]

53. Markham, A. Copanlisib: First Global Approval. Drugs 2017, 77, 2057-2062. [CrossRef] [PubMed]

54. Krause, G.; Hassenrück, F.; Hallek, M. Copanlisib for treatment of B-cell malignancies: The development of a PI3K inhibitor with considerable differences to idelalisib. Drug Des. Dev. Ther. 2018, 12, 2577-2590. [CrossRef] [PubMed]

55. Mensah, F.A.; Blaize, J.-P.; Bryan, L.J. Spotlight on copanlisib and its potential in the treatment of relapsed/refractory follicular lymphoma: Evidence to date. Oncotargets Ther. 2018, 11, 4817-4827. [CrossRef] [PubMed]

56. Scott, W.J.; Hentemann, M.F.; Rowley, R.B.; Bull, C.O.; Jenkins, S.; Bullion, A.M.; Johnson, J.; Redman, A.; Robbins, A.H.; Esler, W.; et al. Discovery and SAR of Novel 2,3-Dihydroimidazo[1,2-c]quinazoline PI3K Inhibitors: Identification of Copanlisib (BAY 80-6946). ChemMedChem 2016, 11, 1517-1530. [CrossRef] [PubMed]

57. Evans, C.A.; Liu, T.; Lescarbeau, A.; Nair, S.J.; Grenier, L.; Pradeilles, J.A.; Glenadel, Q.; Tibbitts, T.; Rowley, A.M.; DiNitto, J.P.; et al. Discovery of a Selective Phosphoinositide-3-Kinase (PI3K)- $\gamma$ Inhibitor (IPI-549) as an Immuno-Oncology Clinical Candidate. ACS Med. Chem. Lett. 2016, 7, 862-867. [CrossRef] [PubMed] 
58. Sasaki, T.; Irie-Sasaki, J.; Jones, R.G.; Oliveira-dos-Santos, A.J.; Stanford, W.L.; Bolon, B.; Wakeham, A.; Itie, A.; Bouchard, D.; Kozieradzki, I.; et al. Function of PI3Kgamma in thymocyte development, T cell activation, and neutrophil migration. Science 2000, 287, 1040-1046. [CrossRef] [PubMed]

59. Hirsch, E.; Katanaev, V.L.; Garlanda, C.; Azzolino, O.; Pirola, L.; Silengo, L.; Sozzani, S.; Mantovani, A.; Altruda, F.; Wymann, M.P. Central role for G protein-coupled phosphoinositide 3-kinase gamma in inflammation. Science 2000, 287, 1049-1053. [CrossRef] [PubMed]

60. Schmid, M.C.; Avraamides, C.J.; Dippold, H.C.; Franco, I.; Foubert, P.; Ellies, L.G.; Acevedo, L.M.; Manglicmot, J.R.E.; Song, X.; Wrasidlo, W.; et al. Receptor tyrosine kinases and TLR/IL1Rs unexpectedly activate myeloid cell PI3k $\gamma$, a single convergent point promoting tumor inflammation and progression. Cancer Cell 2011, 19, 715-727. [CrossRef] [PubMed]

61. Joshi, S.; Singh, A.R.; Zulcic, M.; Durden, D.L. A macrophage-dominant PI3K isoform controls hypoxia-induced HIF $1 \alpha$ and HIF $2 \alpha$ stability and tumor growth, angiogenesis, and metastasis. Mol. Cancer Res. 2014, 12, 1520-1531. [CrossRef] [PubMed]

62. Gunderson, A.J.; Kaneda, M.M.; Tsujikawa, T.; Nguyen, A.V.; Affara, N.I.; Ruffell, B.; Gorjestani, S.; Liudahl, S.M.; Truitt, M.; Olson, P.; et al. Bruton Tyrosine Kinase-Dependent Immune Cell Cross-talk Drives Pancreas Cancer. Cancer Discov. 2016, 6, 270-285. [CrossRef] [PubMed]

63. Rivera, L.B.; Meyronet, D.; Hervieu, V.; Frederick, M.J.; Bergsland, E.; Bergers, G. Intratumoral myeloid cells regulate responsiveness and resistance to antiangiogenic therapy. Cell Rep. 2015, 11, 577-591. [CrossRef] [PubMed]

64. Garces, A.E.; Stocks, M.J. Class 1 PI3K Clinical Candidates and Recent Inhibitor Design Strategies: A Medicinal Chemistry Perspective. J. Med. Chem. 2018. [CrossRef] [PubMed]

65. Furet, P.; Guagnano, V.; Fairhurst, R.A.; Imbach-Weese, P.; Bruce, I.; Knapp, M.; Fritsch, C.; Blasco, F.; Blanz, J.; Aichholz, R.; et al. Discovery of NVP-BYL719 a potent and selective phosphatidylinositol-3 kinase alpha inhibitor selected for clinical evaluation. Bioorg. Med. Chem. Lett. 2013, 23, 3741-3748. [CrossRef] [PubMed]

66. So, L.; Yea, S.S.; Oak, J.S.; Lu, M.; Manmadhan, A.; Ke, Q.H.; Janes, M.R.; Kessler, L.V.; Kucharski, J.M.; Li, L.-S.; et al. Selective Inhibition of Phosphoinositide 3-Kinase p110 $\alpha$ Preserves Lymphocyte Function. J. Biol. Chem. 2013, 288, 5718-5731. [CrossRef] [PubMed]

67. Heffron, T.P.; Heald, R.A.; Ndubaku, C.; Wei, B.; Augistin, M.; Do, S.; Edgar, K.; Eigenbrot, C.; Friedman, L.; Gancia, E.; et al. The Rational Design of Selective Benzoxazepin Inhibitors of the $\alpha$-Isoform of Phosphoinositide 3-Kinase Culminating in the Identification of (S)-2-((2-(1-Isopropyl-1H-1,2,4-triazol-5-yl)5,6-dihydrobenzo[f]imidazo[1,2-d][1,4] oxazepin-9-yl)oxy)propanamide (GDC-0326). J. Med. Chem. 2016, 59, 985-1002. [PubMed]

68. Liu, X.; Xu, Y.; Wang, Y.; Chen, Y.; Wang, B.; Wang, Y.; Chen, Y.; Tan, C.; Hu, L.; Ma, Q.; et al. Decrease in phosphorylated ERK indicates the therapeutic efficacy of a clinical PI3K $\alpha$-selective inhibitor CYH33 in breast cancer. Cancer Lett. 2018, 433, 273-282. [CrossRef] [PubMed]

69. Barlaam, B.; Cosulich, S.; Degorce, S.; Fitzek, M.; Green, S.; Hancox, U.; Lambert-van der Brempt, C.; Lohmann, J.-J.; Maudet, M.; Morgentin, R.; et al. Discovery of (R)-8-(1-(3,5-Difluorophenylamino)ethyl)N,N-dimethyl-2-morpholino-4-oxo-4H-chromene-6-carboxamide (AZD8186): A Potent and Selective Inhibitor of PI3K $\beta$ and PI3K $\delta$ for the Treatment of PTEN-Deficient Cancers. J. Med. Chem. 2015, 58, 943-962. [CrossRef] [PubMed]

70. He, C.; Duan, S.; Dong, L.; Wang, Y.; Hu, Q.; Liu, C.; Forrest, M.L.; Holzbeierlein, J.M.; Han, S.; $\mathrm{Li}, \mathrm{B}$. Characterization of a novel p110ß-specific inhibitor BL140 that overcomes MDV3100-resistance in castration-resistant prostate cancer cells. Prostate 2017, 77, 1187-1198. [CrossRef] [PubMed]

71. Certal, V.; Carry, J.-C.; Halley, F.; Virone-Oddos, A.; Thompson, F.; Filoche-Rommé, B.; El-Ahmad, Y.; Karlsson, A.; Charrier, V.; Delorme, C.; et al. Discovery and Optimization of Pyrimidone Indoline Amide PI3K $\beta$ Inhibitors for the Treatment of Phosphatase and Tensin Homologue (PTEN)-Deficient Cancers. J. Med. Chem. 2014, 57, 903-920. [CrossRef] [PubMed]

72. Cushing, T.D.; Hao, X.; Shin, Y.; Andrews, K.; Brown, M.; Cardozo, M.; Chen, Y.; Duquette, J.; Fisher, B.; Gonzalez-Lopez de Turiso, F.; et al. Discovery and in Vivo Evaluation of (S)-N-(1-(7-Fluoro-2(pyridin-2-yl)quinolin-3-yl)ethyl)-9H-purin-6-amine (AMG319) and Related PI3K $\delta$ Inhibitors for Inflammation and Autoimmune Disease. J. Med. Chem. 2015, 58, 480-511. [CrossRef] [PubMed] 
73. Down, K.; Amour, A.; Baldwin, I.R.; Cooper, A.W.J.; Deakin, A.M.; Felton, L.M.; Guntrip, S.B.; Hardy, C.; Harrison, Z.A.; Jones, K.L.; et al. Optimization of Novel Indazoles as Highly Potent and Selective Inhibitors of Phosphoinositide 3-Kinase $\delta$ for the Treatment of Respiratory Disease. J. Med. Chem. 2015, 58, 7381-7399. [CrossRef] [PubMed]

74. Somoza, J.R.; Koditek, D.; Villaseñor, A.G.; Novikov, N.; Wong, M.H.; Liclican, A.; Xing, W.; Lagpacan, L.; Wang, R.; Schultz, B.E.; et al. Structural, Biochemical, and Biophysical Characterization of Idelalisib Binding

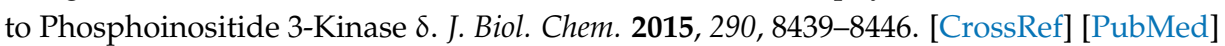

75. Hoegenauer, K.; Soldermann, N.; Zécri, F.; Strang, R.S.; Graveleau, N.; Wolf, R.M.; Cooke, N.G.; Smith, A.B.; Hollingworth, G.J.; Blanz, J.; et al. Discovery of CDZ173 (Leniolisib), Representing a Structurally Novel Class of PI3K Delta-Selective Inhibitors. ACS Med. Chem. Lett. 2017, 8, 975-980. [CrossRef] [PubMed]

76. Winkler, D.G.; Faia, K.L.; DiNitto, J.P.; Ali, J.A.; White, K.F.; Brophy, E.E.; Pink, M.M.; Proctor, J.L.; Lussier, J.; Martin, C.M.; et al. PI3K- $\delta$ and PI3K- $\gamma$ Inhibition by IPI-145 Abrogates Immune Responses and Suppresses Activity in Autoimmune and Inflammatory Disease Models. Chem. Biol. 2013, 20, 1364-1374. [CrossRef] [PubMed]

77. Walker, E.H.; Perisic, O.; Ried, C.; Stephens, L.; Williams, R.L. Structural insights into phosphoinositide 3-kinase catalysis and signalling. Nature 1999, 402, 313-320. [CrossRef] [PubMed]

78. Nassar, N.; Horn, G.; Herrmann, C.A.; Scherer, A.; McCormick, F.; Wittinghofer, A. The 2.2 Å crystal structure of the Ras-binding domain of the serine/threonine kinase c-Raf1 in complex with RaplA and a GTP analogue. Nature 1995, 375, 554-560. [CrossRef] [PubMed]

79. Huang, L.; Hofer, F.; Martin, G.S.; Kim, S.-H. Structural basis for the interaction of Ras with RaIGDS. Nat. Struct. Mol. Biol. 1998, 5, 422-426. [CrossRef]

80. Essen, L.-O.; Perisic, O.; Lynch, D.E.; Katan, M.; Williams, R.L. A Ternary Metal Binding Site in the C2 Domain of Phosphoinositide-Specific Phospholipase C- $\delta 1$. Biochemistry 1997, 36, 2753-2762. [CrossRef] [PubMed]

81. Walker, E.H.; Pacold, M.E.; Perisic, O.; Stephens, L.; Hawkins, P.T.; Wymann, M.P.; Williams, R.L. Structural determinants of phosphoinositide 3-kinase inhibition by wortmannin, LY294002, quercetin, myricetin, and staurosporine. Mol. Cell 2000, 6, 909-919. [CrossRef]

82. Huang, C.-H.; Mandelker, D.; Schmidt-Kittler, O.; Samuels, Y.; Velculescu, V.E.; Kinzler, K.W.; Vogelstein, B.; Gabelli, S.B.; Amzel, L.M. The Structure of a Human p110 $\alpha /$ p $85 \alpha$ Complex Elucidates the Effects of Oncogenic PI3K $\alpha$ Mutations. Science 2007, 318, 1744-1748. [CrossRef] [PubMed]

83. Yu, J.; Wjasow, C.; Backer, J.M. Regulation of the P85/P110 $\alpha$ Phosphatidylinositol 3'-Kinase: Distinct roles for the N-terminal and C-terminal SH2 domains. J. Biol. Chem. 1998, 273, 30199-30203. [CrossRef] [PubMed]

84. Mandelker, D.; Gabelli, S.B.; Schmidt-Kittler, O.; Zhu, J.; Cheong, I.; Huang, C.H.; Kinzler, K.W.; Vogelstein, B.; Amzel, L.M. A frequent kinase domain mutation that changes the interaction between PI3K $\alpha$ and the membrane. Proc. Natl. Acad. Sci. USA 2009, 106, 16996-17001. [CrossRef] [PubMed]

85. Berndt, A.; Miller, S.; Williams, O.; Le, D.D.; Houseman, B.T.; Pacold, J.I.; Gorrec, F.; Hon, W.-C.; Ren, P.; Liu, Y.; et al. The p1108 structure: Mechanisms for selectivity and potency of new PI(3)K inhibitors. Nat. Chem. Biol. 2010, 6, 117-124. [CrossRef] [PubMed]

86. Zhang, X.; Vadas, O.; Perisic, O.; Anderson, K.E.; Clark, J.; Hawkins, P.T.; Stephens, L.R.; Williams, R.L. Structure of Lipid Kinase p110 $\beta /$ p $85 \beta$ Elucidates an Unusual SH2-Domain-Mediated Inhibitory Mechanism. Mol. Cell 2011, 41, 567-578. [CrossRef] [PubMed]

87. Berman, H.M.; Henrick, K.; Nakamura, H. Announcing the worldwide Protein Data Bank. Nat. Struct. Biol. 2003, 10, 980. [CrossRef] [PubMed]

88. Hon, W.-C.; Berndt, A.; Williams, R.L. Regulation of lipid binding underlies the activation mechanism of class IA PI3-kinases. Oncogene 2012, 31, 3655-3666. [CrossRef] [PubMed]

89. Lu, Y.; Knapp, M.; Crawford, K.; Warne, R.; Elling, R.; Yan, K.; Doyle, M.; Pardee, G.; Zhang, L.; Ma, S.; et al. Rationally Designed PI3K $\alpha$ Mutants to Mimic ATR and Their Use to Understand Binding Specificity of ATR Inhibitors. J. Mol. Biol. 2017, 429, 1684-1704. [CrossRef] [PubMed]

90. Zhao, Y.; Zhang, X.; Chen, Y.; Lu, S.; Peng, Y.; Wang, X.; Guo, C.; Zhou, A.; Zhang, J.; Luo, Y.; et al. Crystal Structures of PI3K $\alpha$ Complexed with PI103 and Its Derivatives: New Directions for Inhibitors Design. ACS Med. Chem. Lett. 2014, 5, 138-142. [CrossRef] [PubMed] 
91. Yang, H.; Medeiros, P.F.; Raha, K.; Elkins, P.; Lind, K.E.; Lehr, R.; Adams, N.D.; Burgess, J.L.; Schmidt, S.J.; Knight, S.D.; et al. Discovery of a Potent Class of PI3K $\alpha$ Inhibitors with Unique Binding Mode via Encoded Library Technology (ELT). ACS Med. Chem. Lett. 2015, 6, 531-536. [CrossRef] [PubMed]

92. Chen, P.; Deng, Y.-L.; Bergqvist, S.; Falk, M.D.; Liu, W.; Timofeevski, S.; Brooun, A. Engineering of an isolated p110 $\alpha$ subunit of PI3K $\alpha$ permits crystallization and provides a platform for structure-based drug design. Protein Sci. 2014, 23, 1332-1340. [CrossRef] [PubMed]

93. Liu, Q.; Shi, Q.; Marcoux, D.; Batt, D.G.; Cornelius, L.; Qin, L.-Y.; Ruan, Z.; Neels, J.; Beaudoin-Bertrand, M.; Srivastava, A.S.; et al. Identification of a Potent, Selective, and Efficacious Phosphatidylinositol 3-Kinase $\delta($ PI3K $\delta)$ Inhibitor for the Treatment of Immunological Disorders. J. Med. Chem. 2017, 60, 5193-5208. [CrossRef] [PubMed]

94. Qin, L.-Y.; Ruan, Z.; Cherney, R.J.; Dhar, T.G.M.; Neels, J.; Weigelt, C.A.; Sack, J.S.; Srivastava, A.S.; Cornelius, L.A.M.; Tino, J.A.; et al. Discovery of 7-(3-(piperazin-1-yl)phenyl)pyrrolo[2,1-f][1,2,4]triazin4-amine derivatives as highly potent and selective PI3K $\delta$ inhibitors. Bioorg. Med. Chem. Lett. 2017, 27, 855-861. [CrossRef] [PubMed]

95. Castanedo, G.M.; Blaquiere, N.; Beresini, M.; Bravo, B.; Brightbill, H.; Chen, J.; Cui, H.-F.; Eigenbrot, C.; Everett, C.; Feng, J.; et al. Structure-Based Design of Tricyclic NF-кB Inducing Kinase (NIK) Inhibitors That Have High Selectivity over Phosphoinositide-3-kinase (PI3K). J. Med. Chem. 2017, 60, 627-640. [CrossRef] [PubMed]

96. Frazzetto, M.; Suphioglu, C.; Zhu, J.; Schmidt-Kittler, O.; Jennings, I.G.; Cranmer, S.L.; Jackson, S.P.; Kinzler, K.W.; Vogelstein, B.; Thompson, P.E. Dissecting Isoform Selectivity of PI3 Kinase Inhibitors. The Role of Non-conserved Residues in the Catalytic Pocket. Biochem. J. 2008, 414, 383-390. [CrossRef] [PubMed]

97. Zheng, Z.; Amran, S.I.; Thompson, P.E.; Jennings, I.G. Isoform-Selective Inhibition of Phosphoinositide 3-Kinase: Identification of a New Region of Nonconserved Amino Acids Critical for p110 $\alpha$ Inhibition. Mol. Pharmacol. 2011, 80, 657-664. [CrossRef] [PubMed]

98. Zheng, Z.; Miller, M.S.; Jennings, I.G.; Thompson, P.E. Mechanisms of PI3K $\beta$-Selective Inhibition Revealed by Reciprocal Mutagenesis. ACS Chem. Biol. 2013, 8, 679-683. [CrossRef] [PubMed]

99. Patel, L.; Chandrasekhar, J.; Evarts, J.; Forseth, K.; Haran, A.C.; Ip, C.; Kashishian, A.; Kim, M.; Koditek, D.; Koppenol, S.; et al. Discovery of Orally Efficacious Phosphoinositide 3-Kinase $\delta$ Inhibitors with Improved Metabolic Stability. J. Med. Chem. 2016, 59, 9228-9242. [CrossRef] [PubMed]

100. Perreault, S.; Chandrasekhar, J.; Cui, Z.-H.; Evarts, J.; Hao, J.; Kaplan, J.A.; Kashishian, A.; Keegan, K.S.; Kenney, T.; Koditek, D.; et al. Discovery of a Phosphoinositide 3-Kinase (PI3K) $\beta / \delta$ Inhibitor for the Treatment of Phosphatase and Tensin Homolog (PTEN) Deficient Tumors: Building PI3K $\beta$ Potency in a PI3K $\delta$-Selective Template by Targeting Nonconserved Asp856. J. Med. Chem. 2017, 60, 1555-1567. [CrossRef] [PubMed]

101. Patel, L.; Chandrasekhar, J.; Evarts, J.; Haran, A.C.; Ip, C.; Kaplan, J.A.; Kim, M.; Koditek, D.; Lad, L.; Lepist, E.-I.; et al. 2,4,6-Triaminopyrimidine as a Novel Hinge Binder in a Series of PI3K $\delta$ Selective Inhibitors. J. Med. Chem. 2016, 59, 3532-3548. [CrossRef] [PubMed]

102. Gonzalez-Lopez de Turiso, F.; Shin, Y.; Brown, M.; Cardozo, M.; Chen, Y.; Fong, D.; Hao, X.; He, X.; Henne, K.; $\mathrm{Hu}$, Y.-L.; et al. Discovery and in Vivo Evaluation of Dual PI3K $\beta / \delta$ Inhibitors. J. Med. Chem. 2012, 55, 7667-7685. [CrossRef] [PubMed]

103. Shin, Y.; Suchomel, J.; Cardozo, M.; Duquette, J.; He, X.; Henne, K.; Hu, Y.-L.; Kelly, R.C.; McCarter, J.; McGee, L.R.; et al. Discovery, Optimization, and in Vivo Evaluation of Benzimidazole Derivatives AM-8508 and AM-9635 as Potent and Selective PI3K $\delta$ Inhibitors. J. Med. Chem. 2016, 59, 431-447. [CrossRef] [PubMed]

104. Wei, M.; Zhang, X.; Wang, X.; Song, Z.; Ding, J.; Meng, L.-H.; Zhang, A. SAR study of 5-alkynyl substituted quinazolin-4(3H)-ones as phosphoinositide 3-kinase delta (PI3K $)$ inhibitors. Eur. J. Med. Chem. 2017, 125, 1156-1171. [CrossRef] [PubMed]

105. Williams, O.; Houseman, B.T.; Kunkel, E.J.; Aizenstein, B.; Hoffman, R.; Knight, Z.A.; Shokat, K.M. Discovery

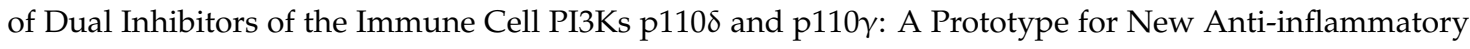
Drugs. Chem. Biol. 2010, 17, 123-134. [CrossRef] [PubMed]

106. Sutherlin, D.P.; Baker, S.; Bisconte, A.; Blaney, P.M.; Brown, A.; Chan, B.K.; Chantry, D.; Castanedo, G.; DePledge, P.; Goldsmith, P.; et al. Potent and selective inhibitors of PI3K $\delta$ : Obtaining isoform selectivity from the affinity pocket and tryptophan shelf. Bioorg. Med. Chem. Lett. 2012, 22, 4296-4302. [CrossRef] [PubMed] 
107. Erra, M.; Taltavull, J.; Bernal, F.J.; Caturla, J.F.; Carrascal, M.; Pagès, L.; Mir, M.; Espinosa, S.; Gràcia, J.; Domínguez, M.; et al. Discovery of a Novel Inhaled PI3K $\delta$ Inhibitor for the Treatment of Respiratory Diseases. J. Med. Chem. 2018, 61, 9551-9567. [CrossRef] [PubMed]

108. Terstiege, I.; Perry, M.; Petersen, J.; Tyrchan, C.; Svensson, T.; Lindmark, H.; Öster, L. Discovery of triazole aminopyrazines as a highly potent and selective series of PI3K $\delta$ inhibitors. Bioorg. Med. Chem. Lett. 2017, 27, 679-687. [CrossRef] [PubMed]

109. Barton, N.; Convery, M.; Cooper, A.W.J.; Down, K.; Hamblin, J.N.; Inglis, G.; Peace, S.; Rowedder, J.; Rowland, P.; Taylor, J.A.; et al. Discovery of Potent, Efficient, and Selective Inhibitors of Phosphoinositide 3-Kinase $\delta$ through a Deconstruction and Regrowth Approach. J. Med. Chem. 2018, 61, 11061-11073. [CrossRef] [PubMed]

110. Safina, B.S.; Sweeney, Z.K.; Li, J.; Chan, B.K.; Bisconte, A.; Carrera, D.; Castanedo, G.; Flagella, M.; Heald, R.; Lewis, C.; et al. Identification of GNE-293, a potent and selective PI3K $\delta$ inhibitor: Navigating in vitro genotoxicity while improving potency and selectivity. Bioorg. Med. Chem. Lett. 2013, 23, 4953-4959. [CrossRef] [PubMed]

111. Murray, J.M.; Sweeney, Z.K.; Chan, B.K.; Balazs, M.; Bradley, E.; Castanedo, G.; Chabot, C.; Chantry, D.; Flagella, M.; Goldstein, D.M.; et al. Potent and Highly Selective Benzimidazole Inhibitors of PI3-Kinase Delta. J. Med. Chem. 2012, 55, 7686-7695. [CrossRef] [PubMed]

112. Safina, B.S.; Elliott, R.L.; Forrest, A.K.; Heald, R.A.; Murray, J.M.; Nonomiya, J.; Pang, J.; Salphati, L.; Seward, E.M.; Staben, S.T.; et al. Design of Selective Benzoxazepin PI3K $\delta$ Inhibitors Through Control of Dihedral Angles. Acs Med. Chem. Lett. 2017, 8, 936-940. [CrossRef] [PubMed]

113. Dalton, S.E.; Dittus, L.; Thomas, D.A.; Convery, M.A.; Nunes, J.; Bush, J.T.; Evans, J.P.; Werner, T.; Bantscheff, M.; Murphy, J.A.; et al. Selectively Targeting the Kinome-Conserved Lysine of PI3K $\delta$ as a General Approach to Covalent Kinase Inhibition. J. Am. Chem. Soc. 2018, 140, 932-939. [CrossRef] [PubMed]

114. Schwehm, C.; Kellam, B.; Garces, A.E.; Hill, S.J.; Kindon, N.D.; Bradshaw, T.D.; Li, J.; Macdonald, S.J.F.; Rowedder, J.E.; Stoddart, L.A.; et al. Design and Elaboration of a Tractable Tricyclic Scaffold To Synthesize Druglike Inhibitors of Dipeptidyl Peptidase-4 (DPP-4), Antagonists of the C-C Chemokine Receptor Type 5 (CCR5), and Highly Potent and Selective Phosphoinositol-3 Kinase $\delta$ (PI3K $\delta$ ) Inhibitors. J. Med. Chem. 2017, 60, 1534-1554. [PubMed]

115. Hamajima, T.; Takahashi, F.; Kato, K.; Mukoyoshi, K.; Yoshihara, K.; Yamaki, S.; Sugano, Y.; Moritomo, A.; Yamagami, K.; Yokoo, K.; et al. Discovery and biological evaluation of novel pyrazolopyridine derivatives as potent and orally available PI3K $\delta$ inhibitors. Bioorg. Med. Chem. 2018, 26, 2410-2419. [CrossRef] [PubMed]

116. Hoegenauer, K.; Soldermann, N.; Stauffer, F.; Furet, P.; Graveleau, N.; Smith, A.B.; Hebach, C.; Hollingworth, G.J.; Lewis, I.; Gutmann, S.; et al. Discovery and Pharmacological Characterization of Novel Quinazoline-Based PI3K Delta-Selective Inhibitors. ACS Med. Chem. Lett. 2016, 7, 762-767. [CrossRef] [PubMed]

117. Bhide, R.S.; Neels, J.; Qin, L.-Y.; Ruan, Z.; Stachura, S.; Weigelt, C.; Sack, J.S.; Stefanski, K.; Gu, X.; Xie, J.H.; et al. Discovery and SAR of pyrrolo[2,1-f][1,2,4]triazin-4-amines as potent and selective PI3K $\delta$ inhibitors. Bioorg. Med. Chem. Lett. 2016, 26, 4256-4260. [CrossRef] [PubMed]

118. Marcoux, D.; Qin, L.-Y.; Ruan, Z.; Shi, Q.; Ruan, Q.; Weigelt, C.; Qiu, H.; Schieven, G.; Hynes, J.; Bhide, R.; et al. Identification of highly potent and selective PI3K $\delta$ inhibitors. Bioorg. Med. Chem. Lett. 2017, 27, 2849-2853. [CrossRef] [PubMed]

119. Bui, M.; Hao, X.; Shin, Y.; Cardozo, M.; He, X.; Henne, K.; Suchomel, J.; McCarter, J.; McGee, L.R.; San Miguel, T.; et al. Synthesis and SAR study of potent and selective PI3K $\delta$ inhibitors. Bioorg. Med. Chem. Lett. 2015, 25, 1104-1109. [CrossRef] [PubMed]

120. Gonzalez-Lopez de Turiso, F.; Hao, X.; Shin, Y.; Bui, M.; Campuzano, I.D.G.; Cardozo, M.; Dunn, M.C.; Duquette, J.; Fisher, B.; Foti, R.S.; et al. Discovery and in Vivo Evaluation of the Potent and Selective PI3K $\delta$ Inhibitors 2-((1S)-1-((6-Amino-5-cyano-4-pyrimidinyl)amino)ethyl)-6-fluoro-N-methyl-3-(2-pyridinyl)-4quinolinecarboxamide (AM-0687) and 2-((1S)-1-((6-Amino-5-cyano-4-pyrimidinyl)amino)ethyl)-5-fluoro-Nmethyl-3-(2-pyridinyl)-4-quinolinecarboxamide (AM-1430). J. Med. Chem. 2016, 59, 7252-7267. [PubMed]

121. Perry, M.W.D.; Björhall, K.; Bonn, B.; Carlsson, J.; Chen, Y.; Eriksson, A.; Fredlund, L.; Hao, H.; Holden, N.S.; Karabelas, K.; et al. Design and Synthesis of Soluble and Cell-Permeable PI3K $\delta$ Inhibitors for Long-Acting Inhaled Administration. J. Med. Chem. 2017, 60, 5057-5071. [CrossRef] [PubMed] 
122. Miller, M.S.; Mountford, S.J.; Pinson, J.-A.; Zheng, Z.; Künzli, M.; Patel, V.; Hogg, S.J.; Shortt, J.; Jennings, I.G.; Thompson, P.E. Development of single and mixed isoform selectivity PI3K $\delta$ inhibitors by targeting Asn836 of PI3Kס. Bioorg. Med. Chem. Lett. 2016, 26, 4790-4794. [CrossRef] [PubMed]

123. Certal, V.; Halley, F.; Virone-Oddos, A.; Thompson, F.; Filoche-Rommé, B.; El-Ahmad, Y.; Carry, J.-C.; Delorme, C.; Karlsson, A.; Abecassis, P.-Y.; et al. Preparation and optimization of new 4-(morpholin-4-yl)(6-oxo-1,6-dihydropyrimidin-2-yl)amide derivatives as PI3K $\beta$ inhibitors. Bioorg. Med. Chem. Lett. 2012, 22, 6381-6384. [CrossRef] [PubMed]

124. Ni, J.; Liu, Q.; Xie, S.; Carlson, C.; Von, T.; Vogel, K.; Riddle, S.; Benes, C.; Eck, M.; Roberts, T.; et al. Functional Characterization of an Isoform-Selective Inhibitor of PI3K-p110 $\beta$ as a Potential Anticancer Agent. Cancer Discov. 2012, 2, 425-433. [CrossRef] [PubMed]

125. Certal, V.; Halley, F.; Virone-Oddos, A.; Delorme, C.; Karlsson, A.; Rak, A.; Thompson, F.; Filoche-Rommé, B.; El-Ahmad, Y.; Carry, J.-C.; et al. Discovery and Optimization of New Benzimidazoleand Benzoxazole-Pyrimidone Selective PI3K $\beta$ Inhibitors for the Treatment of Phosphatase and TENsin homologue (PTEN)-Deficient Cancers. J. Med. Chem. 2012, 55, 4788-4805. [CrossRef] [PubMed]

126. Giordanetto, F.; Wållberg, A.; Cassel, J.; Ghosal, S.; Kossenjans, M.; Yuan, Z.-Q.; Wang, X.; Liang, L. Discovery of 4-morpholino-pyrimidin-6-one and 4-morpholino-pyrimidin-2-one-containing Phosphoinositide 3-kinase (PI3K) p110 $\beta$ isoform inhibitors through structure-based fragment optimisation. Bioorg. Med. Chem. Lett. 2012, 22, 6665-6670. [CrossRef] [PubMed]

127. Lin, H.; Erhard, K.; Hardwicke, M.A.; Luengo, J.I.; Mack, J.F.; McSurdy-Freed, J.; Plant, R.; Raha, K.; Rominger, C.M.; Sanchez, R.M.; et al. Synthesis and structure-activity relationships of imidazo[1,2-a]pyrimidin-5(1H)-ones as a novel series of beta isoform selective phosphatidylinositol 3-kinase inhibitors. Bioorg. Med. Chem. Lett. 2012, 22, 2230-2234. [CrossRef] [PubMed]

128. Sanchez, R.M.; Erhard, K.; Hardwicke, M.A.; Lin, H.; McSurdy-Freed, J.; Plant, R.; Raha, K.; Rominger, C.M.; Schaber, M.D.; Spengler, M.D.; et al. Synthesis and structure-activity relationships of 1,2,4-triazolo[1,5-a]pyrimidin-7(3H)-ones as novel series of potent $\beta$ isoform selective phosphatidylinositol 3-kinase inhibitors. Bioorg. Med. Chem. Lett. 2012, 22, 3198-3202. [CrossRef] [PubMed]

129. Chandrasekhar, J.; Dick, R.; Van Veldhuizen, J.; Koditek, D.; Lepist, E.-I.; McGrath, M.E.; Patel, L.; Phillips, G.; Sedillo, K.; Somoza, J.R.; et al. Atropisomerism by Design: Discovery of a Selective and Stable Phosphoinositide 3-Kinase (PI3K) $\beta$ Inhibitor. J. Med. Chem. 2018, 61, 6858-6868. [CrossRef] [PubMed]

130. Robinson, D.; Bertrand, T.; Carry, J.-C.; Halley, F.; Karlsson, A.; Mathieu, M.; Minoux, H.; Perrin, M.-A.; Robert, B.; Schio, L.; et al. Differential Water Thermodynamics Determine PI3K-Beta/Delta Selectivity for Solvent-Exposed Ligand Modifications. J. Chem. Inf. Model. 2016, 56, 886-894. [CrossRef] [PubMed]

131. Pinson, J.-A.; Zheng, Z.; Miller, M.S.; Chalmers, D.K.; Jennings, I.G.; Thompson, P.E. L-Aminoacyl-triazine Derivatives Are Isoform-Selective PI3K $\beta$ Inhibitors That Target Nonconserved Asp 862 of PI3K $\beta$. ACS Med. Chem. Lett. 2013, 4, 206-210. [CrossRef] [PubMed]

132. Zheng, Z.; Pinson, J.A.; Mountford, S.J.; Orive, S.; Schoenwaelder, S.M.; Shackleford, D.; Powell, A.; Nelson, E.M.; Hamilton, J.R.; Jackson, S.; et al. Discovery and antiplatelet activity of a selective PI3K $\beta$ inhibitor (MIPS-9922). Eur. J. Med. Chem. 2016, 122, 339-351. [CrossRef] [PubMed]

133. Cao, S.; Cao, R.; Liu, X.; Luo, X.; Zhong, W. Design, Synthesis and Biological Evaluation of Novel Benzothiazole Derivatives as Selective PI3K $\beta$ Inhibitors. Molecules 2016, 21, 876. [CrossRef] [PubMed]

134. Giordanetto, F.; Wållberg, A.; Ghosal, S.; Iliefski, T.; Cassel, J.; Yuan, Z.-Q.; von Wachenfeldt, H.; Andersen, S.M.; Inghardt, T.; Tunek, A.; et al. Discovery of phosphoinositide 3-kinases (PI3K) p110 $\beta$ isoform inhibitor 4-[2-hydroxyethyl(1-naphthylmethyl)amino]-6-[(2S)-2-methylmorpholin-4-yl]-1H-pyrimidin-2-one, an effective antithrombotic agent without associated bleeding and insulin resistance. Bioorg. Med. Chem. Lett. 2012, 22, 6671-6676. [CrossRef] [PubMed]

135. Giordanetto, F.; Barlaam, B.; Berglund, S.; Edman, K.; Karlsson, O.; Lindberg, J.; Nylander, S.; Inghardt, T. Discovery of 9-(1-phenoxyethyl)-2-morpholino-4-oxo-pyrido[1,2-a]pyrimidine-7-carboxamides as oral PI3K $\beta$ inhibitors, useful as antiplatelet agents. Bioorg. Med. Chem. Lett. 2014, 24, 3936-3943. [CrossRef] [PubMed]

136. Lin, H.; Schulz, M.J.; Xie, R.; Zeng, J.; Luengo, J.I.; Squire, M.D.; Tedesco, R.; Qu, J.; Erhard, K.; Mack, J.F.; et al. Rational Design, Synthesis, and SAR of a Novel Thiazolopyrimidinone Series of Selective PI3K-beta Inhibitors. ACS Med. Chem. Lett. 2012, 3, 524-529. [CrossRef] [PubMed] 
137. Yu, H.; Moore, M.L.; Erhard, K.; Hardwicke, M.A.; Lin, H.; Luengo, J.I.; McSurdy-Freed, J.; Plant, R.; Qu, J.; Raha, K.; et al. [3a,4]-Dihydropyrazolo[1,5a]pyrimidines: Novel, Potent, and Selective Phosphatidylinositol3-kinase $\beta$ Inhibitors. ACS Med. Chem. Lett. 2013, 4, 230-234. [CrossRef] [PubMed]

138. Greshock, J. Abstract IA17: Exploiting the synthetic lethal properties of selective PI3K- $\beta$ inhibition in PTEN deficient cells with GSK2636771. Mol. Cancer Ther. 2013, 12, IA17. [CrossRef]

139. Hayakawa, M.; Kawaguchi, K.; Kaizawa, H.; Koizumi, T.; Ohishi, T.; Yamano, M.; Okada, M.; Ohta, M.; Tsukamoto, S.; Raynaud, F.I.; et al. Synthesis and biological evaluation of sulfonylhydrazone-substituted imidazo [1, 2-a] pyridines as novel PI3 kinase p110 $\alpha$ inhibitors. Bioorg. Med. Chem. 2007, 15, 5837-5844. [CrossRef] [PubMed]

140. Schmidt-Kittler, O.; Zhu, J.; Yang, J.; Liu, G.; Hendricks, W.; Lengauer, C.; Gabelli, S.B.; Kinzler, K.W.; Vogelstein, B.; Huso, D.L.; et al. PI3K $\alpha$ inhibitors that inhibit metastasis. Oncotarget 2010, 1, 339. [PubMed]

141. Kendall, J.D.; O'Connor, P.D.; Marshall, A.J.; Frédérick, R.; Marshall, E.S.; Lill, C.L.; Lee, W.-J.; Kolekar, S.; Chao, M.; Malik, A.; et al. Discovery of pyrazolo[1,5-a]pyridines as p110 $\alpha$-selective PI3 kinase inhibitors. Bioorg. Med. Chem. 2012, 20, 69-85. [CrossRef] [PubMed]

142. Kendall, J.D.; Giddens, A.C.; Tsang, K.Y.; Frédérick, R.; Marshall, E.S.; Singh, R.; Lill, C.L.; Lee, W.-J.; Kolekar, S.; Chao, M.; et al. Novel pyrazolo[1,5-a]pyridines as p110 $\alpha$-selective PI3 kinase inhibitors: Exploring the benzenesulfonohydrazide SAR. Bioorg. Med. Chem. 2012, 20, 58-68. [CrossRef] [PubMed]

143. Kendall, J.D.; Rewcastle, G.W.; Frédérick, R.; Mawson, C.; Denny, W.A.; Marshall, E.S.; Baguley, B.C.; Chaussade, C.; Jackson, S.P.; Shepherd, P.R. Synthesis, biological evaluation and molecular modelling of sulfonohydrazides as selective PI3K p110alpha inhibitors. Bioorg. Med. Chem. 2007, 15, 7677-7687. [CrossRef] [PubMed]

144. Kendall, J.D.; Giddens, A.C.; Tsang, K.Y.; Marshall, E.S.; Lill, C.L.; Lee, W.-J.; Kolekar, S.; Chao, M.; Malik, A.; $\mathrm{Yu}, \mathrm{S}$.; et al. Novel pyrazolo[1,5-a]pyridines with improved aqueous solubility as p110 $\alpha$-selective PI3 kinase inhibitors. Bioorg. Med. Chem. Lett. 2017, 27, 187-190. [CrossRef] [PubMed]

145. Hayakawa, M.; Kaizawa, H.; Kawaguchi, K.; Ishikawa, N.; Koizumi, T.; Ohishi, T.; Yamano, M.; Okada, M.; Ohta, M.; Tsukamoto, S.; et al. Synthesis and biological evaluation of imidazo[1,2-a]pyridine derivatives as novel PI3 kinase p110 $\alpha$ inhibitors. Bioorg. Med. Chem. 2007, 15, 403-412. [CrossRef] [PubMed]

146. Frédérick, R.; Denny, W.A. Phosphoinositide-3-kinases (PI3Ks): Combined Comparative Modeling and 3D-QSAR To Rationalize the Inhibition of p110 $\alpha$. J. Chem. Inf. Model. 2008, 48, 629-638. [CrossRef] [PubMed]

147. Han, M.; Zhang, J.Z.H. Class I Phospho-inositide-3-kinases (PI3Ks) Isoform-Specific Inhibition Study by the Combination of Docking and Molecular Dynamics Simulation. J. Chem. Inf. Model. 2010, 50, 136-145. [CrossRef] [PubMed]

148. Li, Y.; Wang, Y.; Zhang, F. Pharmacophore modeling and 3D-QSAR analysis of phosphoinositide 3-kinase p110 $\alpha$ inhibitors. J. Mol. Model. 2010, 16, 1449-1460. [CrossRef] [PubMed]

149. Sabbah, D.A.; Vennerstrom, J.L.; Zhong, H. Docking Studies on Isoform-Specific Inhibition of Phosphoinositide-3-Kinases. J. Chem. Inf. Model. 2010, 50, 1887-1898. [CrossRef] [PubMed]

150. Tesch, R.; Becker, C.; Müller, M.P.; Beck, M.E.; Quambusch, L.; Getlik, M.; Lategahn, J.; Uhlenbrock, N.; Costa, F.N.; Polêto, M.D.; et al. An Unusual Intramolecular Halogen Bond Guides Conformational Selection. Angew. Chem. Int. Ed. 2018, 57, 9970-9975. [CrossRef] [PubMed]

151. Heffron, T.P.; Wei, B.; Olivero, A.; Staben, S.T.; Tsui, V.; Do, S.; Dotson, J.; Folkes, A.J.; Goldsmith, P.; Goldsmith, R.; et al. Rational Design of Phosphoinositide 3-Kinase $\alpha$ Inhibitors That Exhibit Selectivity over the Phosphoinositide 3-Kinase $\beta$ Isoform. J. Med. Chem. 2011, 54, 7815-7833. [CrossRef] [PubMed]

152. Nacht, M.; Qiao, L.; Sheets, M.P.; St. Martin, T.; Labenski, M.; Mazdiyasni, H.; Karp, R.; Zhu, Z.; Chaturvedi, P.; Bhavsar, D.; et al. Discovery of a Potent and Isoform-Selective Targeted Covalent Inhibitor of the Lipid Kinase PI3K $\alpha$. J. Med. Chem. 2013, 56, 712-721. [CrossRef] [PubMed]

153. Staben, S.T.; Ndubaku, C.; Blaquiere, N.; Belvin, M.; Bull, R.J.; Dudley, D.; Edgar, K.; Gray, D.; Heald, R.; Heffron, T.P.; et al. Discovery of thiazolobenzoxepin PI3-kinase inhibitors that spare the PI3-kinase $\beta$ isoform. Bioorg. Med. Chem. Lett. 2013, 23, 2606-2613. [CrossRef] [PubMed]

154. Ndubaku, C.; Heffron, T.P.; Staben, S.T.; Baumgardner, M.; Blaquiere, N.; Bradley, E.; Bull, R.; Do, S.; Dotson, J.; Dudley, D.; et al. Discovery of 2-\{3-[2-(1-isopropyl-3-methyl-1H-1,2-4-triazol-5-yl)-5,6-dihydrobenzo [f]imidazo[1,2-d][1,4]oxazepin-9-yl]-1H-pyrazol-1-yl\}-2-methylpropanamide (GDC-0032): A $\beta$-sparing phosphoinositide 3-kinase (PI3K) inhibitor with high unbound exposure and robust in vivo anti-tumor activity. J. Med. Chem. 2013, 56, 4597-4610. [PubMed] 
155. Bruce, I.; Akhlaq, M.; Bloomfield, G.C.; Budd, E.; Cox, B.; Cuenoud, B.; Finan, P.; Gedeck, P.; Hatto, J.; Hayler, J.F.; et al. Development of isoform selective PI3-kinase inhibitors as pharmacological tools for elucidating the PI3K pathway. Bioorg. Med. Chem. Lett. 2012, 22, 5445-5450. [CrossRef] [PubMed]

156. Gerspacher, M.; Fairhurst, R.A.; Mah, R.; Roehn-Carnemolla, E.; Furet, P.; Fritsch, C.; Guthy, D.A. Discovery of a novel tricyclic $4 \mathrm{H}$-thiazolo[ $\left.5^{\prime}, 4^{\prime}: 4,5\right]$ pyrano[2,3-c]pyridine-2-amino scaffold and its application in a PI3K $\alpha$ inhibitor with high PI3K isoform selectivity and potent cellular activity. Bioorg. Med. Chem. Lett. 2015, 25, 3582-3584. [CrossRef] [PubMed]

157. Jamieson, S.; Flanagan, J.U.; Kolekar, S.; Buchanan, C.; Kendall, J.D.; Lee, W.; Rewcastle, G.W.; Denny, W.A.; Singh, R.; Dickson, J.; et al. A drug targeting only p110 $\alpha$ can block phosphoinositide 3-kinase signalling and tumour growth in certain cell types. Biochem. J. 2011, 438, 53-62. [CrossRef] [PubMed]

158. Zheng, Z.; Amran, S.I.; Zhu, J.; Schmidt-Kittler, O.; Kinzler, K.W.; Vogelstein, B.; Shepherd, P.R.; Thompson, P.E.; Jennings, I.G. Definition of the binding mode of a new class of phosphoinositide 3-kinase $\alpha$-selective inhibitors using in vitro mutagenesis of non-conserved amino acids and kinetic analysis. Biochem. J. 2012, 444, 529-535. [CrossRef] [PubMed]

159. Barlaam, B.; Cosulich, S.; Fitzek, M.; Germain, H.; Green, S.; Hanson, L.L.; Harris, C.S.; Hancox, U.; Hudson, K.; Lambert-van der Brempt, C.; et al. Discovery of a novel aminopyrazine series as selective PI3K $\alpha$ inhibitors. Bioorg. Med. Chem. Lett. 2017, 27, 3030-3035. [CrossRef] [PubMed]

160. Barlaam, B.; Cosulich, S.; Fitzek, M.; Green, S.; Harris, C.S.; Hudson, K.; Lambert-van der Brempt, C.; Ouvry, G.; Page, K.; Ruston, L.; et al. Design of selective PI3K $\alpha$ inhibitors starting from a promiscuous pan kinase scaffold. Bioorg. Med. Chem. Lett. 2015, 25, 2679-2685. [CrossRef] [PubMed]

161. Barlaam, B.; Cosulich, S.; Delouvrié, B.; Ellston, R.; Fitzek, M.; Germain, H.; Green, S.; Hancox, U.; Harris, C.S.; Hudson, K.; et al. Discovery of 1-(4-(5-(5-amino-6-(5-tert-butyl-1,3,4-oxadiazol-2-yl)pyrazin-2-yl)-1-ethyl1,2,4-triazol-3-yl)piperidin-1-yl)-3-hydroxypropan-1-one (AZD8835): A potent and selective inhibitor of $\mathrm{PI} 3 \mathrm{~K} \alpha$ and PI3K $\delta$ for the treatment of cancers. Bioorg. Med. Chem. Lett. 2015, 25, 5155-5162. [CrossRef] [PubMed]

162. Fan, Y.-H.; Ding, H.-W.; Liu, D.-D.; Song, H.-R.; Xu, Y.-N.; Wang, J. Novel 4-aminoquinazoline derivatives induce growth inhibition, cell cycle arrest and apoptosis via PI3K $\alpha$ inhibition. Bioorg. Med. Chem. 2018, 26, 1675-1685. [CrossRef] [PubMed]

163. Camps, M.; Rückle, T.; Ji, H.; Ardissone, V.; Rintelen, F.; Shaw, J.; Ferrandi, C.; Chabert, C.; Gillieron, C.; Françon, B.; et al. Blockade of $\mathrm{PI} 3 \mathrm{~K} \gamma$ suppresses joint inflammation and damage in mouse models of rheumatoid arthritis. Nat. Med. 2005, 11, 936-943. [CrossRef] [PubMed]

164. Pomel, V.; Klicic, J.; Covini, D.; Church, D.D.; Shaw, J.P.; Roulin, K.; Burgat-Charvillon, F.; Valognes, D.; Camps, M.; Chabert, C.; et al. Furan-2-ylmethylene Thiazolidinediones as Novel, Potent, and Selective Inhibitors of Phosphoinositide 3-Kinase $\gamma$. J. Med. Chem. 2006, 49, 3857-3871. [CrossRef] [PubMed]

165. Collier, P.N.; Martinez-Botella, G.; Cornebise, M.; Cottrell, K.M.; Doran, J.D.; Griffith, J.P.; Mahajan, S.; Maltais, F.; Moody, C.S.; Huck, E.P.; et al. Structural Basis for Isoform Selectivity in a Class of Benzothiazole Inhibitors of Phosphoinositide 3-Kinase $\gamma$. J. Med. Chem. 2015, 58, 517-521. [CrossRef] [PubMed]

166. Bell, K.; Sunose, M.; Ellard, K.; Cansfield, A.; Taylor, J.; Miller, W.; Ramsden, N.; Bergamini, G.; Neubauer, G. SAR studies around a series of triazolopyridines as potent and selective PI3K $\gamma$ inhibitors. Bioorg. Med. Chem. Lett. 2012, 22, 5257-5263. [CrossRef] [PubMed]

167. Bergamini, G.; Bell, K.; Shimamura, S.; Werner, T.; Cansfield, A.; Müller, K.; Perrin, J.; Rau, C.; Ellard, K.; Hopf, C.; et al. A selective inhibitor reveals $\mathrm{PI} 3 \mathrm{~K} \gamma$ dependence of $\mathrm{T}_{\mathrm{H}} 17$ cell differentiation. Nat. Chem. Biol. 2012, 8, 576-582. [CrossRef] [PubMed]

168. Sunose, M.; Bell, K.; Ellard, K.; Bergamini, G.; Neubauer, G.; Werner, T.; Ramsden, N. Discovery of 5-(2-amino-[1,2,4]triazolo[1,5-a]pyridin-7-yl)- $N$-(tert-butyl)pyridine-3-sulfonamide (CZC24758), as a potent, orally bioavailable and selective inhibitor of PI3K for the treatment of inflammatory disease. Bioorg. Med. Chem. Lett. 2012, 22, 4613-4618. [CrossRef] [PubMed]

169. Ellard, K.; Sunose, M.; Bell, K.; Ramsden, N.; Bergamini, G.; Neubauer, G. Discovery of novel PI3K $\gamma / \delta$ inhibitors as potential agents for inflammation. Bioorg. Med. Chem. Lett. 2012, 22, 4546-4549. [CrossRef] [PubMed]

170. Collier, P.N.; Panchagnula, A.; O’Dowd, H.; Le Tiran, A.; Aronov, A.M. Synthesis of a 6-Aza-IsoindolinoneBased Inhibitor of Phosphoinositide 3-Kinase $\gamma$ via Ruthenium-Catalyzed [ $2+2+2]$ Cyclotrimerization. ACS Med. Chem. Lett. 2019, 10, 117-120. [CrossRef] [PubMed] 
171. Collier, P.N.; Messersmith, D.; Le Tiran, A.; Bandarage, U.K.; Boucher, C.; Come, J.; Cottrell, K.M.; Damagnez, V.; Doran, J.D.; Griffith, J.P.; et al. Discovery of Highly Isoform Selective Thiazolopiperidine Inhibitors of Phosphoinositide 3-Kinase $\gamma$. J. Med. Chem. 2015, 58, 5684-5688. [CrossRef] [PubMed]

172. Come, J.H.; Collier, P.N.; Henderson, J.A.; Pierce, A.C.; Davies, R.J.; Le Tiran, A.; O’Dowd, H.; Bandarage, U.K.; Cao, J.; Deininger, D.; et al. Design and Synthesis of a Novel Series of Orally Bioavailable, CNS-Penetrant, Isoform Selective Phosphoinositide 3-Kinase $\gamma(\mathrm{PI} 3 \mathrm{~K} \gamma$ ) Inhibitors with Potential for the Treatment of Multiple Sclerosis (MS). J. Med. Chem. 2018, 61, 5245-5256. [CrossRef] [PubMed]

173. Pemberton, N.; Mogemark, M.; Arlbrandt, S.; Bold, P.; Cox, R.J.; Gardelli, C.; Holden, N.S.; Karabelas, K.; Karlsson, J.; Lever, S.; et al. Discovery of Highly Isoform Selective Orally Bioavailable Phosphoinositide 3-Kinase (PI3K)- $\gamma$ Inhibitors. J. Med. Chem. 2018, 61, 5435-5441. [CrossRef] [PubMed]

174. Folkes, A.J.; Ahmadi, K.; Alderton, W.K.; Alix, S.; Baker, S.J.; Box, G.; Chuckowree, I.S.; Clarke, P.A.; Depledge, P.; Eccles, S.A.; et al. The Identification of 2-(1H-Indazol-4-yl)-6-(4-methanesulfonyl-piperazin1-ylmethyl)-4-morpholin-4-yl-thieno[3,2-d]pyrimidine (GDC-0941) as a Potent, Selective, Orally Bioavailable Inhibitor of Class I PI3 Kinase for the Treatment of Cancer. J. Med. Chem. 2008, 51, 5522-5532. [CrossRef] [PubMed]

175. Luo, J.; Sobkiw, C.L.; Hirshman, M.F.; Logsdon, M.N.; Li, T.Q.; Goodyear, L.J.; Cantley, L.C. Loss of class IA PI3K signaling in muscle leads to impaired muscle growth, insulin response, and hyperlipidemia. Cell Metab. 2006, 3, 355-366. [CrossRef] [PubMed]

176. Taniguchi, C.M.; Kondo, T.; Sajan, M.; Luo, J.; Bronson, R.; Asano, T.; Farese, R.; Cantley, L.C.; Kahn, C.R. Divergent regulation of hepatic glucose and lipid metabolism by phosphoinositide 3-kinase via Akt and PKC $\lambda / \zeta$. Cell Metab. 2006, 3, 343-353. [CrossRef] [PubMed]

177. Wang, J.; Gong, G.Q.; Zhou, Y.; Lee, W.-J.; Buchanan, C.M.; Denny, W.A.; Rewcastle, G.W.; Kendall, J.D.; Dickson, J.M.J.; Flanagan, J.U.; et al. High-throughput screening campaigns against a PI3K $\alpha$ isoform bearing the H1047R mutation identified potential inhibitors with novel scaffolds. Acta Pharmacol. Sin. 2018, 39, 1816-1822. [CrossRef] [PubMed]

178. Sabbah, D.A.; Simms, N.A.; Wang, W.; Dong, Y.; Ezell, E.L.; Brattain, M.G.; Vennerstrom, J.L.; Zhong, H.A. N-Phenyl-4-hydroxy-2-quinolone-3-carboxamides as selective inhibitors of mutant H1047R phosphoinositide-3-kinase (PI3K $\alpha$ ). Bioorg. Med. Chem. 2012, 20, 7175-7183. [CrossRef] [PubMed]

179. Gkeka, P.; Papafotika, A.; Christoforidis, S.; Cournia, Z. Exploring a Non-ATP Pocket for Potential Allosteric Modulation of PI3K $\alpha$. J. Phys. Chem. B 2015, 119, 1002-1016. [CrossRef] [PubMed]

180. Miller, M.S.; Maheshwari, S.; McRobb, F.M.; Kinzler, K.W.; Amzel, L.M.; Vogelstein, B.; Gabelli, S.B. Identification of allosteric binding sites for PI3K $\alpha$ oncogenic mutant specific inhibitor design. Bioorg. Med. Chem. 2017, 25, 1481-1486. [CrossRef] [PubMed] 